\title{
The Evaluation of the RapidHITTM 200 on Degraded Biological Samples
}

\author{
Alice Kim \\ WVU, ahkim@mix.wvu.edu
}

Follow this and additional works at: https://researchrepository.wvu.edu/etd

Part of the Bioinformatics Commons, and the Molecular Biology Commons

\section{Recommended Citation}

Kim, Alice, "The Evaluation of the RapidHITTM 200 on Degraded Biological Samples" (2019). Graduate Theses, Dissertations, and Problem Reports. 7408.

https://researchrepository.wvu.edu/etd/7408

This Thesis is protected by copyright and/or related rights. It has been brought to you by the The Research Repository @ WVU with permission from the rights-holder(s). You are free to use this Thesis in any way that is permitted by the copyright and related rights legislation that applies to your use. For other uses you must obtain permission from the rights-holder(s) directly, unless additional rights are indicated by a Creative Commons license in the record and/ or on the work itself. This Thesis has been accepted for inclusion in WVU Graduate Theses, Dissertations, and Problem Reports collection by an authorized administrator of The Research Repository @ WVU. For more information, please contact researchrepository@mail.wvu.edu. 
The Evaluation of the RapidHIT ${ }^{\mathrm{TM}} 200$ on Degraded Biological Samples

\author{
Alice Kim \\ Thesis submitted \\ to the Eberly College of Arts and Sciences \\ at West Virginia University \\ in partial fulfillment of the requirements for the degree of \\ Master of Science in \\ Forensic and Investigative Science \\ Jeremy Dawson, Ph.D., Chair \\ Clif Bishop, Ph.D. \\ Tina Moroose, M.S. \\ Department of Forensic and Investigative Science
}

Morgantown, West Virginia

2019

Keywords: DNA, Degradation, RapidHIT ${ }^{\mathrm{TM}}$

Copyright 2019 Alice Kim 


\begin{abstract}
The Evaluation of the RapidHIT ${ }^{\mathrm{TM}} 200$ on Degraded Biological Samples
\end{abstract}

\begin{abstract}
Alice Kim
DNA (deoxyribonucleic acid) has become an integral part of forensic science in the last couple of decades since its discovery to this application by Alec Jeffreys. Although there have been many advances throughout the years, the time it takes to obtain a DNA profile using conventional methods in a laboratory setting is approximately 24 to 72 hours. Due to this length of time and the increase in demand for DNA testing, it has caused a tremendous amount of backlog throughout the country. In 2009, the FBI (Federal Bureau of Investigation) in collaboration with the US Department of Defense of Homeland Security provided incentives for the development of hands free, non-laboratory DNA typing equipment. Due to these incentives, two instruments were created in the United States in 2012 that met the FBI's Rapid DNA initiative to produce CODIS (Combined DNA Index System) compatible DNA profiles within two hours. One of these instruments known as the RapidHIT ${ }^{\mathrm{TM}} 200$ was developed by IntegenX. Initially, the focus for rapid DNA technology was for buccal swabs but other forensic type materials have been analyzed and DNA profiles were successfully obtained with RapidHIT ${ }^{\mathrm{TM}}$ 200. Most often though, recovering DNA found in biological samples at crime scenes can be challenging since it may be degraded and therefore limited in its quality and quantity. This study evaluated the DNA profile generated by RapidHIT ${ }^{\mathrm{TM}} 200$ and the DNA profile obtained using conventional methods in a laboratory setting with blood samples that have been degraded. Degradation of blood samples occurred with either exposure to UV light for varying times or by incubating in extreme heat with added humidity for 24 hours with varying temperatures. The results of the study have determined if profiles from degraded samples are concordant between the RapidHIT ${ }^{\mathrm{TM}} 200$ and conventional laboratory methods.
\end{abstract}




\section{TABLE OF CONTENTS}

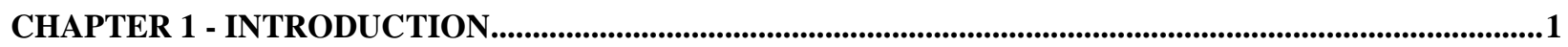

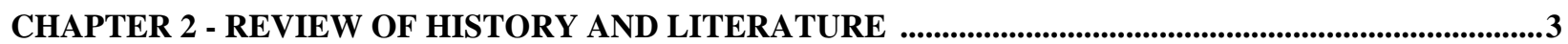

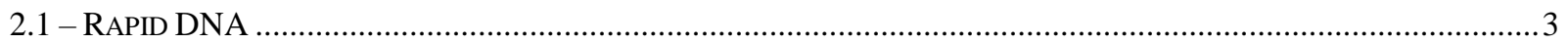

2.1.1 - Commercially Available Rapid DNA Technologies by IntegenX ….................................................... 4

2.1.2 - Commercially Available Rapid DNA Technologies by ANDE............................................................

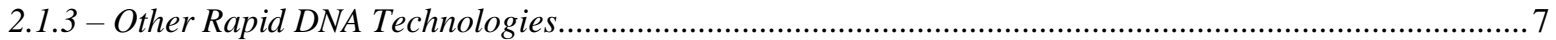

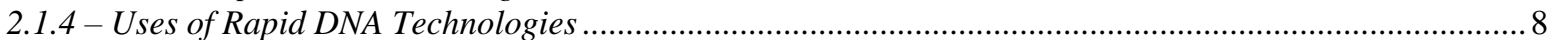

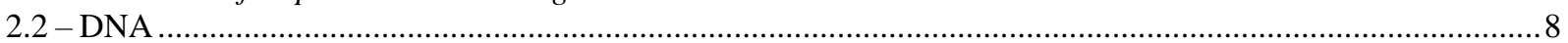

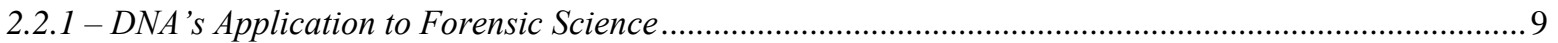

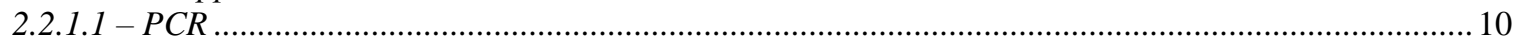

2.2.1.2 - STR

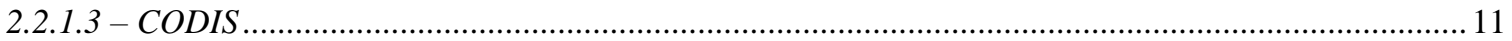

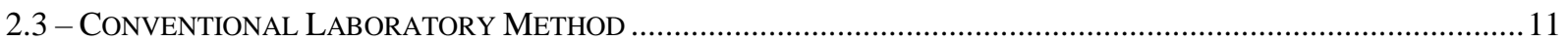

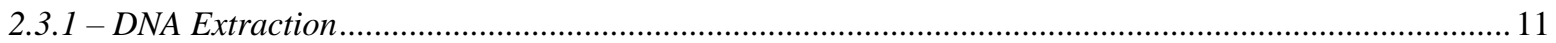

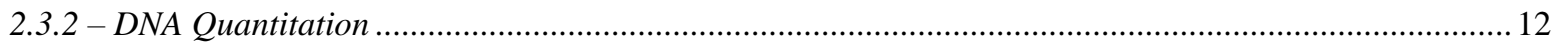

2.3.3 - DNA Amplification, Separation and Detection …….................................................................... 13

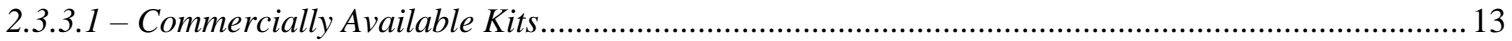

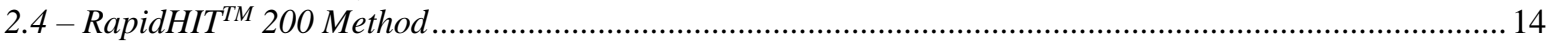

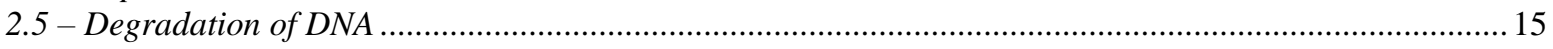

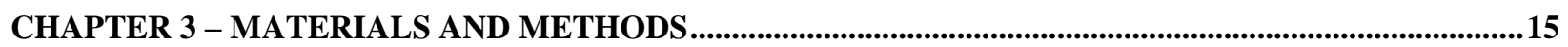

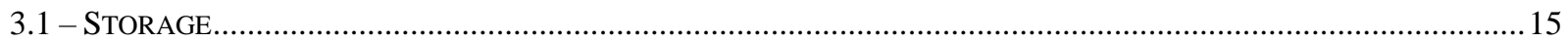

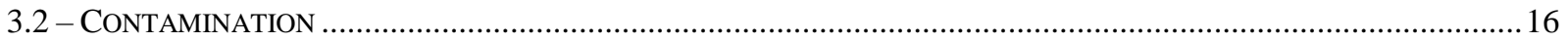

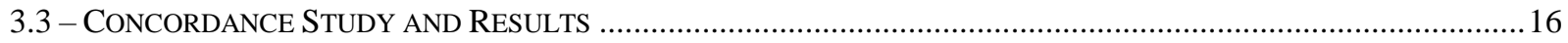

3.4 - PRELIMINARY DEGRADATION STUDY FOR HEAT/HUMIDITY AND RESULTS ..................................................16

3.5 - COLLECTION OF BIOLOGICAL SAMPLES FROM INDIVIDUALS FOR HEAT/HUMIDITY …..................................... 18

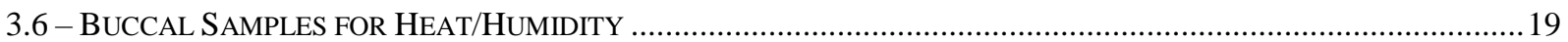

3.7 - DEGRADATION OF BIOLOGICAL SAMPLES FROM INDIVIDUALS FOR HEAT/HUMIDITY .................................... 19

3.8 - EXTRACTION AND QUANTITATION OF DNA FROM DEGRADED BIOLOGICAL SAMPLES FOR HEAT/HUMIDITY

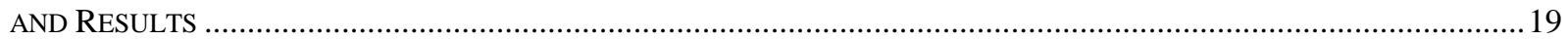

3.9 - AMPLIFICATION OF DNA FROM DEGRADED BIOLOGICAL SAMPLES FOR HEAT/HUMIDITY AND RESULTS .......20

3.10 - RAPIDHIT ${ }^{\text {TM }} 200$ ANALYSIS OF DEGRADED SAMPLES FOR HEAT/HUMIDITY AND RESULTS ...........................34

3.11 - CONCORDANCE STUDY OF DEGRADED SAMPLES FOR HEAT/HUMIDITY AND RESULTS................................47

3.12 - PRELIMINARY DEGRADATION STUDY FOR UV AND RESULTS ...........................................................................4

3.13 - COLLECTION OF BIOLOGICAL SAMPLES FROM INDIVIDUALS FOR UV …….............................................50

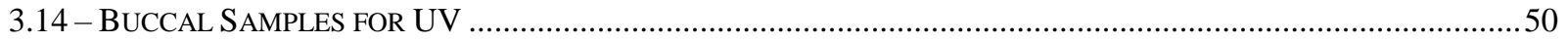

3.15 - DEGRADATION OF BIOLOGICAL SAMPLES FROM INDIVIDUALS FOR UV ..................................................50

3.16 - EXTRACTION AND QUANTITATION OF DNA FROM DEGRADED BIOLOGICAL SAMPLES FOR UV AND RESULTS

3.17 - AMPLIFICATION OF DNA FROM DEGRADED BIOLOGICAL SAMPLES FOR UV AND RESULTS ………………....52

3.18 - RAPIDHIT ${ }^{\mathrm{TM}} 200$ ANALYSIS OF DEGRADED SAMPLES FOR UV AND RESULTS ...........................................62

3.19 - CONCORDANCE STUDY OF DEGRADED SAMPLES FOR UV AND RESULTS .................................................. 72

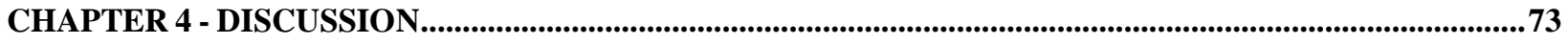

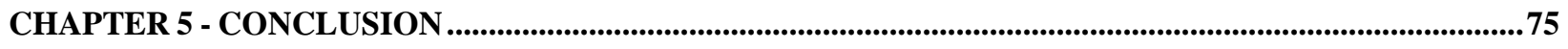

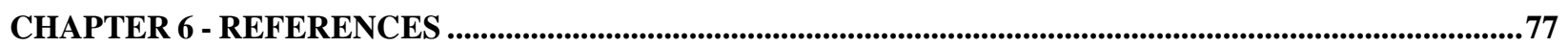




\section{INTRODUCTION}

DNA has been an essential piece of evidence in criminal investigations after it was discovered in 1984 by Dr. Alec Jeffreys that a genetic fingerprint is specific to an individual (Butler, 2010). However, as useful as DNA can be, one of its main weakness is the length of processing time on the instrument it takes for a DNA profile to be generated from a biological sample. Another drawback is that a trained professional would need to perform a number of processes in a laboratory setting. Due to the challenges associated with bench-top forensic DNA analysis, the FBI (Federal Bureau of Investigation) in collaboration with the US Department of Defense and Department of Homeland Security initiated a program to foster the development of hands free, non-laboratory DNA typing equipment which has become known as rapid DNA (Callaghan, n.d.). Since the introduction of Rapid DNA technology in 2009, the start to end processing time required to generate a DNA profile has been reduced from a number of days to a number of hours.

Although Rapid DNA technology has been around for almost a decade, it is still not widely used since only high-quality samples collected at the time of booking can be uploaded and compared against a special 'rapid' section of CODIS (Combined DNA Index System) database (Jackman, 2018). The reason for this is that the instruments were originally developed for use with buccal swabs, a biological sample with a sufficient amount of DNA from a single donor and that is quickly processed after collection from the donor (Jackman, 2018). According to the FBI, the instruments have still not been proven to handle crime scene type samples (Jackman, 2018). Crime scene samples can be a mixture of DNA from different sources, become contaminated due to its surroundings or degraded due to environmental factors (Jackman, 2018).

Instrument manufacturer and independent researchers have performed assessments of Rapid DNA performance on non-buccal type samples including blood and saliva and have determined that these samples show success in generating DNA profiles using Rapid DNA technology (Gangano et al., 2013; Verheij et al., 2013; Alshehhi, A. \& Roy, R., 2015). However, there is a lack of studies on forensic casework samples in which degradation has occurred or containing a mixture that can exhibit the robustness and capability of these instruments when compared to the traditional analysis methods used to extract DNA from these sample types in the laboratory. This uncertainty to its reliability on challenging DNA samples is causing the limited use of this instrument in the forensic field. The goal of this research effort is 
to evaluate the performance of RapidHIT ${ }^{\mathrm{TM}} 200$ in generating STR profiles from blood samples that have been degraded by controlled exposure to heat and humidity or UV light. Preliminary studies were focused on determining the level of exposure to that heat and humidity or UV light that causes degradation yet still can generate either a full or partial DNA profile. It has already been demonstrated by another study that exposure to heat and humidity did not adversely affect the yielding of a complete and concordant DNA profile (Alshehhi, A. \& Roy, R., 2015). However, the work described herein will provide further information on environmental degradation and its impact on Rapid DNA technology.

As previously stated, the goal of this research effort is to understand how Rapid DNA technology specifically the RapidHIT ${ }^{\mathrm{TM}} 200$ instrument distributed by IntegenX performs with forensic casework samples. The tasks necessary to achieve this goal are as follows:

- Sample Collection and Preparation - Biological samples were collected from participants and degraded by either exposure to heat/humidity or UV light

- Sample Processing and Profile Generation - Samples were processed by benchtop analysis or with RapidHIT ${ }^{\mathrm{TM}} 200$ instrument generating the DNA profiles

- Data Analysis - DNA profiles were analyzed for correct allele calls and peak drop out with the two different sample processing types compared using the t-test

The success of this research will indicate how much and what kind of limitation Rapid DNA technology has on generating DNA profiles of degraded blood samples. Since time is of the essence in the field of forensic science, quickly obtaining an accurate DNA profile can either exclude a person of interest and move on to another or point out the possible assailant to law enforcement officers. It can also help in reducing the backlog of casework samples to try and bring closure to the victims and their families. Due to the size of the instrument, it is already being placed in police stations. However, with proven reliability, Rapid DNA technology can be mobile and be present for use at a crime scene. There will be no need for concern over contamination because all processes are enclosed within the instrument. Therefore, the shortterm benefit of this research will be the development of investigative leads for investigators using the DNA profile evidence since a major hurdle with Rapid DNA technology may be in overcoming the policy issues. 


\section{REVIEW OF HISTORY AND LITERATURE}

\subsection{RAPID DNA}

From 1984 to today, the methods of obtaining a genetic fingerprint and identifying an individual have changed dramatically. However, even with all the advancements in the technique, generating a DNA profile takes a long time. It requires approximately 24 to 72 hours using conventional methods in a laboratory setting. An arrestee is usually already released by the time results are returned. The FBI's incentive for Rapid DNA technology created two instruments in the United States in 2012 that met the FBI's Rapid DNA initiative to produce CODIS compatible DNA profiles within two hours. Both instruments take about 90 minutes from swab in to profile out without human intervention. This could allow an arrestee to still be in police custody during the booking process with a definitive determination as to whether or not the individual has been involved in an unsolved crime. The speed in which the results are obtained makes Rapid DNA technology's significance be observed in many other areas other than crime such as natural disasters.

It not only renders the suspect who is responsible for a crime to be held in custody rather than being released into the public permitting more crimes to be committed but causes the innocent to be set free. The Innocence Project clearly demonstrates the high number of DNA exonerations of the wrongly convicted. Whether it is plea bargaining, false confessions or faulty eyewitness testimony, the injustice of innocent individuals remaining incarcerated urgently needs to be fixed (Innocence Project, n.d.). In a study conducted by Dr. Gould and his team, it has been determined through quantitative and qualitative analysis that prevention of wrongful convictions begins at the police station followed by opportunities to identify the innocent before they are wrongfully convicted. An example given of that opportunity is that if forensic testing was conducted earlier and results became available sooner to investigators, innocent suspects could be freed (Johnson, 2013). Then the investigation can be focused on apprehending the actual offender.

There has been a tremendous amount of backlog in DNA testing throughout the country due to the length of time conventional methods in a laboratory setting takes along with other factors. The demand for DNA testing has increased overall because of the rising awareness of the potential for DNA evidence to help solve criminal cases (OJP, 2011). The National Institute 
of Justice (NIJ) defines a backlogged case as one that remains untested for 30 days after it has been submitted to a laboratory (OJP, 2011). There are three main types of backlogs in the laboratory. They are the casework backlog, convicted offender backlog or the arrestee backlog. Forensic samples gathered from crime scenes and suspect and victim samples make up the casework backlog (OJP, 2011). The convicted offender backlog is because of the requirement that the convicted offender's DNA profiles be uploaded to CODIS. The arrestee backlog occurred as a result of Congress passing the DNA Fingerprint Act of 2005 stating that as of January 1, 2009, any adult arrested for a federal crime must provide a DNA sample (NIJ, 2012). More than half of the states have followed Congress's example and enacted this law. However, the convicted offender backlog and arrestee backlog can be addressed by the FBI with the development of rapid DNA technology unlike the casework backlog. Since forensic materials have limitations in quality and quantity, studies are needed to see the potential of rapid DNA technology in these types of samples to aid in the reduction of casework backlogs.

In order to have rapid results for DNA testing, a number of methods ranging from services provided to technology have been initiated by different companies. Bode Cellmark Forensics provides a service known as BodeHITS ${ }^{\mathrm{TM}}$ to law enforcement agencies designed to quickly develop DNA profiles from evidence and reference samples collected from crime scenes, ideally suited for property and drug crimes (Bode Cellmark, n.d.). ThermoFisher Scientific has revolutionized the technique by producing a 6 dye chemistry for generating DNA profiles in the laboratory known as Applied Biosystems ${ }^{\mathrm{TM}}$ GlobalFiler $^{\mathrm{TM}}$ PCR Amplification Kit. This kit has expanded the previous 13 CODIS core loci to 24 loci in order to be more compatible with international databases as well as to increase the discriminating power. However, a key feature is its fast amplification time compared to previous generation kits (ThermoFisher Scientific, 2016).

\subsubsection{COMMERCIALLY AVAILABLE RAPID DNA TECHNOLOGIES BY INTEGENX}

One of the instruments previously mentioned for rapid DNA technology was developed by IntegenX. A company based in California, it brought to market RapidHIT ${ }^{\mathrm{TM}} 200$. IntegenX was acquired by ThermoFisher in early 2018 (PR Newswire, 2018). RapidHIT ${ }^{\mathrm{TM}} 200$ is a fully automated sample-to answer system for STR-based human identification (IntegenX, 2016). It produces a DNA profile that is compatible with national databases. Mostly described as a 
machine the size of a large desktop printer as seen in Figure 1, it contains all necessary reagents for the process of generating a profile (Figarelli, 2014). With only a few minutes of hands on intervention by an individual with minimal training, the press of a green button and choice of either running buccal samples or other samples yields the genetic makeup of a person in approximately 1.5 hours (Jovanovich, 2014).

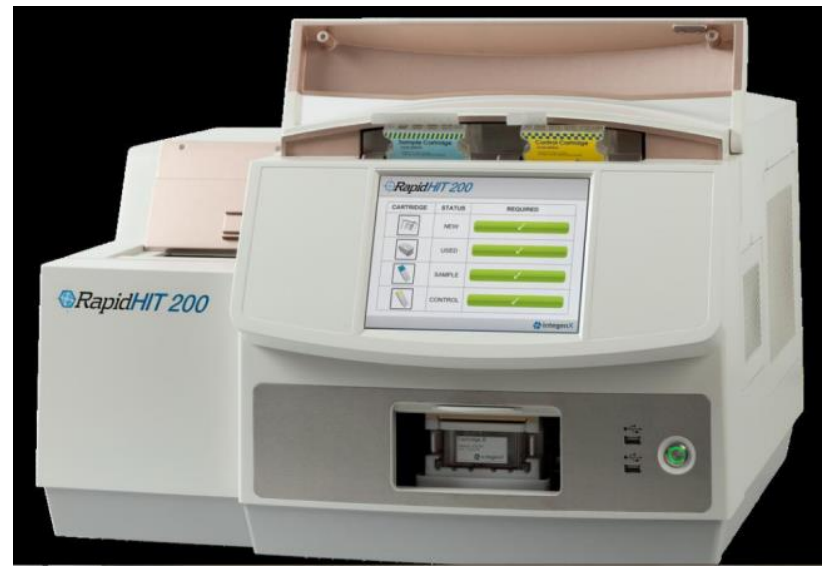

Figure 1. RapidHIT ${ }^{\mathrm{TM}} 200$ instrument by IntegenX (Figarelli, 2014)

The instrument uses extraction, PCR (polymerase chain reaction) and CE (capillary electrophoresis) technologies similar to the conventional method utilized in a laboratory without the need for quantitation. Since RapidHIT ${ }^{\mathrm{TM}} 200$ was optimized for reference samples, with reproducible results obtained by normalizing the amount of DNA entering PCR using Promega's DNA IQ ${ }^{\mathrm{TM}}$ purification chemistry, quantitation is unnecessary since the amount of recovered DNA is nearly constant regardless of the sample size (IntegenX, 2012). This process combined with the validated chemistries such as Promega's Powerplex ${ }^{\circledR} 16$ or ThermoFisher's GlobalFiler ${ }^{\mathrm{TM}}$ Express within the separate cartridges provided lends to the generation of a DNA profile (Jovanovich, 2014).

RapidHIT $^{\mathrm{TM}} 200$ can have up to seven samples in a single run. The samples are placed in slots on two disposable single use cartridges. An anode or polymer cartridge and a buffer cartridge, both of which are also disposable, has to be inserted into the instrument in order to supply the polymer and buffer for CE separation as seen in Figure 2 (DiZinno, 2013). Although the benefits of using the instrument are high, the overall cost of using RapidHIT ${ }^{\mathrm{TM}} 200$ is expensive. 


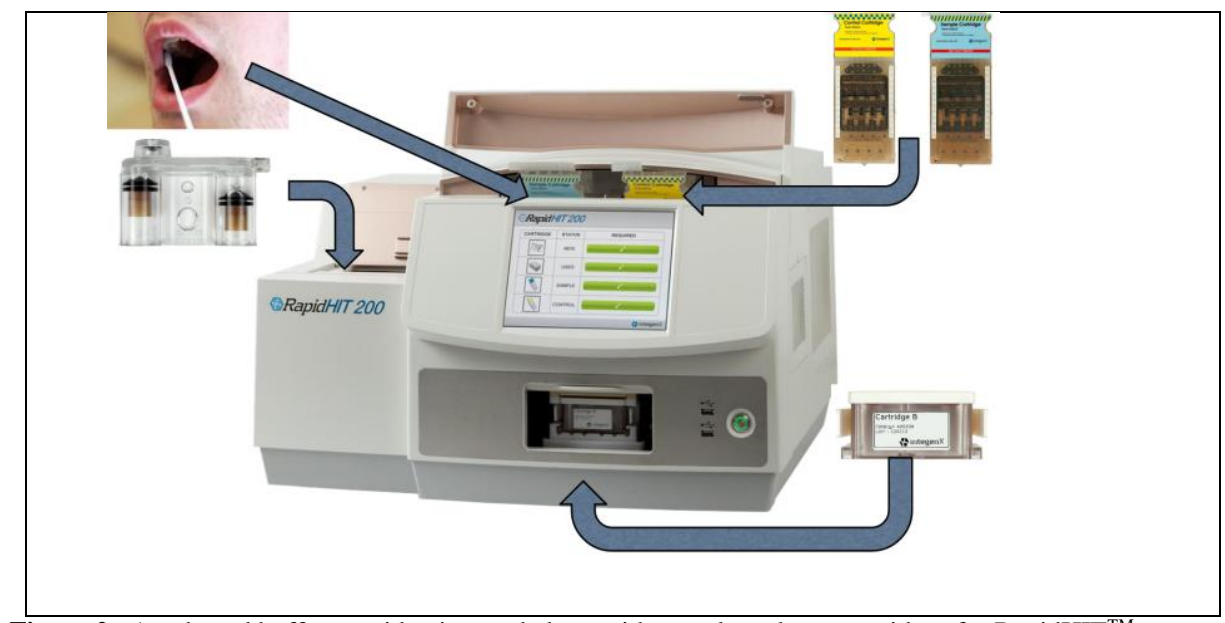

Figure 2. Anode and buffer cartridge inserted along with sample and two cartridges for RapidHIT ${ }^{\mathrm{TM}}$ 200 instrument (DiZinno, 2013)

IntegenX has expanded their products in rapid DNA technology in 2015 with their launch of RapidHIT ${ }^{\circledR}$ ID. The size of this instrument is smaller than the original and has some new features that maximize security by facial or fingerprint recognition of users and a built-in camera to scan sample bar codes (Johnson, 2015). It generates a DNA profile compatible with national databases and the United Kingdom using the NGM Select ${ }^{\mathrm{TM}}$ Express or GlobalFiler ${ }^{\mathrm{TM}}$ Express chemistry by ThermoFisher Scientific (IntegenX, 2016). Only a single sample can be run at a time making it efficient at a police booking station and cost effective because 250 samples can be processed using one cartridge (Johnson, 2015).

\subsubsection{COMMERCIALLY AVAILABLE RAPID DNA TECHNOLOGIES BY ANDE}

The other instrument for rapid DNA technology was developed by ANDE (formerly NetBio and GE Healthcare) and is known as DNAscan ${ }^{\mathrm{TM}}$ Rapid DNA Analysis ${ }^{\mathrm{TM}}$ System (DNAscan/ANDE ${ }^{\mathrm{TM}}$ ). It is a fully automated, tabletop system for use in processing up to five DNA samples in less than 90 minutes (GE Healthcare Life Sciences, 2016). There is no need for highly trained technical personnel since it is considered to be easy to use and takes about 10 minutes to prepare the run of a single source reference sample to generate a DNA profile compatible with CODIS. DNAscan ${ }^{\mathrm{TM}}$ has on-screen instructions that requests sample information, placing the DNA sample and loading the NetBio PP16 BioChipSet ${ }^{\mathrm{TM}}$ Cassette. The NetBio PP16 BioChipSet ${ }^{\mathrm{TM}}$ Cassette which can be stored at room temperature is a disposable, single-use containment where all the reagents and materials necessary are factory preloaded and is also storage for all waste generated during the process (GE Healthcare Life Sciences, 2016). 
Essentially a lab-on-a-chip, from sample in to result out, the instrument performs fully automated purification, PCR amplification, electrophoresis and Expert System data analysis to create a profile (GE Healthcare Life Sciences, 2016). It uses the Powerplex ${ }^{\circledR} 16$ chemistry along with an allelic ladder and Internal Lane Standard for controls. A DNAscan ${ }^{\mathrm{TM}}$ Collection Kit is required for this instrument because it holds the NetBio BioChipSet ${ }^{\mathrm{TM}}$ Swab that has to be used to collect the DNA sample. The collected sample on the BioChipSet ${ }^{\mathrm{TM}}$ Swab locks into place on the BioChipSet ${ }^{\mathrm{TM}}$ Cassette sample chamber for security purposes and prevention of any mix-up of samples. In order to aid in this and maintain chain-of-custody as well, DNAscan ${ }^{\mathrm{TM}}$ has RFID readers located both on the outside and inside the instrument (GE Healthcare Life Sciences, 2016).

In 2015, ANDE revealed their DNAscan ${ }^{\mathrm{TM}}$ 6C Rapid DNA ${ }^{\mathrm{TM}}$ (ANDE ${ }^{\mathrm{TM}}$ ) Analysis System. It is similar to DNAscan ${ }^{\mathrm{TM}}$ Rapid DNA ${ }^{\mathrm{TM}}$ Analysis System but increased to a 6-dye from a 4-dye system and uses the Flexplex ${ }^{\mathrm{TM}}$ chemistry instead of the Powerplex ${ }^{\circledR} 16$. The loading of an A-Chip will generate a DNA profile with 27 loci that makes it compatible with databases globally and allows for a greater discriminatory power. The 27 loci include 23 autosomal, 3 Y-chromosomal and amelogenin (Carney et al., 2019). This instrument has been approved by the FBI as the first to comply with the new standards under the Rapid DNA Act of 2017 (Genomeweb, 2018). The Rapid DNA Act of 2017 amends previous acts allowing the FBI to either issue standards and procedures for using Rapid DNA instruments to analyze DNA samples or to waive existing requirements (Augenstein, 2017).

\subsubsection{OTHER RAPID DNA TECHNOLOGIES}

The United States is not the only country that sought to develop rapid DNA technology. NEC Corporation, a company based in Japan had been working on a Portable DNA Analyzer specific for criminal investigations. This disposable lab-on-a-chip is described as the size of a suitcase and is fully portable to be able to function at a crime scene preventing time lost during transfer of DNA samples to a laboratory. It provides results within 60 minutes and can be handled by anyone due to its ease of use. All reagents needed for the process are in a capsule (NEC, 2016). DNA analysis is executed by simply taking a sample and placing it on the analysis chip that performs the processes of DNA extraction, PCR amplification and electrophoresis 
completely automatically with waste produced captured on the chip (NEC, 2016). Then after STR analysis, a profile is generated that can be entered into a database.

\subsubsection{USES OF RAPID DNA TECHNOLOGIES}

Rapid DNA technology is not only significant in the field of forensics but in kinship assessment and missing person identification in mass disasters. This is the reason behind the Department of Homeland Security's involvement with its development. In recent years, there has been a tremendous need for an efficient way to verify claimed relationships for refugee applicants seeking immigration to the Unites States (DHS, 2013). A family reunification program had to be suspended in 2008 because of kinship fraud and was only reinstated by the State Department in 2012 with the requirement of a DNA submission (Kofman, 2016). Also, DNA identification instead of fingerprinting and dental comparisons may be the sole method to return the remains to a family involved in mass disasters such as was the case during 9/11 (Ritter, 2007).

\subsection{DNA}

DNA (deoxyribonucleic acid) is found within the nucleus of a cell which is the basic unit of life and carries genetic instructions. Each cell has the complete set of genes or otherwise known as the genome that stores genetic information passing down through the generation. The same DNA is incorporated in all the cells of a person and is composed of a nucleobase, a sugar and a phosphate. The sugar and phosphate form the backbone structure of DNA and the nucleobase can be one of four different nucleotides. The four nucleobases are A (adenine), T (thymine), C (cytosine) and G (guanine) and their sequence through its varied combinations creates the differences noticed among humans. DNA polymerase, the enzyme that copies DNA, writes the sequence from the 5' end to 3' end. However, DNA in its original form is a doublehelix structure with two strands (one strand is in a 5' -3' position and the other strand is in a 3' -5' position) held together by base pairing (Figure 3). The adenine is paired with thymine and cytosine is paired with guanine (Butler, 2010). 


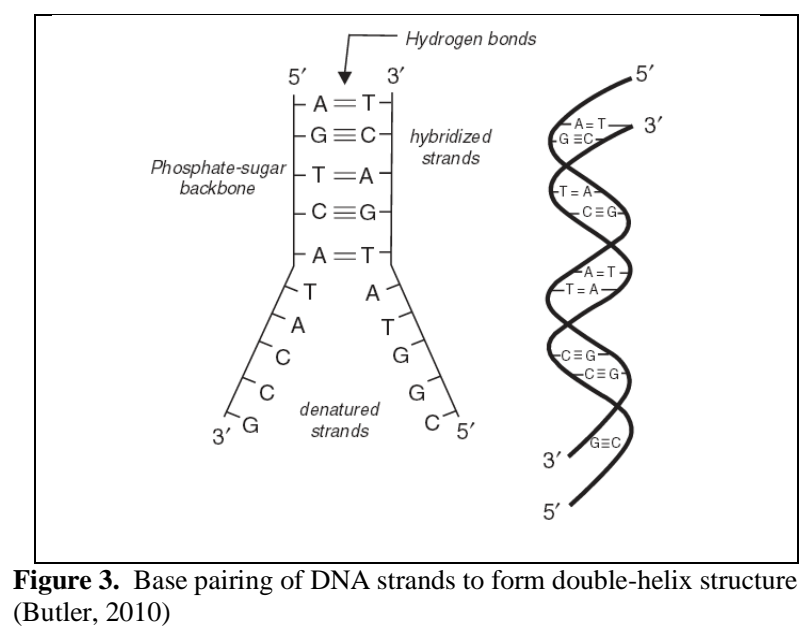

\subsubsection{DNA's APPLICATION TO FORENSIC SCIENCE}

In the nucleus, DNA is divided into dense packets called chromosomes. The human genome is composed of 22 matched pairs of autosomal and 2 sex determining chromosomes (Figure 4). Males are designated with the XY chromosomes and females with the XX chromosomes. Each of the matched pair of autosomal chromosomes is homologous and the pair is inherited from the parents, one from the father and the other from the mother. Genetic fingerprinting is performed by markers on autosomal chromosomes and gender determination is accomplished with markers on sex chromosomes. The chromosomal location of the marker is identified as a locus and each of the distinct possibilities for that locus is referred to as an allele. If the two alleles at a specific locus on homologous chromosomes are not the same, it is heterozygous but if the alleles are identical, then it is homozygous. The ability to detect differences in alleles at corresponding loci is necessary for identity testing. The determination of which allele is present at a locus is known as genotyping and the consolidation of genotypes for multiple loci produces a DNA profile (Butler, 2010).

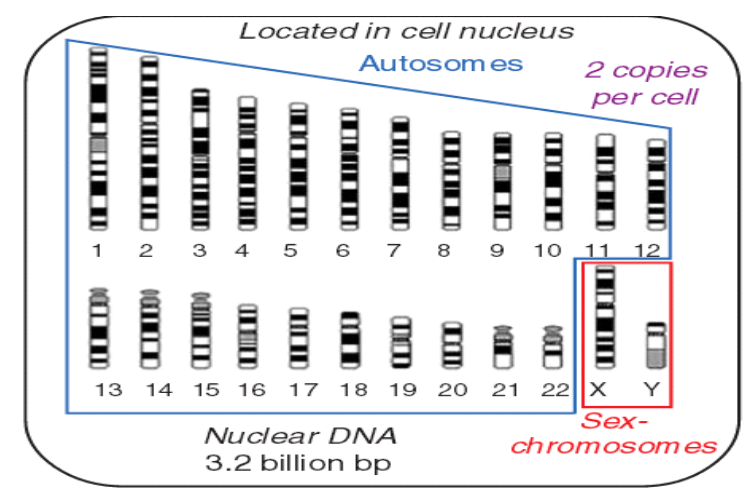

Figure 4. Cell nucleus consists of 23 pairs of chromosomes (Butler, 2010) 
Alec Jeffreys explained DNA's unique capability to identify an individual and its usefulness as a tool in forensics. He recognized that certain areas of the DNA had DNA sequences that were repeated continuously designated as VNTR (variable number of tandem repeats). The technique he used to study VNTRs is called RFLP (restriction fragment length polymorphism) because a restriction enzyme was used to cut the neighboring area of VNTR. The number of VNTRs distinguishes one person from another and in forensics, only a small portion of the genome is examined for this distinction (Butler, 2010). From 1984 and over the years, the speed, technique and markers utilized have constantly evolved to increase the power of discrimination while decreasing time and labor spent on DNA analysis.

\subsubsection{PCR}

An important development in the application of DNA to forensics was DNA amplification through the invention of PCR by Kary Mullis. Although DNA can help in identifying a person, the amount of DNA left behind at crime scenes is normally insufficient. However, PCR enables the processing of these insufficient amounts by making exponential copies with DNA polymerase to targeted regions of DNA. It is an enzymatic process that renders the double-helix structure into single strands and involves a cyclical pattern of heating and cooling for about 30 cycles (Figure 5). Currently, automation and multiplexed commercial kits are available that provide all components required for amplification of two or more targeted regions of DNA at one time. The range for the quantity of DNA initially needed for optimal amplification results is dependent on the kit and is approximately $1 \mathrm{ng}$. Also, positive and negative controls are set up to monitor proper functioning of the PCR process. The presence of inhibitors and possible DNA contamination are issues leading to inaccurate DNA amplification (Butler, 2010).

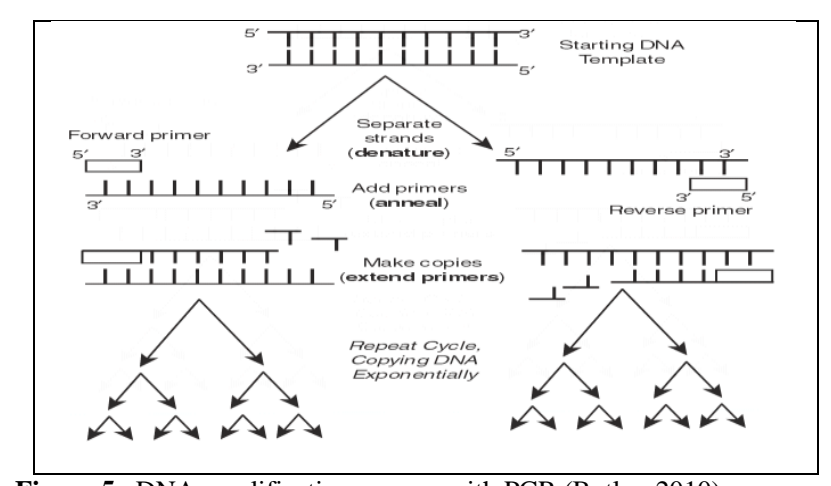

Figure 5. DNA amplification process with PCR (Butler, 2010) 


\subsubsection{STR}

Another development was the discovery within the genome of shorter bp (base pair) repeat units between 2-7 bp compared with VNTR's that are 8-100 bases in length. These STR (short tandem repeat) markers are more beneficial because they are easily amplified, highly variable in humans and work well with degraded DNA since short fragments of DNA are still able to be analyzed. The multiplexed commercially available STR kits for DNA typing contain an allelic ladder and include gender determination with amelogenin, a sex-typing locus. An allelic ladder allows for accurate genotyping by being a reference guide for DNA size on all possible alleles at a given locus. In 1997, 13 core STR loci were established so a universal set of standardized markers can be incorporated into a national DNA database (Butler, 2010).

\subsubsection{CODIS}

The national DNA database was launched by the FBI in 1998. CODIS is comprised of DNA profiles belonging to convicted offenders, arrestees and forensic unknown samples. It is a method to share information between law enforcement agencies by linking biological evidence from crimes to suspects and associate any unsolved crimes to one another. In 2012, the FBI proposed to expand the number of CODIS core loci in the United States from 13 to 20 STR loci to reduce the potential of adventitious types of matches occurring within CODIS, to increase international compatibility for data sharing and to increase discrimination power (Steffen et al., n.d.). The addition of the 7 extra core loci to the 13 existing ones became effective on January 1, 2017.

\subsection{CONVENTIONAL LABORATORY METHOD}

The conventional method of generating a DNA profile from a biological sample in a laboratory consists of four basic steps: DNA extraction, quantitation, amplification, separation and detection (Butler, 2010).

\subsubsection{DNA EXTRACTION}

A biological sample has cellular materials other than DNA so DNA needs to be extracted and isolated as the initial step. There are a number of techniques for DNA extraction of which 
one is known as Chelex. In the Chelex technique, a chelating resin suspension is added to a sample after washing to remove any contamination and inhibitors that are present. For certain samples, Pro K (proteinase k) is also added for the destruction of proteins in cell lysates. The purpose of the resin is to chelate metal ions such as magnesium so that nucleases are inactivated and DNA molecules protected. This protection is required during the process where exposure to high temperatures is necessary to break open the cells in order to release the DNA. However, due to exposure to high temperatures, the DNA does become single stranded. After centrifuging the mixture, the resulting supernatant is used for DNA quantitation. Chelex ${ }^{\circledR} 100$ is a product developed for this technique by Bio-Rad Laboratories. Another DNA extraction method is the solid-phase that includes the DNA IQ ${ }^{\mathrm{TM}}$ system by Promega. In solid-phase DNA extraction, DNA is selectively bound to a substrate and then released following stringent washes that purify the bound DNA. DNA IQ ${ }^{\mathrm{TM}}$ utilizes silica-coated paramagnetic resin and with this approach, the quantity of DNA is already defined by the number and capacity of magnetic particles used without going through a separate quantitation step (Butler, 2010).

\subsubsection{DNA QUANTITATION}

After the extraction process, it is required by the FBI to quantify human DNA in order to verify that recovered DNA in questioned samples is not from another source. It is also needed since most PCR-STR kits require a certain amount of input DNA for optimal results. If there is too much DNA, then the electropherograms are overblown and if there is too little DNA, then it can cause a loss of alleles (Butler, 2010). A couple of the commercial kits that are available to provide quantitation are Quantifiler ${ }^{\circledR}$ Duo and Quantifiler ${ }^{\circledR}$ Trio by ThermoFisher Scientific.

The Quantifiler ${ }^{\circledR}$ Trio assay targets are the following:

- Small Autosomal (SA) Target - The SA target is the primary quantification target for total human genomic DNA. Its amplicon length is 80 bases.

- Large Autosomal (LA) Target - The LA target is used mainly as an indicator of DNA degradation. Its amplicon length is 214 bases.

- Y chromosome Target - The Y target allows the quantification of a sample's human male genomic DNA component. Its amplicon length is 75 bases. 
An advantage of using Quantifiler ${ }^{\circledR}$ Trio is that it can lead to results that help determine whether the DNA is degraded (ThermoFisher Scientific, 2017).

\subsubsection{DNA AMPLIFICATION, SEPARATION AND DETECTION}

Once quantitation is accomplished and isolated DNA is adjusted for optimal results, amplification through PCR can take place. The final step would be to separate the DNA fragments by size through $\mathrm{CE}$ and detect the different colored fluorescent dyes incorporated into PCR products for STR allele labeling before genotyping via GeneMapper ${ }^{\mathrm{TM}}$ ID-X Software. The DNA profile is then manually reviewed (Butler, 2010).

\subsubsection{COMMERCIALLY AVAILABLE KITS}

There are two well-known multiplexed PCR-STR commercially available kits: PowerPlex 16 by Promega and AmpFLSTR ${ }^{\mathrm{TM}}$ Identifiler $^{\mathrm{TM}}$ PCR Amplification by ThermoFisher Scientific. Both are used to type DNA by co-amplification of 16 loci (15 STR loci and amelogenin) except Promega's kit has 3-color detection and ThermoFisher Scientific's kit has 5color detection (Promega, n.d.; ThermoFisher Scientific, n.d.). When ThermoFisher Scientific introduced GlobalFiler Express and GlobalFiler ${ }^{\mathrm{TM}}$ PCR Amplification Kit in 2012, there was a vast improvement in all areas from the previous approved chemistries (ThermoFisher Scientific, 2012). GlobalFiler Express was specifically designed to facilitate the processing of reference samples collected for the purpose of database submissions. As seen in Table 1, the spatial configuration of the GlobalFiler Express Kit is as follows: D3S1358, vWA, D16S539, CSF1PO,

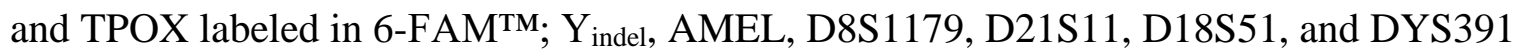
labeled in VIC ${ }^{\circledR}$; D2S441, D19S433, TH01 and FGA labeled in NED ${ }^{\mathrm{TM}}$; D22S1045, D5S818, D13S317, D7S820 and SE33 labeled in TAZTM; D10S1248, D1S1656, D12S391, and D2S1338 labeled in $\mathrm{SID}^{\mathrm{TM}}$. The sixth dye, LIZ ${ }^{\circledR}$ labels the size standard (ThermoFisher Scientific, 2012; Wang et al., 2015). This spatial configuration is the same for GlobalFiler PCR Amplification Kit but the kit is optimized for casework samples (ThermoFisher Scientific, 2016). Studies have shown that reliable DNA typing results from samples can be obtained using GlobalFiler Express Kit and GlobalFiler PCR Amplification Kit (Gouveia et al., 2015; Wang et al., 2015). 


\begin{tabular}{|c|c|c|c|c|}
\hline Locus designation & $\begin{array}{l}\text { Chromosome } \\
\text { location }\end{array}$ & Alleles included in Allelic Ladder & $\begin{array}{l}\text { Dye } \\
\text { label }\end{array}$ & $\begin{array}{l}\text { DNA Control } \\
007\end{array}$ \\
\hline D3S1358 & $3 \mathrm{p} 21.31$ & $9,10,11,12,13,14,15,16,17,18,19,20$ & \multirow[t]{5}{*}{ 6-FAM } & 15,16 \\
\hline WA & $12 p 13.31$ & $\begin{array}{l}11,12,13,14,15,16,17,18,19,20,21,22,23, \\
24\end{array}$ & & 14,16 \\
\hline D165539 & $16 \mathrm{q} 24.1$ & $5,8,9,10,11,12,13,14,15$ & & 9.10 \\
\hline CSF1PO & $5 q 33.3-34$ & $6,7,8,9,10,11,12,13,14,15$ & & 11,12 \\
\hline TPQ & $2 \mathrm{p} 23-2 \mathrm{per}$ & $5,6,7,8,9,10,11,12,13,14,15$ & & 8.8 \\
\hline$Y$ indel & 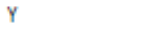 & 1,2 & \multirow[t]{6}{*}{ ИC' } & 2 \\
\hline Amelogenin & $\begin{array}{l}X: p 22.1-22.3 \\
Y: p 11.2\end{array}$ & $X, Y$ & & $X, Y$ \\
\hline DBS1179 & $8 q 24.13$ & $\begin{array}{l}5,6,7,8,910,11,12,13,14,15,16,17,18 \\
19\end{array}$ & & 12,13 \\
\hline D21S11 & $21 q 11.2-q 21$ & $\begin{array}{l}24,24.2,25,26,27,28,28.2,29,29.2,30 \\
30.2,31,31.2,32,322,33,33.2,34,34.2,35 \\
35.2,36,37,38\end{array}$ & & 28,31 \\
\hline D18551 & $18 q 21.33$ & $\begin{array}{l}7,9,10,10.2,11,12,13,132,14,14.2,15,16 \\
17,18,19,20,21,22,23,24,25,26,27\end{array}$ & & 12,15 \\
\hline DYS391 & $\mathrm{Y}$ & $7,8,9,10,11,12,13$ & & 11 \\
\hline 025441 & $2 \mathrm{p} 14$ & $8,9,10,11,113,12,13,14,15,16,17$ & \multirow[t]{4}{*}{$\mathrm{NED}^{*}$} & 14,15 \\
\hline D19S433 & $19 q 12$ & $\begin{array}{l}6,7,8,9,10,11,12,122,13,13.2,14,14.2 \\
15,15.2,16,16.2,17,17.2,18.2,19.2\end{array}$ & & 14,15 \\
\hline TH01 & $11 \mathrm{p} 15.5$ & $4,5,6,7,8,9,9.3,10,11,13.3$ & & 7.9 .3 \\
\hline FGA & $4 q 28$ & $\begin{array}{l}13,14,15,16,17,18,19,20,21,22,23,24, \\
25,26,262,27,28,29,30,30.2,31.2,32.2 \\
33.2,422,432,44.2,45.2,46.2,47.2,48.2 \\
50.2,51.2\end{array}$ & & 24,26 \\
\hline 02251045 & $22 \mathrm{q} 12.3$ & $8,9,10,11,12,13,14,15,16,17,18,19$ & \multirow[t]{5}{*}{ TAZ } & 11,16 \\
\hline D5S818 & $5 q 21-31$ & $7,8,9,10,11,12,13,14,15,16,17,18$ & & 11,11 \\
\hline 0135317 & $13 q 22-31$ & $5,6,7,8,9,10,11,12,13,14,15,16$ & & 11,11 \\
\hline D75820 & $7 q 11.21-22$ & $6,7,8,9,10,11,12,13,14,15$ & & 7.12 \\
\hline SE33 & $6 q 14$ & $\begin{array}{l}4.2,6.3,8,9,11,12,13,14,15,16,17,18,19, \\
20,20.2,21,21.2,22.2,23.2,24.2,25.2,26.2, \\
27.2,282,29.2,30.2,31.2,32.2,33.2,34.2, \\
35,35.2,36,37\end{array}$ & & $17,25.2$ \\
\hline D10S1248 & $10 q 26.3$ & $8,9,10,11,12,13,14,15,16,17,18,19$ & \multirow[t]{4}{*}{$S I D^{\prime *}$} & 12,15 \\
\hline D1S1656 & $1 q 42.2$ & $\begin{array}{l}9,10,11,12,13,14,14.3,15,15.3,16,16.3, \\
17,17.3,18.3,19.3,20.3\end{array}$ & & 13,16 \\
\hline D12S391 & $12 \mathrm{p} 13.2$ & $\begin{array}{l}14,15,16,17,18,19,19.3,20,21,22,23,24, \\
25,26,27\end{array}$ & & 18,19 \\
\hline D251338 & $2 q 35$ & $\begin{array}{l}11,12,13,14,15,16,17,18,19,20,21,22 \\
23,24,25,26,27,28\end{array}$ & & 20,23 \\
\hline
\end{tabular}

Table 1. GlobalFiler Express PCR Amplification Kit 24 loci and alleles (ThermoFisher Scientific, 2012)

\subsection{RAPIDHIT ${ }^{\mathrm{TM}} 200$ METHOD}

After RapidHIT ${ }^{\mathrm{TM}} 200$ was introduced in 2012, studies have been performed to evaluate its performance even with the more recently approved chemistry of GlobalFiler ${ }^{\mathrm{TM}}$ Express (DateChong, M., Hudlow, W., \& Buoncristiani, M., 2016; Holland, M., \& Wendt, F., 2015). In order to validate the results generated with RapidHIT ${ }^{\mathrm{TM}} 200$, the same analysis must be performed with standard STR typing methods already practiced in forensic DNA laboratories. The results generated by both of the methods is compared for concordance and quality of profiles. The 
results support consideration of the RapidHIT ${ }^{\mathrm{TM}} 200$ as an acceptable alternative to conventional, laboratory based STR analysis for the testing of single source buccal samples (Holland, M., \&Wendt, F., 2015). Although there have been studies of single source non buccal type samples including those that have been degraded, only limited information is provided and it is unclear what quantity and quality of DNA is needed to obtain profiles with RapidHIT ${ }^{\mathrm{TM}}$ 200. However, as stated before, successful genotyping results have occurred with these types of samples and Rapid DNA technology.

\subsection{DEGRADATION OF DNA}

In forensics, the challenge of recovering DNA from degraded samples due to UV light, heat, humidity and microorganisms are enormous. Many casework samples can be exposed to these factors leading to interference with the integrity of DNA. Degradation can cause short DNA fragments resulting in lack of amplification of some of these fragments and as a consequence, stochastic effects such as locus and allele dropout occur (Butler, 2010). Therefore, in some studies, DNA within a biological fluid is deliberately degraded in a controlled environment to mimic these samples. The substrate in which biological fluid is found along with the nature of harsh environment exposed to precipitates different properties being exhibited when extracting and isolating DNA (Thacker et al., 2006). The outcome tends to be an increase in these stochastic effects for the higher molecular weight markers (Butler, 2010). Artificially degraded DNA can be attained by a UV Crosslinker or a laminar hood with UV light where biological samples can be exposed to UV light for different time intervals or by the use of an oven or water bath of different temperature intervals for extreme heat and humidity.

\section{MATERIALS AND METHODS}

\subsection{STORAGE}

- After any buccal sample collection from participants, all samples were stored at room temperature

- After any blood sample collection from participants, all wet samples were thoroughly dried for at least 30 minutes away from light before being stored in a refrigerator $\left(2\right.$ to $\left.8^{\circ} \mathrm{C}\right)$

- After any degradation process, the degraded samples were stored in a refrigerator $\left(2\right.$ to $\left.8^{\circ} \mathrm{C}\right)$

- After any extraction process, the extracted product was stored in a freezer $\left(-12\right.$ to $\left.-20^{\circ} \mathrm{C}\right)$ 


\subsection{CONTAMINATION}

- All materials used were sterile or were sterilized by disinfecting with ethanol and exposure to UV light for at least 10 minutes

- During handling of materials from sample collection to generation of profiles, gloves and proper attire were worn

\subsection{CONCORDANCE STUDY}

Two buccal samples from a participant were collected following the appropriate Institutional Review Board (IRB) and Institutional Biosafety Committee (IBC) protocol by using a sterile swab to gently swipe against each inner cheek 5 times. The first sample was run on RapidHIT $^{\mathrm{TM}} 200$ instrument with a positive control, negative control and allelic ladder. It was run using "run buccal sample" until a profile was generated by the GeneMarker ${ }^{\circledR}$ HID software. The second sample was analyzed using the conventional laboratory method. Extraction was performed according to the technique recommended for $\mathrm{Chelex}^{\circledR} 100$. The extracted product was quantified according to the manufacturer's recommendation using Quantifiler ${ }^{\circledR}$ Trio Kit and Applied Biosystems 7500 Real-Time PCR System. After review of data, amplification was

performed in duplicate according to the manufacturer's recommendation using GlobalFiler ${ }^{\mathrm{TM}}$ PCR Amplification Kit and GeneAmp ${ }^{\mathrm{TM}}$ PCR System 9700. The amplified products were separated according to the manufacturer's recommendation using Applied Biosystems 3130 Genetic Analyzer and a profile was generated utilizing the GeneMapper ${ }^{\mathrm{TM}}$ ID-X Software. Evaluation was performed between profiles of samples generated from both methods. Data analysis was completed by the percent of correct allele calls between the two different methods using the t-test.

\section{RESULTS}

The percent of correct allele calls using the RapidHIT ${ }^{\mathrm{TM}} 200$ instrument as compared to the conventional laboratory method was $100 \%$ for the concordance study. Therefore, the two methods are not significantly different when buccal swabs are used to generate the DNA profiles.

\subsection{PRELIMINARY DEGRADATION STUDY FOR HEAT/HUMIDITY}

Blood samples were prepared by placing a drop of blood obtained by pricking a finger with a lancet onto a filter paper for a total of 3 drops. After thoroughly drying, each filter paper 
was cut as equally as possible into half and stored in a paper envelope. The halved blood drops were exposed to the following combination of heat/humidity for 24 hours using the 6105 Fingerprint Chamber by Caron as indicated in Table 2.

\begin{tabular}{|l|l|}
\hline Degree $\left({ }^{\circ} \mathrm{C}\right)$ & humidity \\
\hline $45^{\circ}$ & $50 \%$ \\
\hline $55^{\circ}$ & $50 \%$ \\
\hline $65^{\circ}$ & $50 \%$ \\
\hline $75^{\circ}$ & $50 \%$ \\
\hline $85^{\circ}$ & $50 \%$ \\
\hline $95^{\circ}$ & $40-50 \%$ \\
\hline
\end{tabular}

Table 2. The combination of heat in degree $\left({ }^{\circ} \mathrm{C}\right)$

and humidity the halved blood drops are exposed

to for 24 hours in 6105 Fingerprint Chamber

A total of 6 degraded samples were analyzed using the conventional laboratory method. Extraction was performed according to the technique recommended for Chelex ${ }^{\circledR} 100$. The extracted product was quantified according to the manufacturer's recommendation using Quantifiler $^{\circledR}$ Trio Kit and Applied Biosystems 7500 Real-Time PCR System. After review of data, amplification was performed in duplicate according to the manufacturer's recommendation using GlobalFiler ${ }^{\mathrm{TM}}$ PCR Amplification Kit and GeneAmp ${ }^{\mathrm{TM}}$ PCR System 9700. The amplified products were separated according to the manufacturer's recommendation using Applied Biosystems 3130 Genetic Analyzer and a profile was generated utilizing the GeneMapper ${ }^{\text {TM }}$ IDX Software. This complete process from preparation of blood sample to separation of amplified product in duplicate was repeated for reproducibility of the degradation process (1st and 2nd round).

\section{RESULTS}

Some profiles were not able to be generated using Applied Biosystems 3130 Genetic Analyzer. Therefore, review of the degradation indices provided by the analysis using Quantifiler $^{\circledR}$ Trio kit and interpretation of generated profiles were used to determine the three heat/humidity exposures to be chosen for the main study. Degradation index refers to the data observed when a sample displays a decrease in signal for large DNA fragments compared to small DNA fragments. The degradation index is automatically calculated by the HID Real-Time PCR software using the following formula: 


$$
\mathrm{DI}=\frac{\text { Small autosomal target DNA conc. }(\mathrm{ng} / \mathrm{uL})}{\text { Large autosomal target DNA conc. }(\mathrm{ng} / \mathrm{uL})}
$$

A degradation index of less than 1 typically indicates that DNA is not degraded or inhibited while a degradation index between 1 and 10 typically indicates that DNA is slightly to moderately degraded and a degradation index of greater than 10 indicates significant degradation (ThermoFisher Scientific, 2017). Table 3 provides the degradation index (DI) that was generated for samples in $1^{\text {st }}$ and $2^{\text {nd }}$ rounds for the various combinations of heat/humidity.

\begin{tabular}{|c|c|c|c|c|}
\hline SAMPLE & ROUND & $\begin{array}{l}\text { DEGREE } \\
\left({ }^{\circ} \mathrm{C}\right) / \text { humidity }\end{array}$ & $\mathrm{DI}$ & DNA PROFILE \\
\hline 1B & $1^{\mathrm{ST}}$ & $45 / 50$ & 0.493 & $\sqrt{ }$ \\
\hline $1 \mathrm{C}$ & $1^{S T}$ & $55 / 50$ & 0.496 & \\
\hline $1 \mathrm{E}$ & $1^{S T}$ & $65 / 50$ & 0.563 & \\
\hline $1 \mathrm{G}$ & $1^{S T}$ & $75 / 50$ & 0.639 & $\sqrt{ }$ \\
\hline $\mathrm{AA}$ & $1^{\mathrm{ST}}$ & $85 / 50$ & 1.076 & $\sqrt{ }$ \\
\hline 11 & $1^{\mathrm{ST}}$ & $95 / 50$ & 4.269 & $\sqrt{ }$ \\
\hline $2 \mathrm{G}$ & $2^{\mathrm{ND}}$ & $45 / 50$ & 0.644 & \\
\hline $2 B$ & $2^{\mathrm{ND}}$ & $55 / 50$ & 0.525 & $\sqrt{ }$ \\
\hline $2 \mathrm{C}$ & $2^{\mathrm{ND}}$ & $65 / 50$ & 0.527 & $\sqrt{ }$ \\
\hline $2 J$ & $2^{\mathrm{ND}}$ & $75 / 50$ & 0.619 & \\
\hline $2 K$ & $2^{\mathrm{ND}}$ & $85 / 50$ & 0.899 & \\
\hline $2 \mathrm{~L}$ & $2^{\mathrm{ND}}$ & $95 / 45$ & 4.222 & \\
\hline
\end{tabular}

The DNA profiles for samples 1B, 2B, 2C and 1G show complete correct allele calls and no degradation is indicated from the DI generated. Therefore, 75/50, 85/50 and 95/40-50 were selected for further study.

\subsection{COLLECTION OF BIOLOGICAL SAMPLES FROM INDIVIDUALS FOR HEAT/HUMIDITY}

Biological samples from seven participants (A through $\mathrm{G}$ ) were collected following the appropriate Institutional Review Board (IRB) and Institutional Biosafety Committee (IBC) protocol. Two buccal samples from a participant were obtained by using a sterile swab to gently swipe against each inner cheek 5 times. Each sample was stored in a swab box. Seven drops of 
blood (six for study and one additional) from a participant were collected on filter papers by pricking a finger with a lancet. After thoroughly drying, each filter paper was cut as equally as possible into half and stored in a paper envelope.

\subsection{BUCCAL SAMPLES FOR HEAT/HUMIDITY}

Buccal samples from participants were analyzed using the conventional laboratory method. Extraction was performed according to the technique recommended for Chelex ${ }^{\circledR} 100$. The extracted product was quantified according to the manufacturer's recommendation using Quantifiler ${ }^{\circledR}$ Trio Kit and Applied Biosystems 7500 Real-Time PCR System. After review of data, amplification was performed in duplicate according to the manufacturer's recommendation using GlobalFiler ${ }^{\mathrm{TM}}$ PCR Amplification Kit and GeneAmp ${ }^{\mathrm{TM}}$ PCR System 9700. The amplified products were separated according to the manufacturer's recommendation using Applied Biosystems 3130 or 3500 Genetic Analyzer and a profile was generated utilizing the GeneMapper ${ }^{\mathrm{TM}} \mathrm{ID}-\mathrm{X}$ Software. This profile was used as a reference profile for comparison to the degraded profile.

\subsection{DEGRADATION OF BIOLOGICAL SAMPLES FROM INDIVIDUALS FOR HEAT/HUMIDITY}

The three pairs of halved blood drops were incubated in extreme heat for 24 hours while varying the temperature and humidity for each pair as determined by the preliminary study of 75/50, 85/50 and 95/40-50 using the 6105 Fingerprint Chamber by Caron.

\subsection{EXTRACTION AND QUANTITATION OF DNA FROM DEGRADED BIOLOGICAL SAMPLES FOR HEAT/HUMIDITY}

One half of the degraded blood samples was extracted for DNA according to the technique recommended for $C_{\text {Chelex }}{ }^{\circledR} 100$. The other half was allotted for the RapidHIT ${ }^{\mathrm{TM}} 200$ instrument. The extracted product was quantified according to the manufacturer's recommendation using Quantifiler ${ }^{\circledR}$ Trio Kit and Applied Biosystems 7500 Real-Time PCR System. Some samples were concentrated by use of Amicon ${ }^{\circledR}$ Ultra- 0.5 centrifugal filter devices due to low quantity of T. Small Autosomal. Data generated is indicated in Table 4. 


\section{RESULTS}

\begin{tabular}{|c|c|c|c|}
\hline SAMPLE & $\begin{array}{l}\text { DEGREE } \\
\left({ }^{\circ} \mathrm{C}\right) / \text { humidity }\end{array}$ & $\begin{array}{l}\text { QUANTITY } \\
\text { ng/uL }\end{array}$ & DI \\
\hline $6 A$ & $75 / 50$ & 0.292 & 0.875 \\
\hline $6 B$ & $75 / 50$ & 0.266 & 0.647 \\
\hline $6 C$ & $75 / 50$ & 0.311 & 0.698 \\
\hline 6D (conc) & $75 / 50$ & 0.553 & 0.919 \\
\hline $6 \mathrm{E}$ & $75 / 50$ & 0.585 & 0.642 \\
\hline $6 F$ (conc) & $75 / 50$ & 0.429 & 0.929 \\
\hline $6 G$ & $75 / 50$ & 0.451 & 0.733 \\
\hline $5 A$ & $85 / 50$ & 0.265 & 1.349 \\
\hline $5 B$ & $85 / 50$ & 0.139 & 1.904 \\
\hline $5 C$ & $85 / 50$ & 0.051 & 0.942 \\
\hline $5 \mathrm{D}$ & $85 / 50$ & 0.126 & 1.860 \\
\hline $5 \mathrm{E}$ & $85 / 50$ & 0.231 & 1.430 \\
\hline $5 \mathrm{~F}$ & $85 / 50$ & 0.058 & 2.029 \\
\hline $5 G$ & $85 / 50$ & 0.121 & 1.367 \\
\hline $7 A$ (conc) & $95 / 40$ & 0.377 & 7.911 \\
\hline 7B (conc) & $95 / 40$ & 1.086 & 5.358 \\
\hline 7C (conc) & $95 / 40$ & 0.735 & 4.716 \\
\hline 7D (conc) & $95 / 40$ & 0.197 & 12.565 \\
\hline $7 E$ (conc) & $95 / 40$ & 0.641 & 5.686 \\
\hline $7 F$ (conc) & $95 / 40$ & 0.806 & 6.194 \\
\hline $7 G$ (conc) & $95 / 40$ & 0.633 & 5.202 \\
\hline
\end{tabular}

Table 4. The Quantity and Degradation Index (DI) for the participants' degraded samples in the various combinations of heat/humidity

\subsection{AMPLIFICATION OF DNA FROM DEGRADED BIOLOGICAL SAMPLES FOR HEAT/HUMIDITY}

Amplification was performed in duplicate according to the manufacturer's recommendation using GlobalFiler ${ }^{\mathrm{TM}}$ PCR Amplification Kit and GeneAmp ${ }^{\mathrm{TM}}$ PCR System 9700. The amplified products were separated according to the manufacturer's recommendation using Applied Biosystems 3500 Genetic Analyzer and a profile was generated utilizing the GeneMapper ${ }^{\mathrm{TM}}$ ID-X Software.

\section{RESULTS}

For the seven participants and each of the three different combinations of heat/humidity, a total of 42 profiles were generated and reviewed. All the profiles in the 75/50 heat/humidity 
combination of degradation had all the correct alleles called with no drop out. The profiles for four of the participants (B, D, F and G) are shown in Figures 6, 7, 8 and 9.

All the profiles in the $85 / 50$ heat/humidity combination of degradation had all the correct alleles called with some profiles having drop out. The profiles that had drop out all occurred on the TPOX locus. The profiles for four of the participants (B, D, F and G) are shown in Figures $10,11,12$ and 13.

All the profiles in the 95/40 heat/humidity combination of degradation had all the correct alleles called with all profiles having significant drop out. The profiles for four of the participants (B, D, F and G) are shown in Figures 14, 15, 16 and 17.

The profiles had markers specified in panel with color-coded headers that reflect GQ (Genotype Quality) results. Green would indicate that GQ is within the passing range. Yellow would indicate that GQ is between the passing range and low quality range. Red would indicate that GQ is within the low quality range (ThermoFisher Scientific, 2015). 

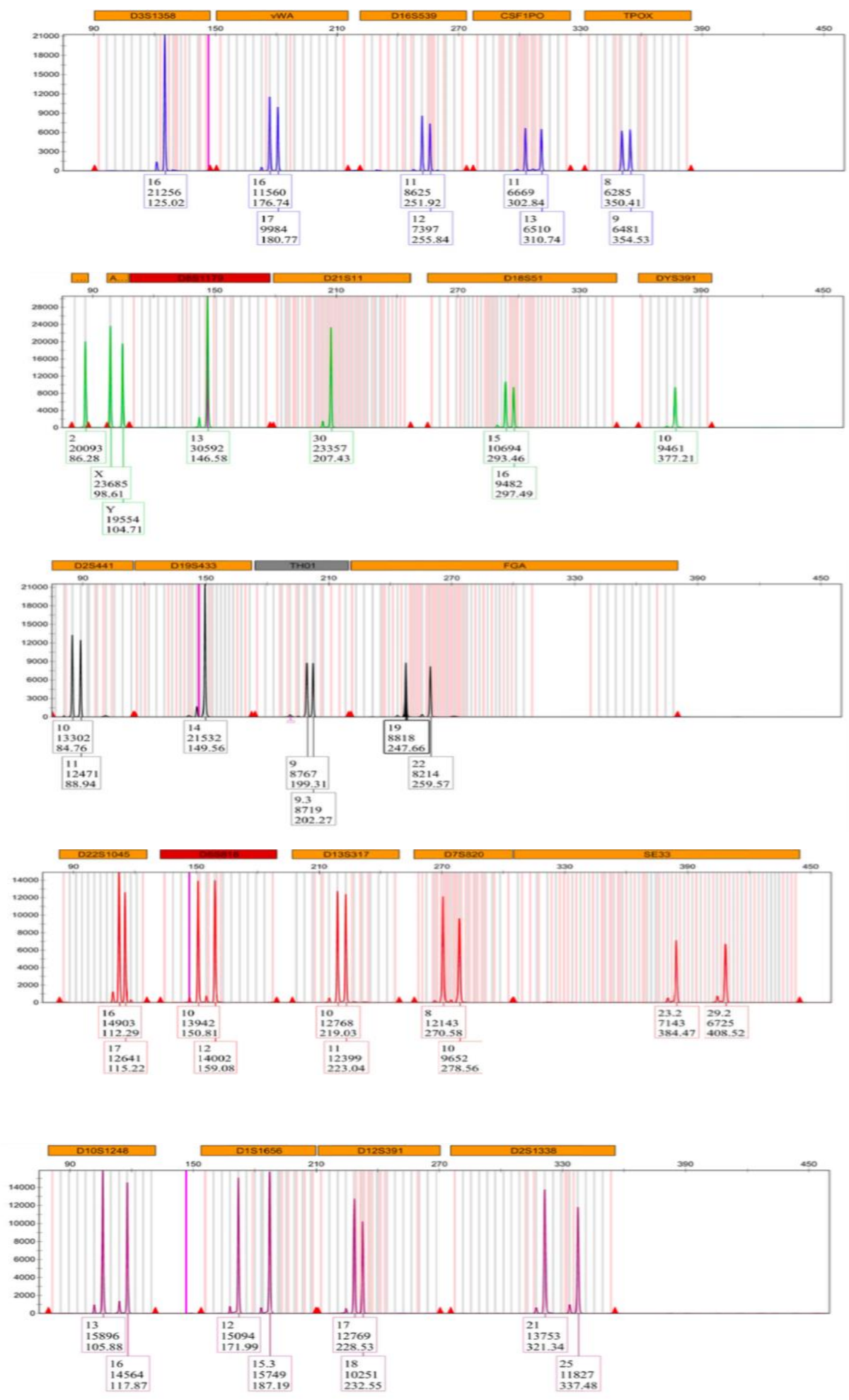

Figure 6. DNA profile for participant B degraded under 75/50 

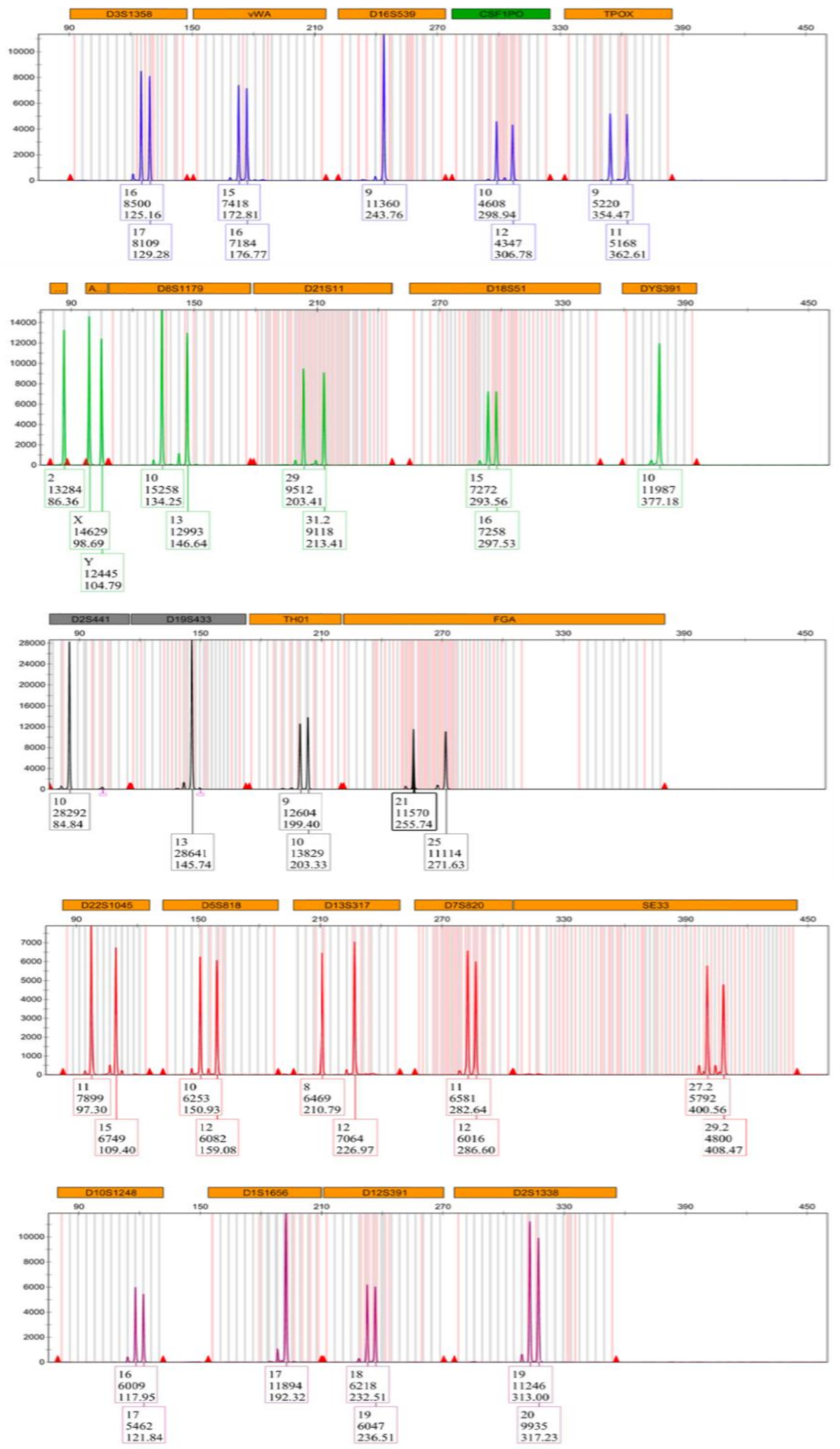

Figure 7. DNA profile for participant $\mathrm{D}$ degraded under $75 / 50$ 

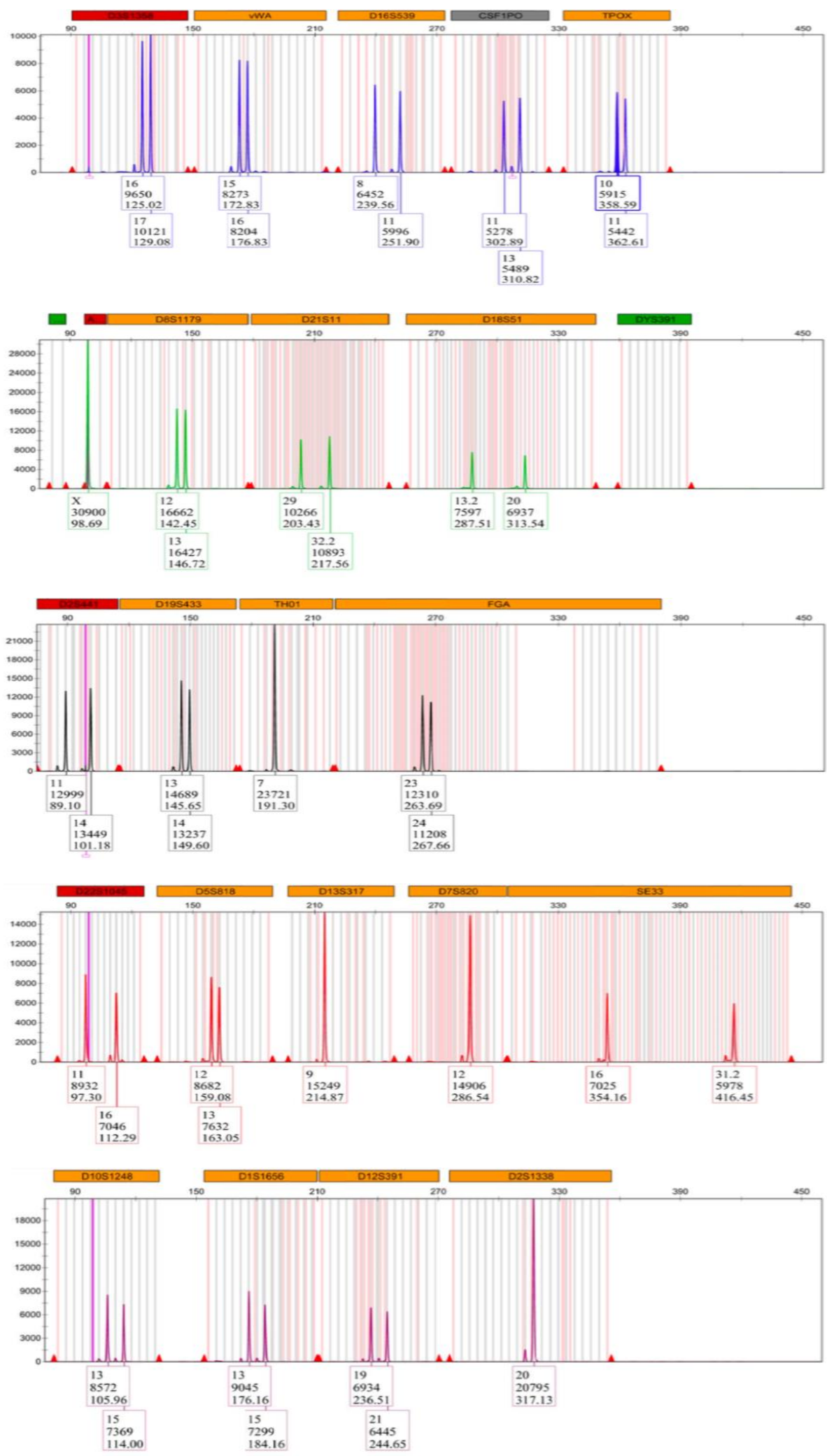

Figure 8. DNA profile for participant $\mathrm{F}$ degraded under $75 / 50$ 

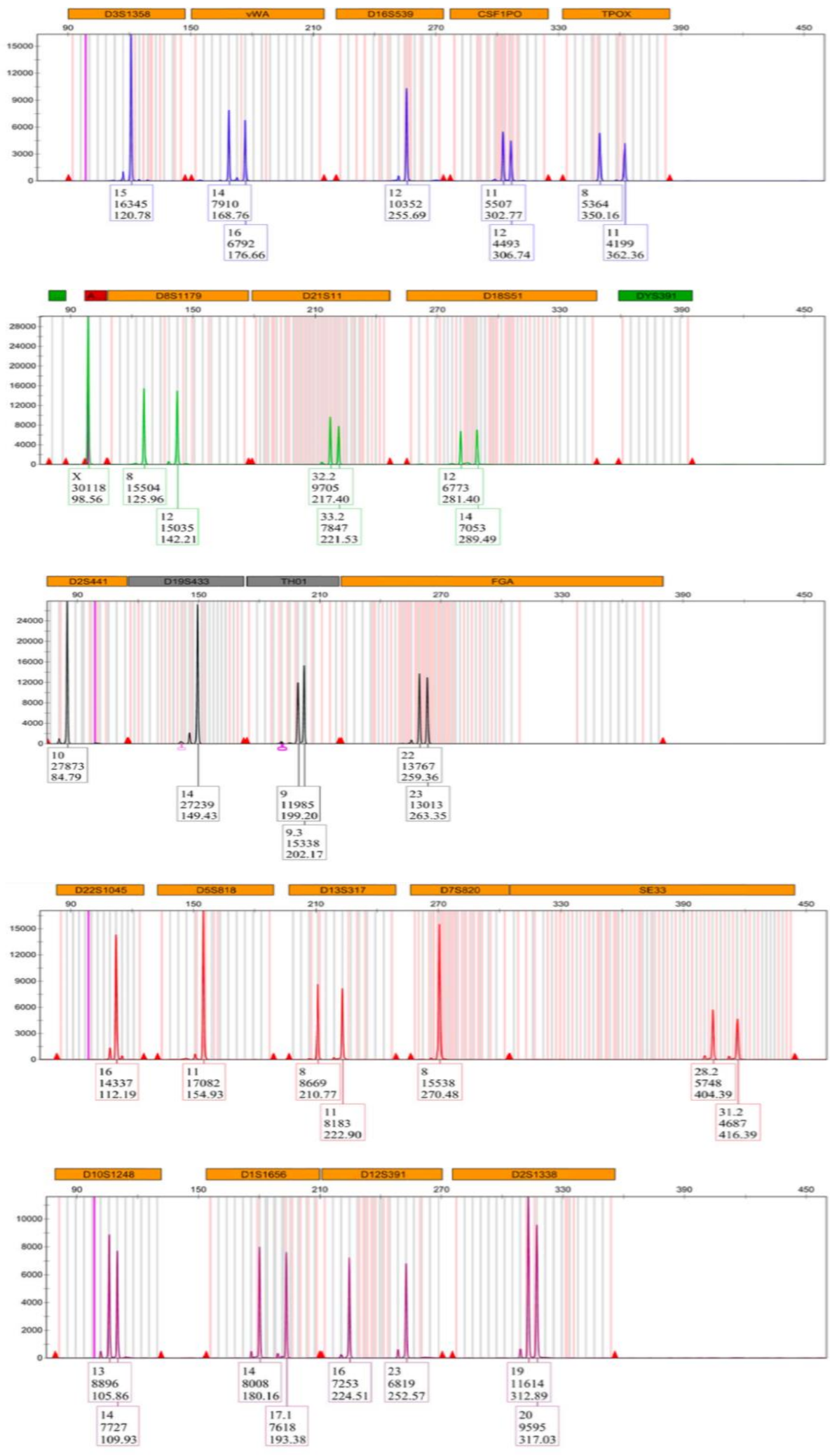

Figure 9. DNA profile for participant $\mathrm{G}$ degraded under 75/50 

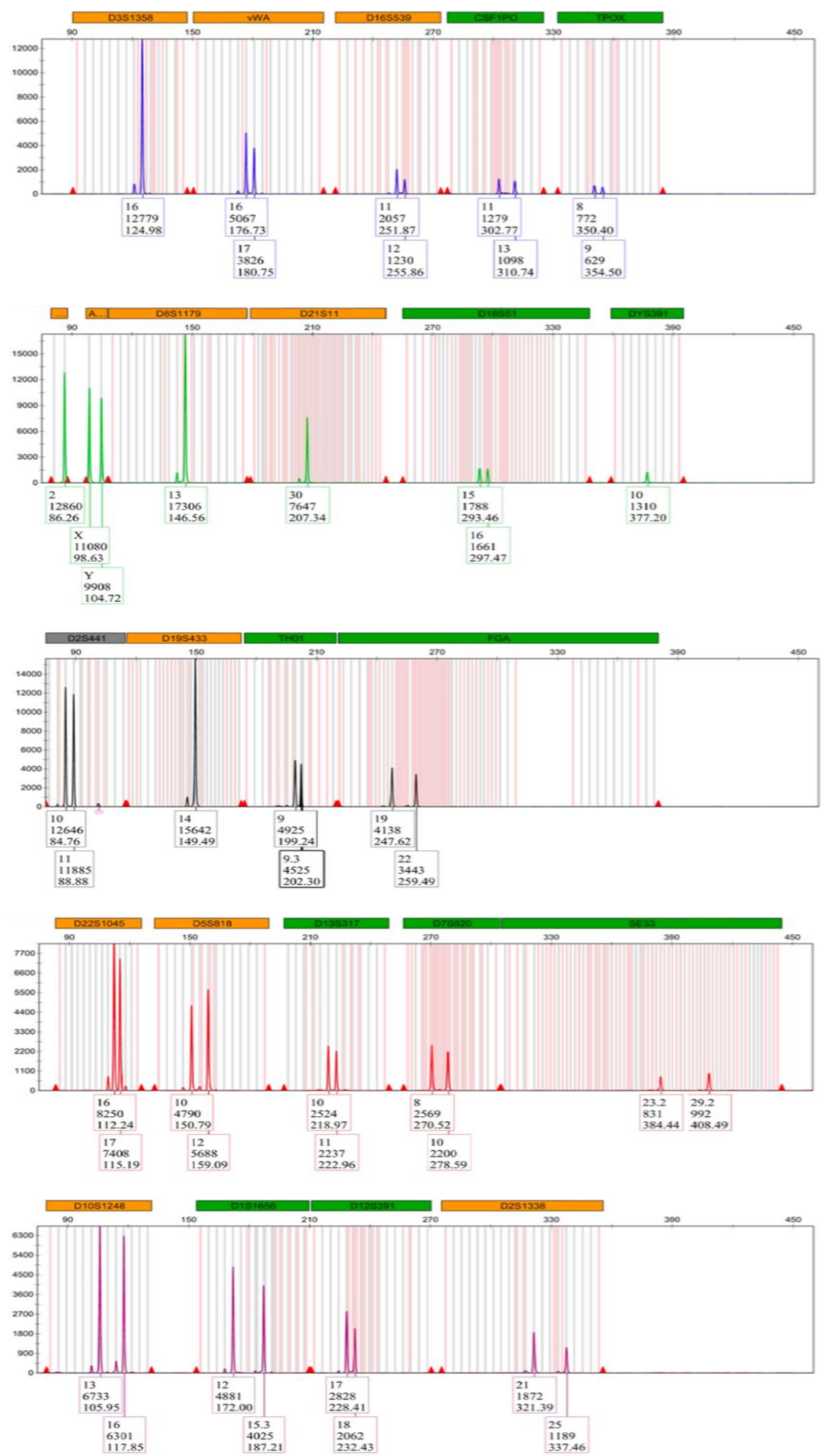

Figure 10. DNA profile for participant B degraded under $85 / 50$ 

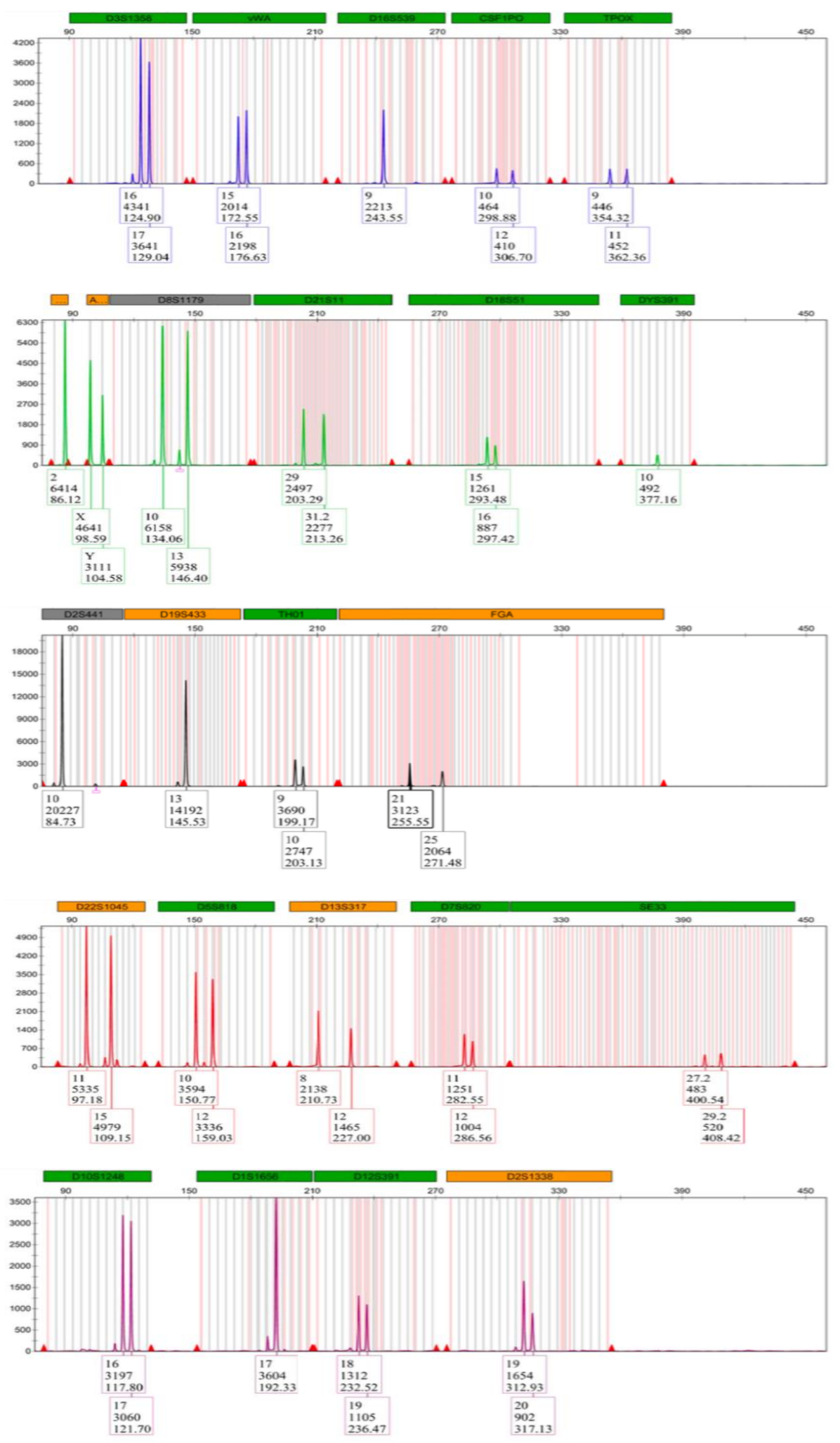

Figure 11. DNA profile for participant $D$ degraded under $85 / 50$ 

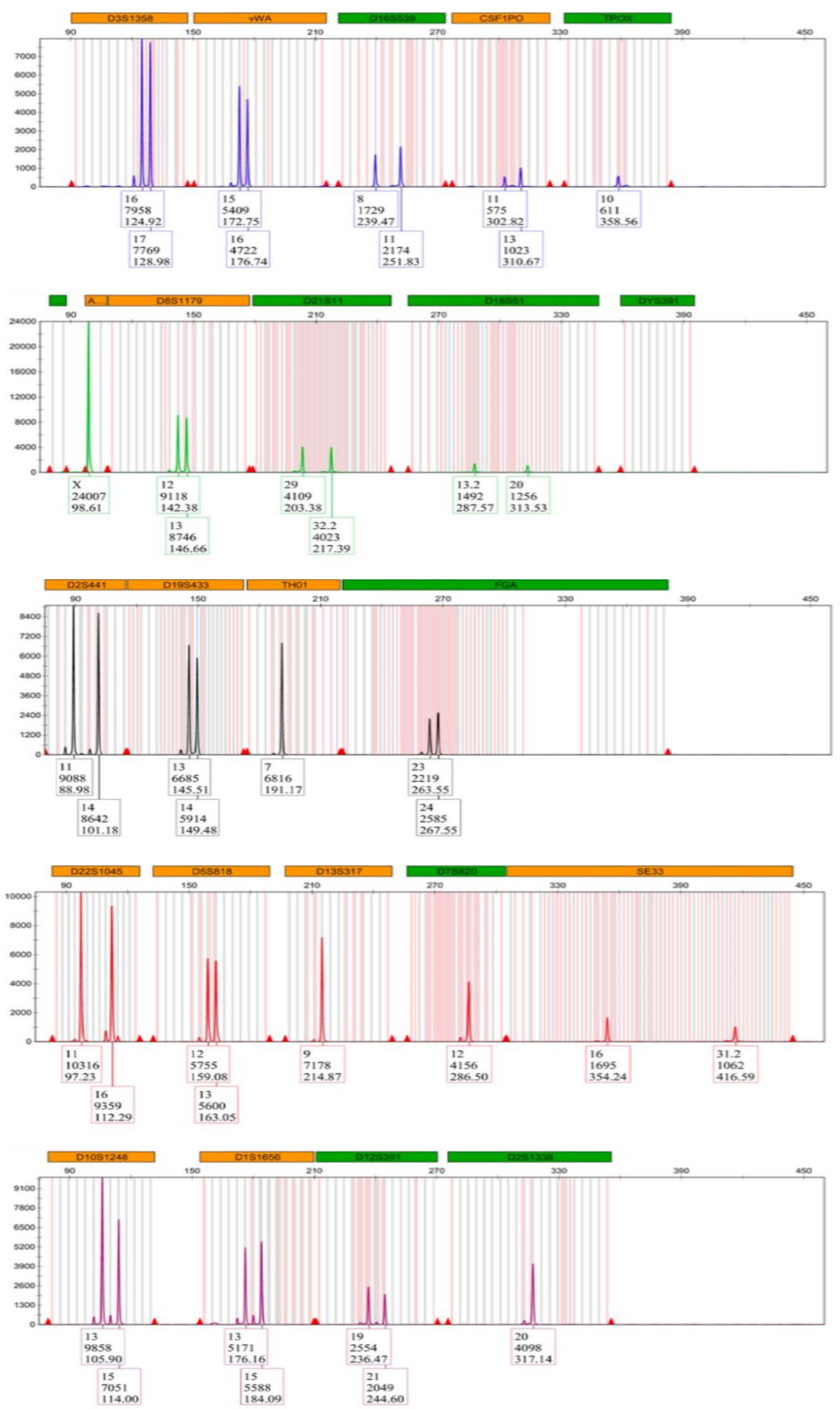

Figure 12. DNA profile for participant $F$ degraded under $85 / 50$ 

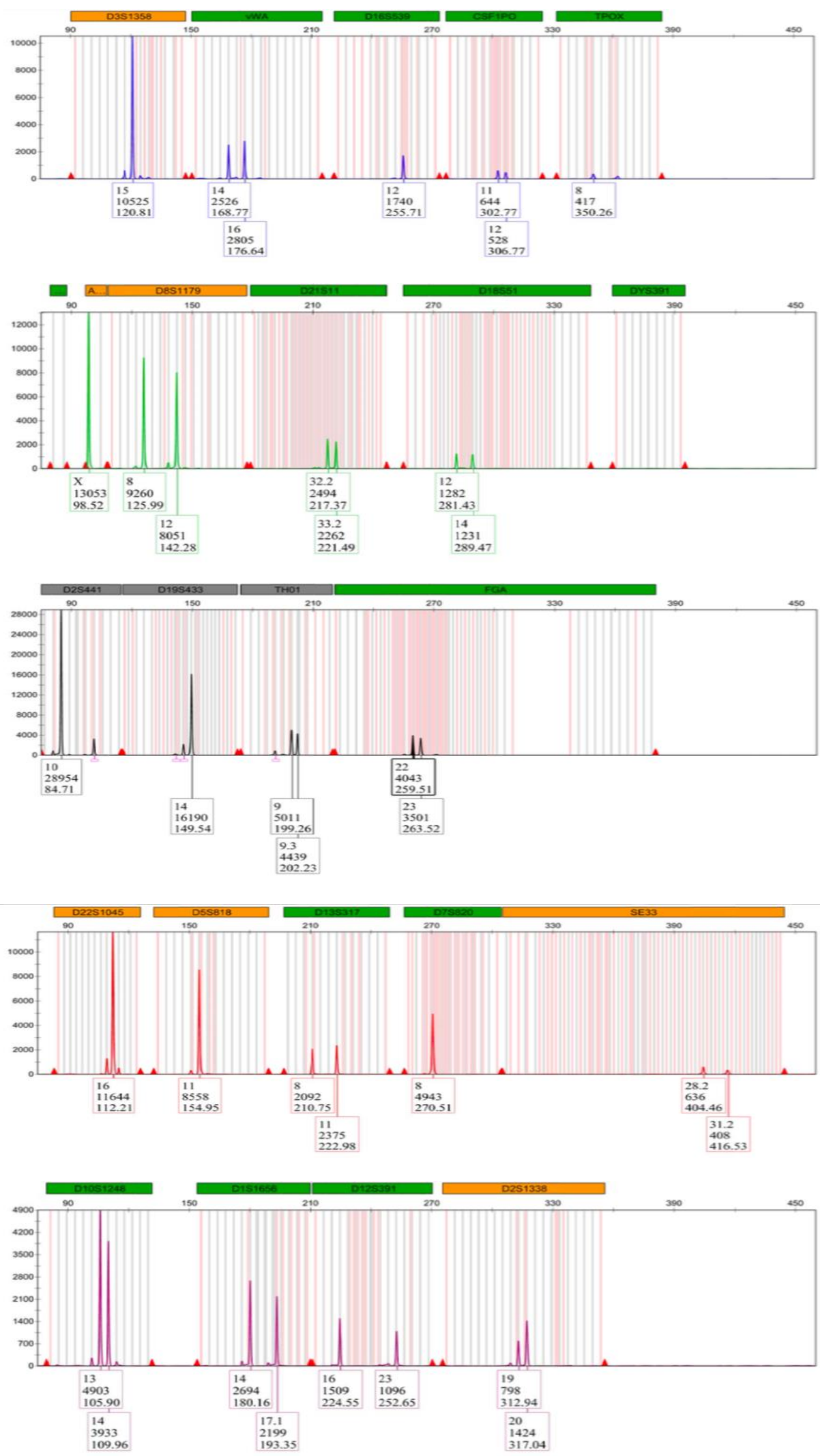

Figure 13. DNA profile for participant $\mathrm{G}$ degraded under $85 / 50$ 

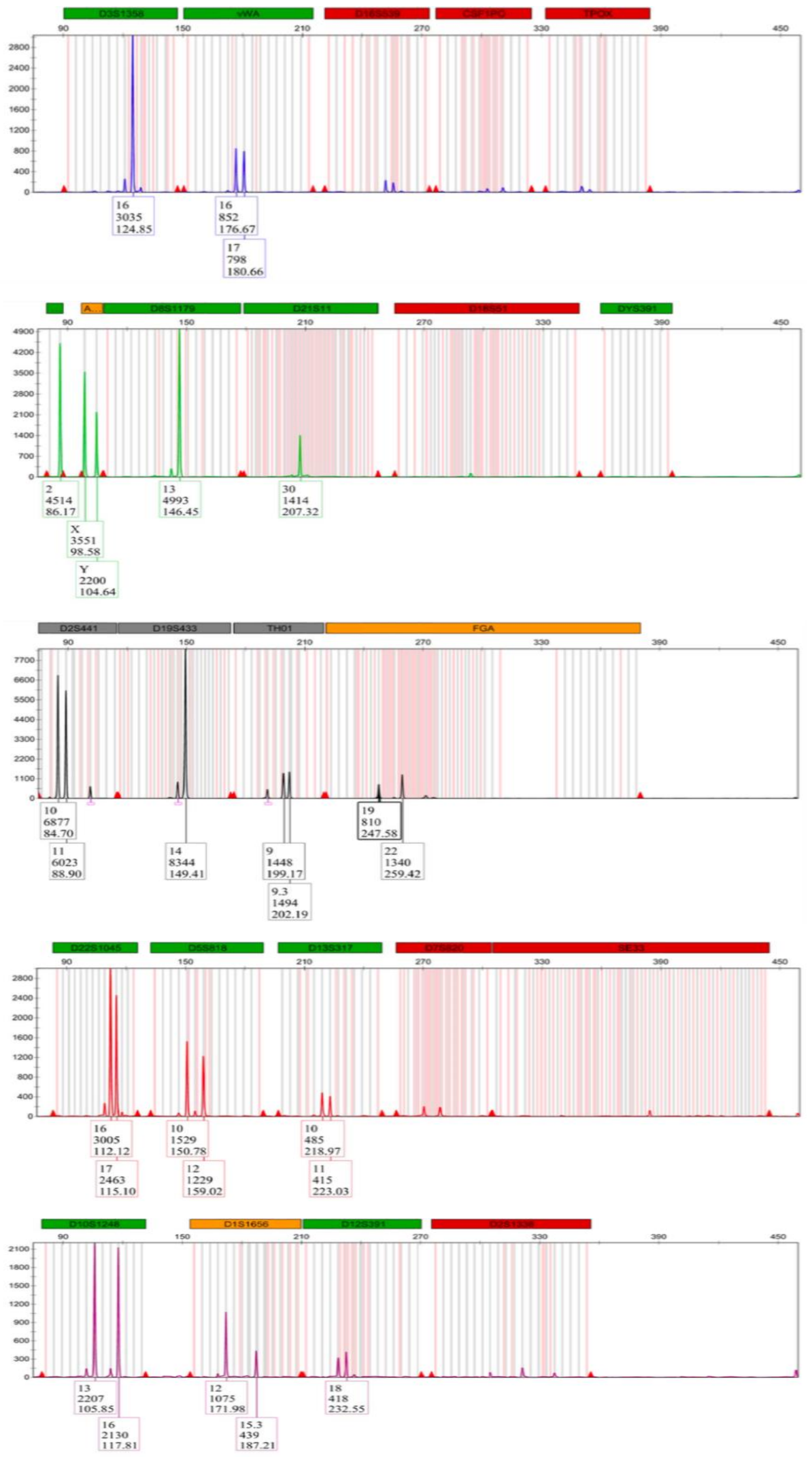

Figure 14. DNA profile for participant B degraded under $95 / 40$ 

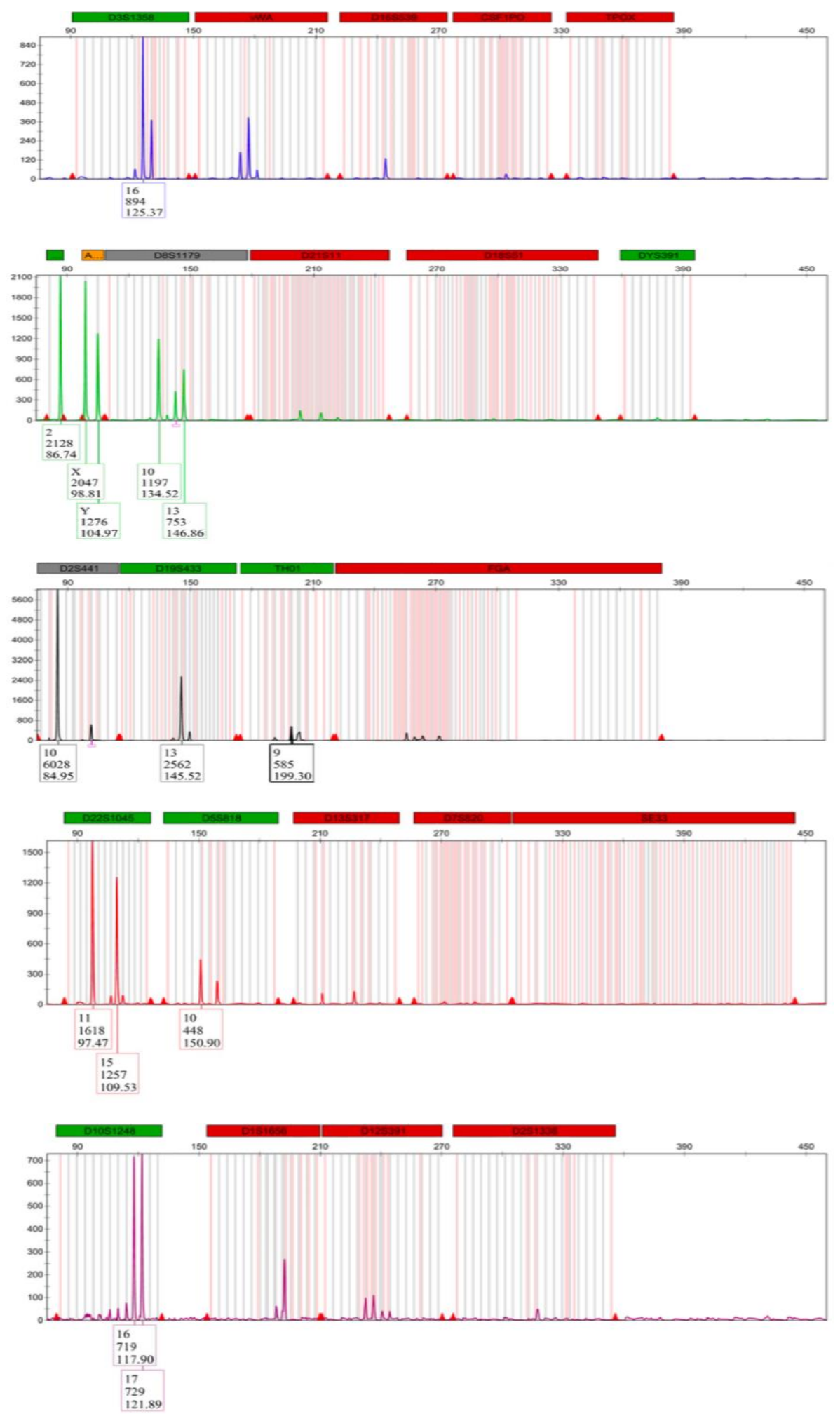

Figure 15. DNA profile for participant D degraded under $95 / 40$ 

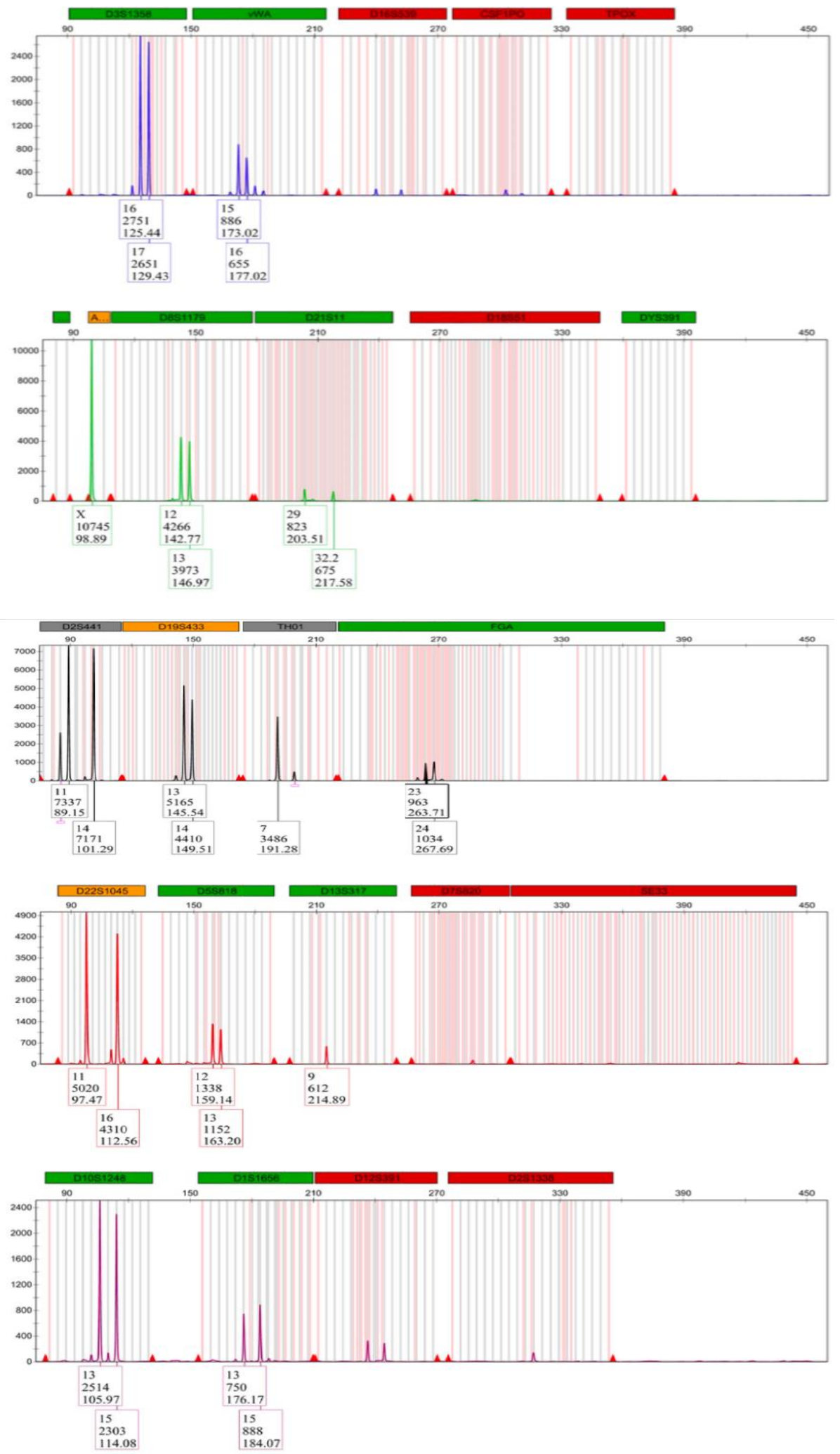

Figure 16. DNA profile for participant $\mathrm{F}$ degraded under $95 / 40$ 

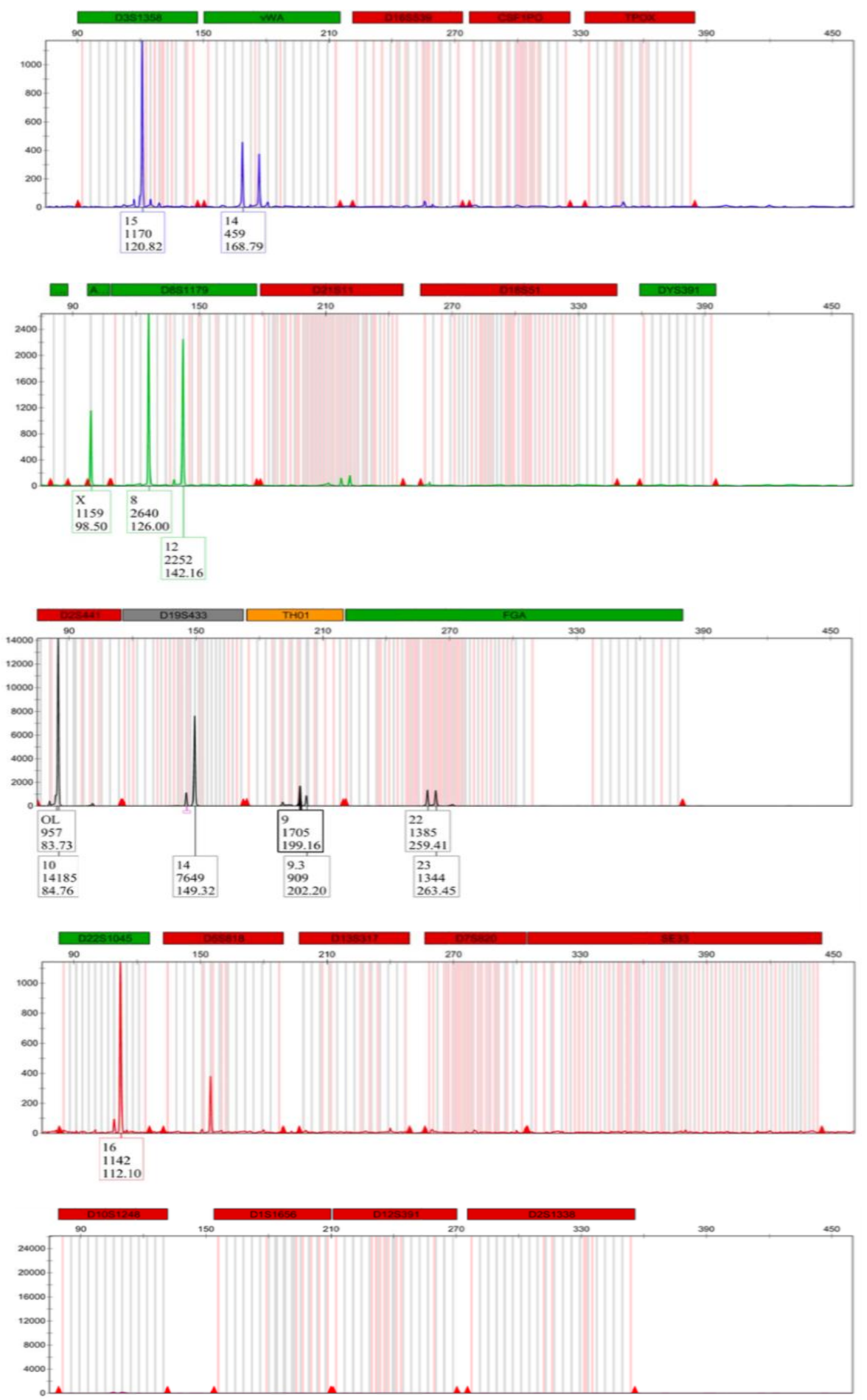

Figure 17. DNA profile for participant $\mathrm{G}$ degraded under $95 / 40$ 


\subsection{RAPIDHIT ${ }^{\text {TM }} 200$ ANALYSIS OF DEGRADED SAMPLES FOR HEAT/HUMIDITY}

All degraded samples were run on RapidHIT ${ }^{\mathrm{TM}} 200$ instrument with an allelic ladder. Samples were run using "run other samples" and profiles were generated by the GeneMarker ${ }^{\circledR}$ HID software.

\section{RESULTS}

For the seven participants and each of the three different combinations of heat/humidity, a total of 21 profiles were generated and reviewed. Two of the profiles in the 75/50 heat/humidity combination of degradation had drop out and one profile had a drop in. A drop in can be recognized when comparing the DNA profile to the reference buccal DNA profile. The profiles for four of the participants (B, D, F and G) are shown in Figures 18, 19, 20 and 21.

All the profiles in the $85 / 50$ heat/humidity combination of degradation had drop out and some had drop in. The profiles for four of the participants (B, D, F and G) are shown in Figures $22,23,24$ and 25.

All the profiles in the $95 / 40$ heat/humidity combination of degradation had significant drop out and some had drop in. The profiles for four of the participants (B, D, F and G) are shown in Figures 26, 27, 28 and 29. 

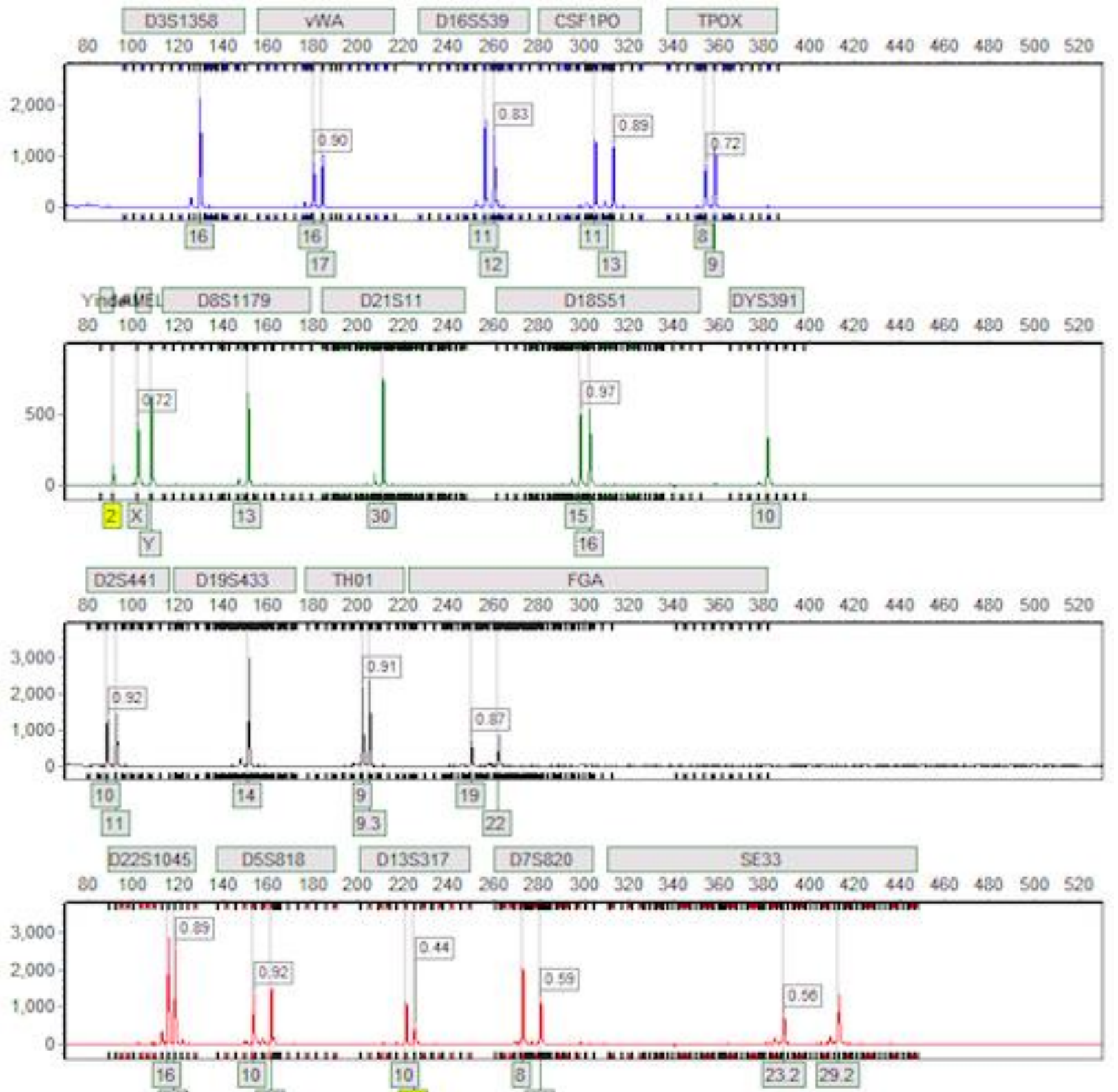

$16[10] 10$

10

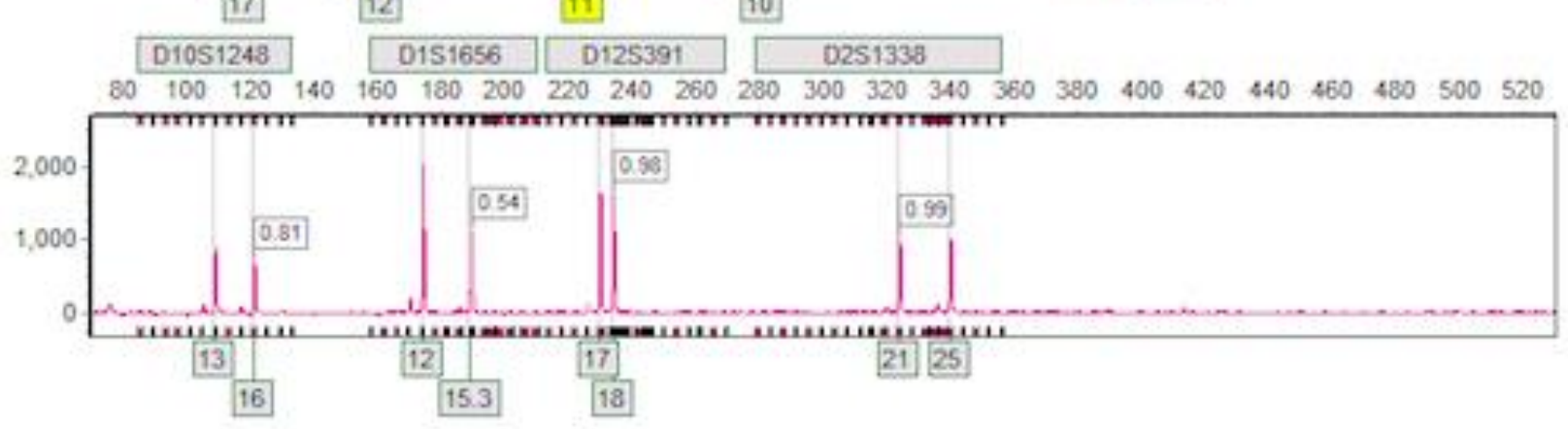

Figure 18. RapidHIT ${ }^{\mathrm{TM}} 200$ DNA profile for participant B degraded under $75 / 50$ 


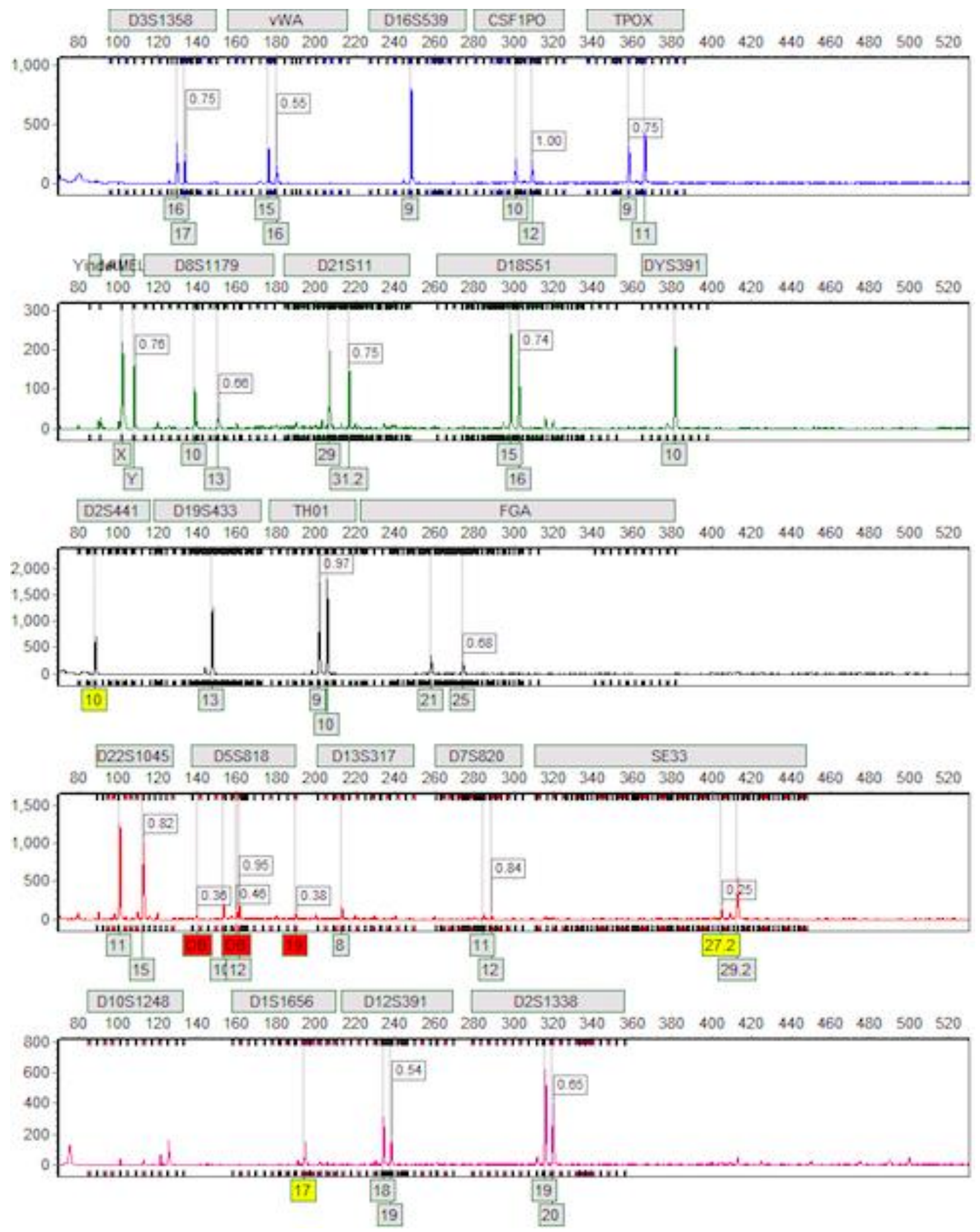

Figure 19. RapidHIT ${ }^{\mathrm{TM}} 200$ DNA profile for participant $\mathrm{D}$ degraded under $75 / 50$ 


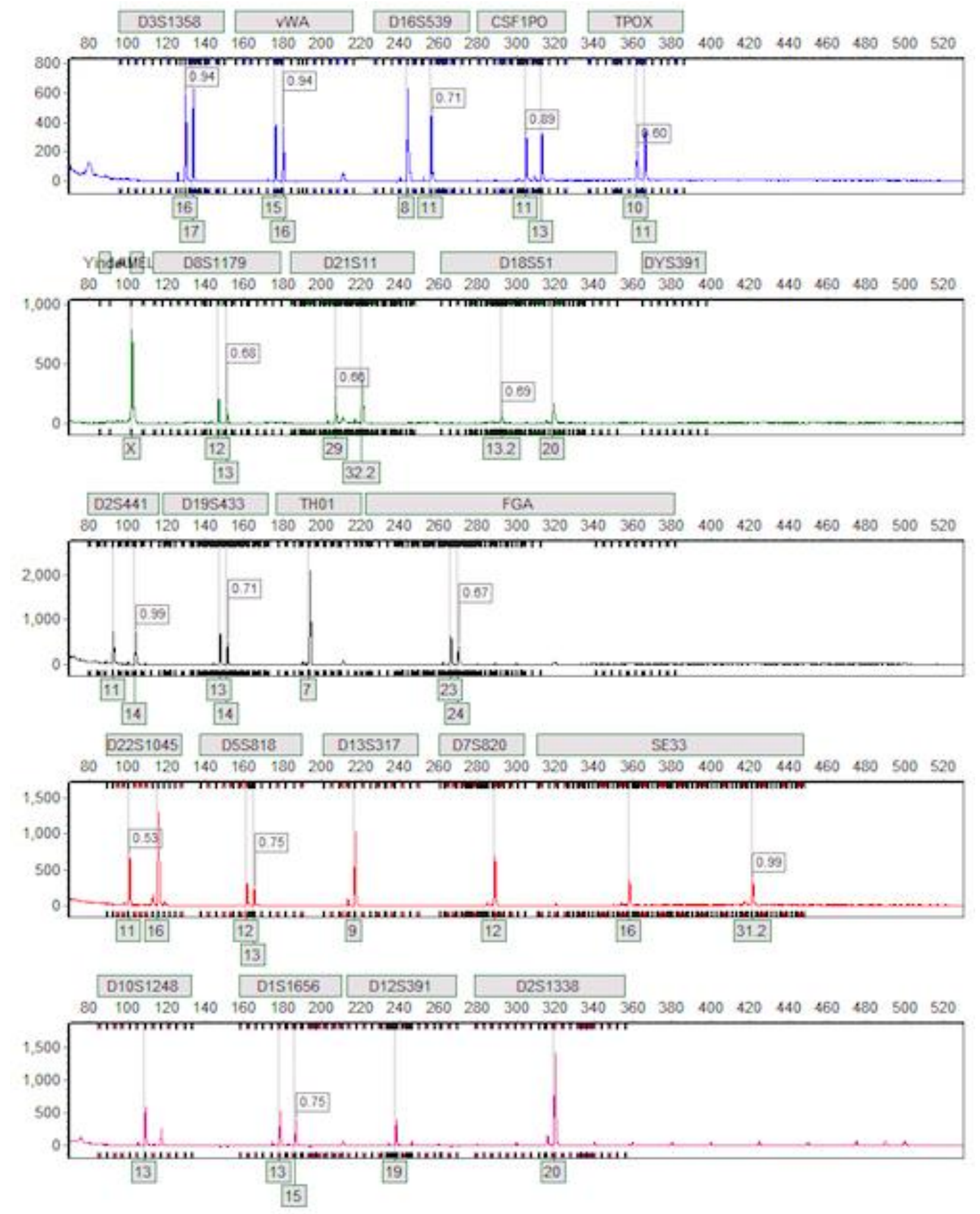

Figure 20. RapidHIT ${ }^{\mathrm{TM}} 200$ DNA profile for participant $\mathrm{F}$ degraded under 75/50 

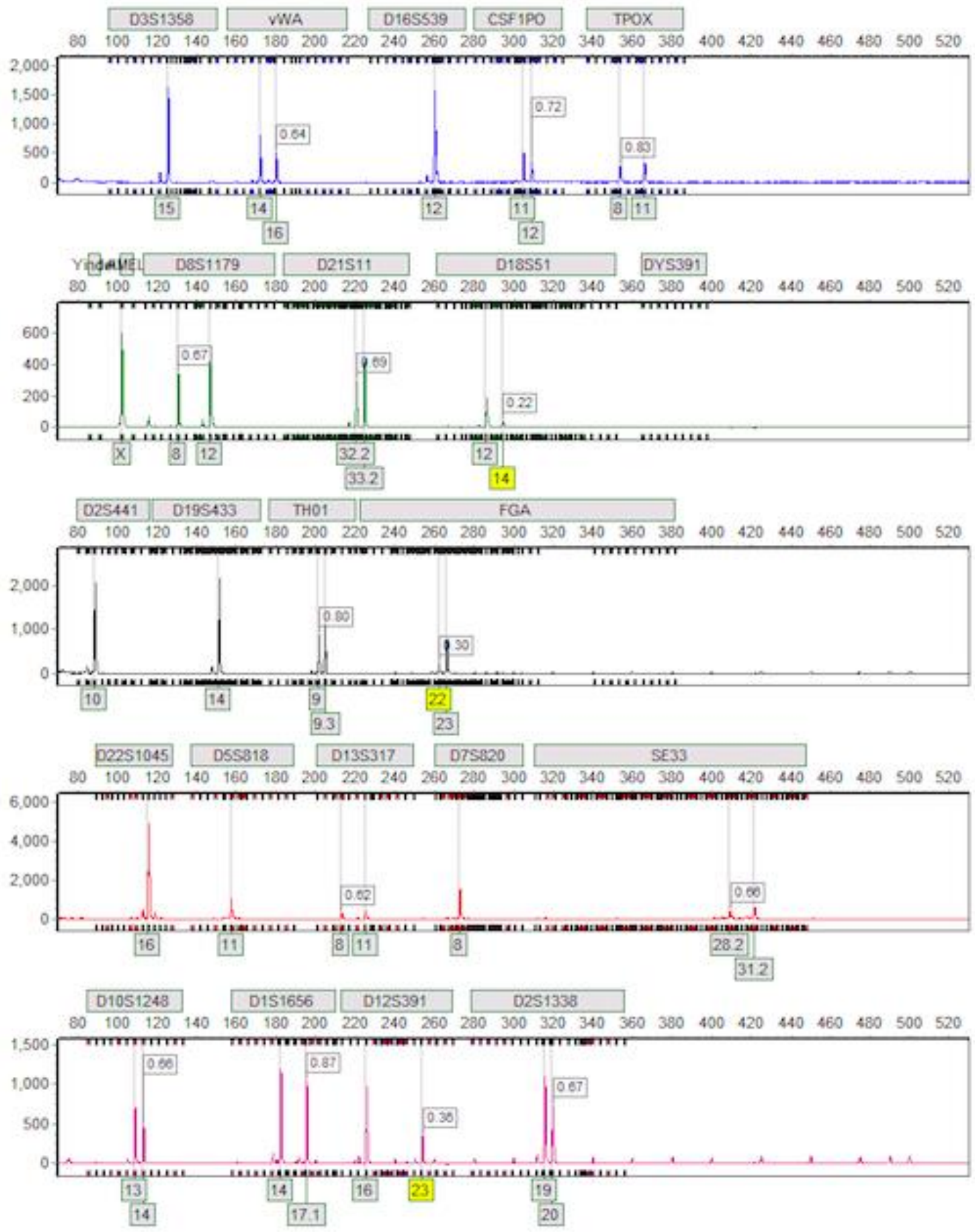

Figure 21. RapidHIT ${ }^{\mathrm{TM}} 200$ DNA profile for participant $\mathrm{G}$ degraded under $75 / 50$ 

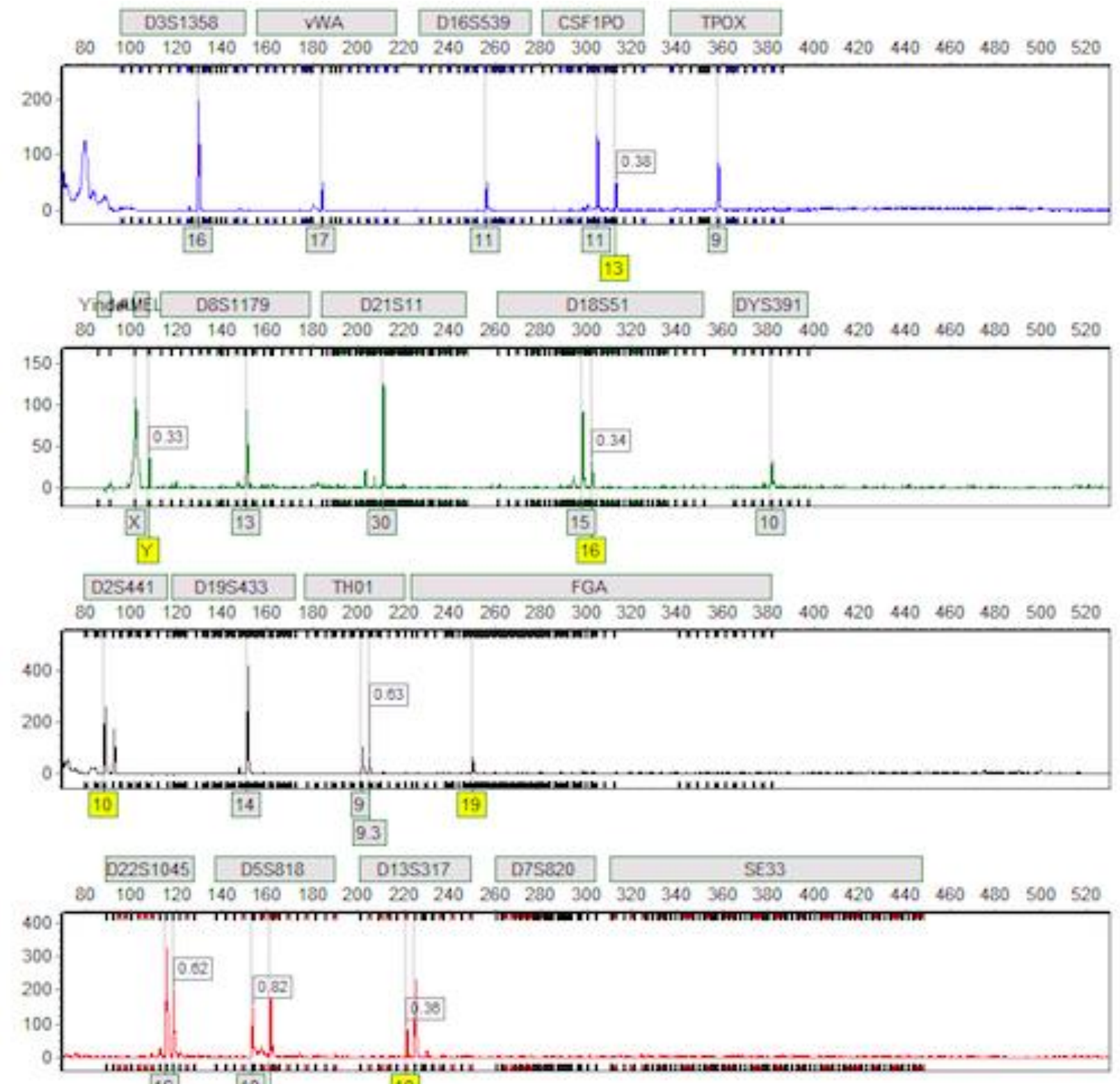

0

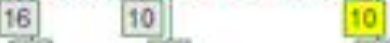

17 12 11

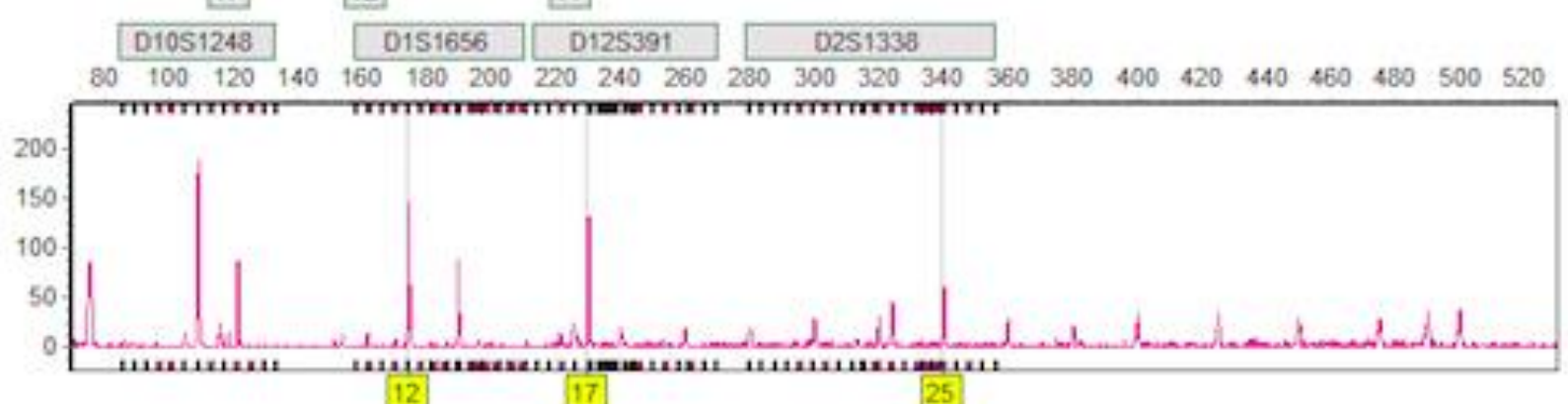

Figure 22. RapidHIT ${ }^{\mathrm{TM}} 200$ DNA profile for participant B degraded under $85 / 50$ 

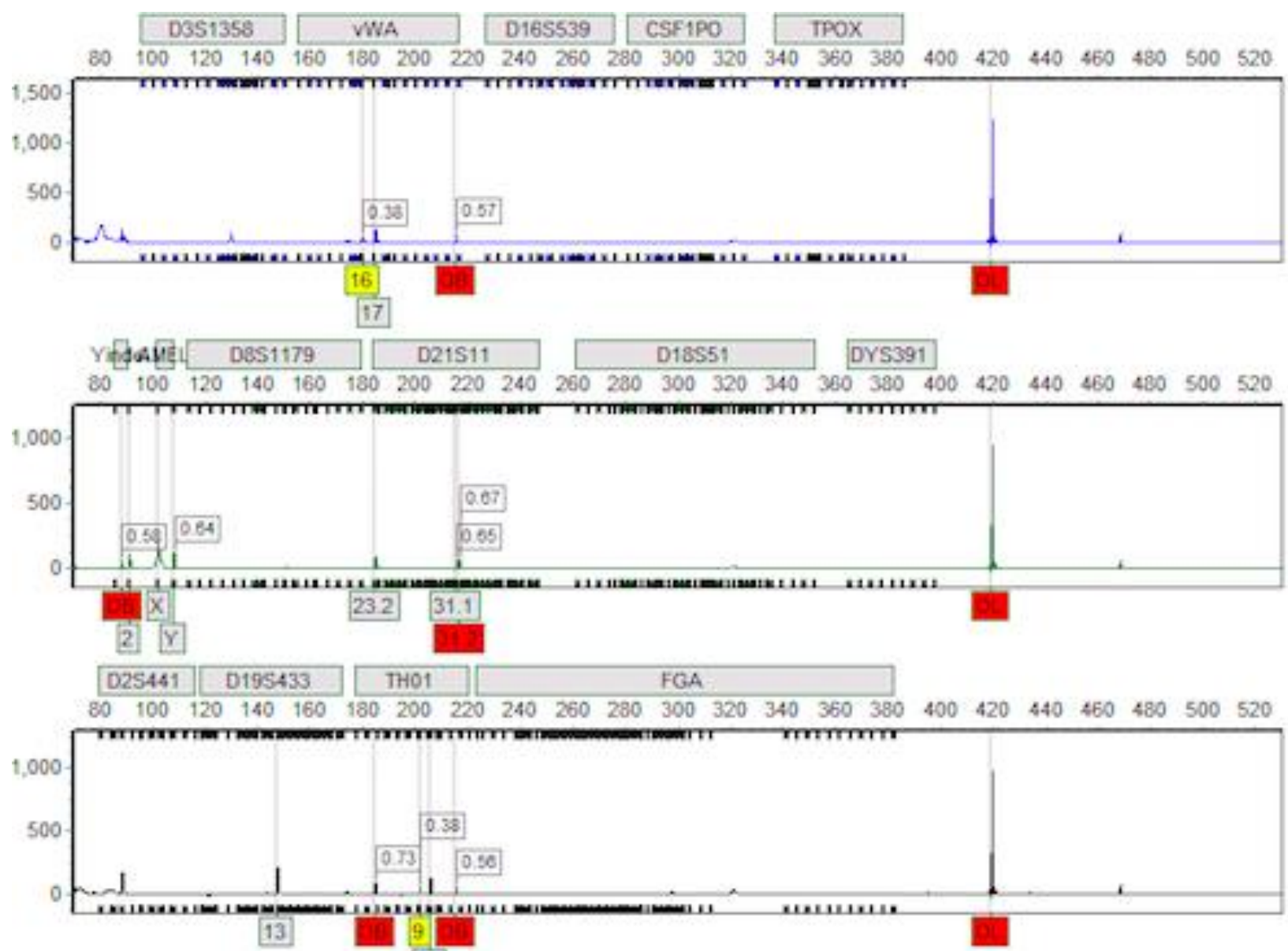

10.

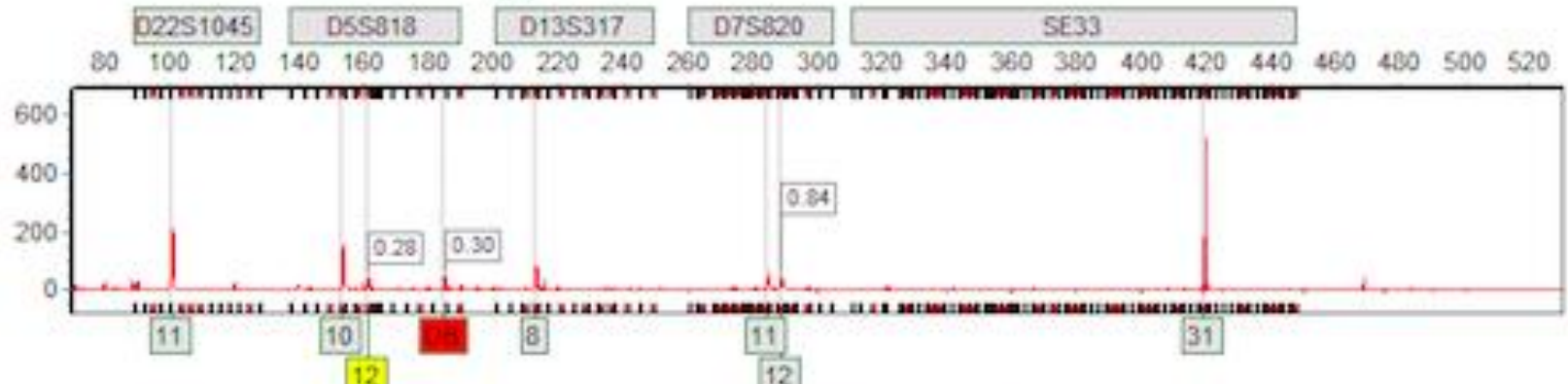

12.

12

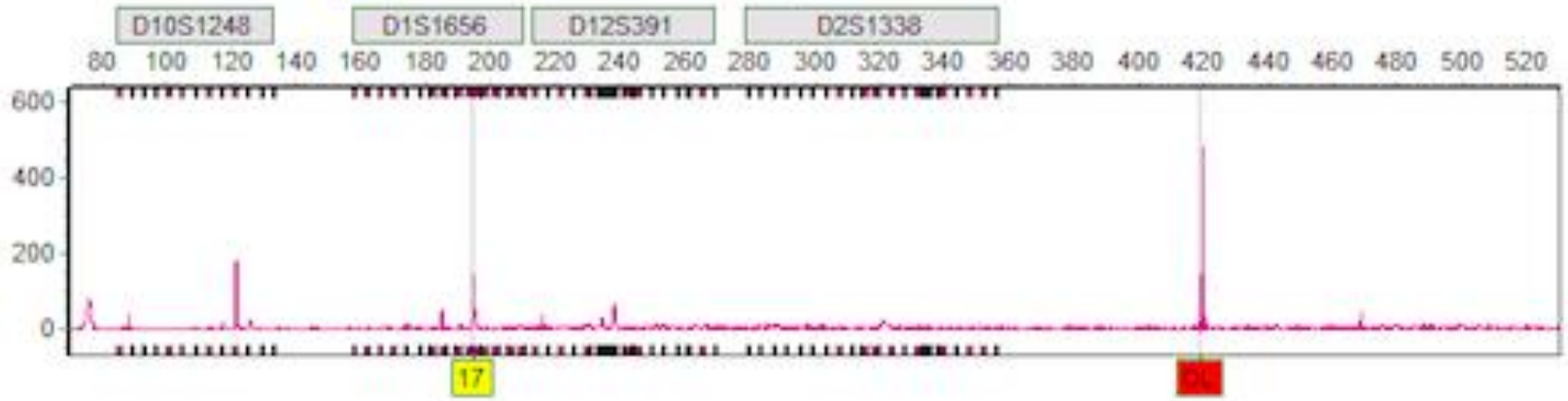

Figure 23. RapidHIT ${ }^{\mathrm{TM}} 200$ DNA profile for participant D degraded under $85 / 50$ 


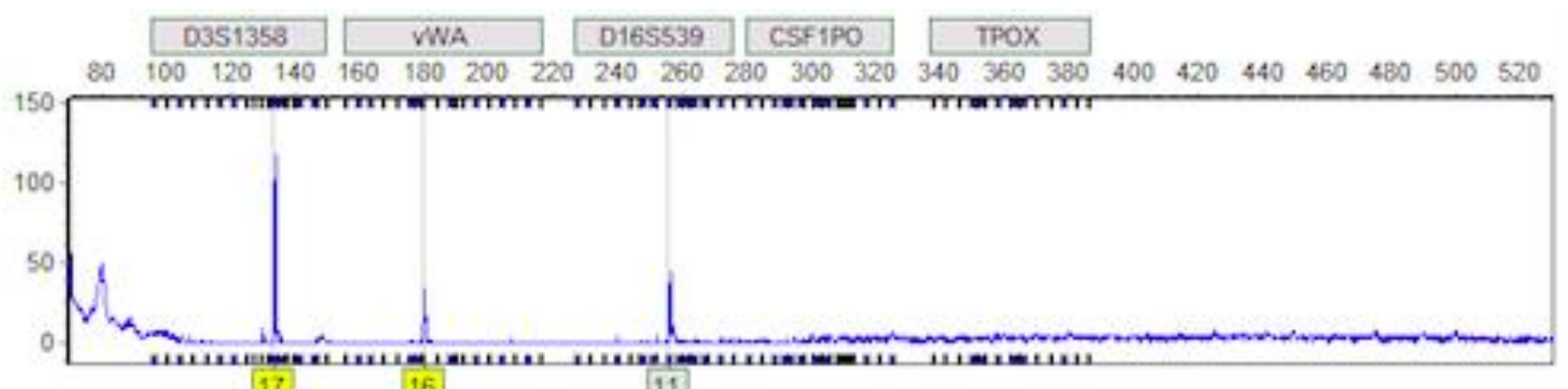
17 16 116
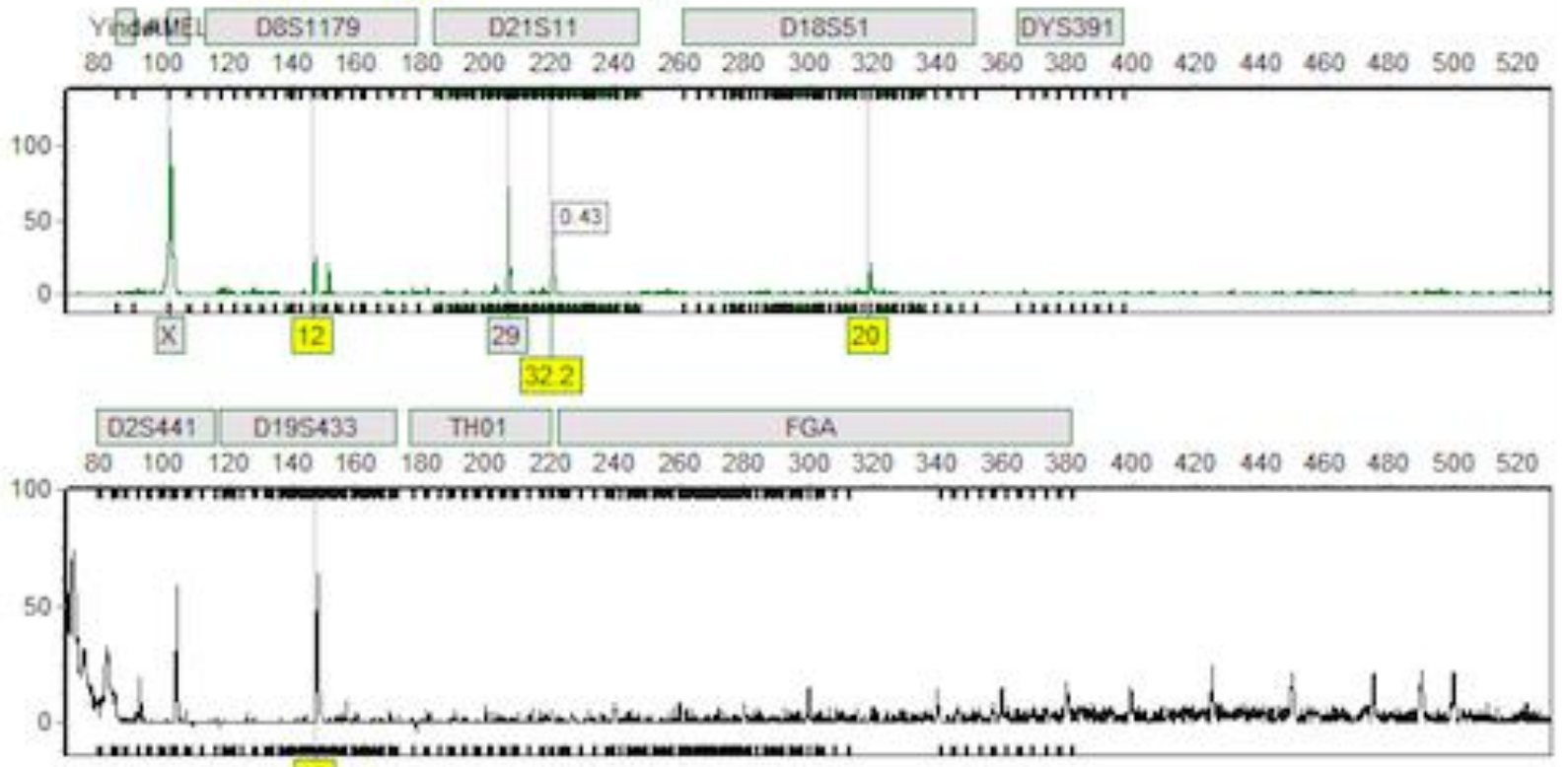

13

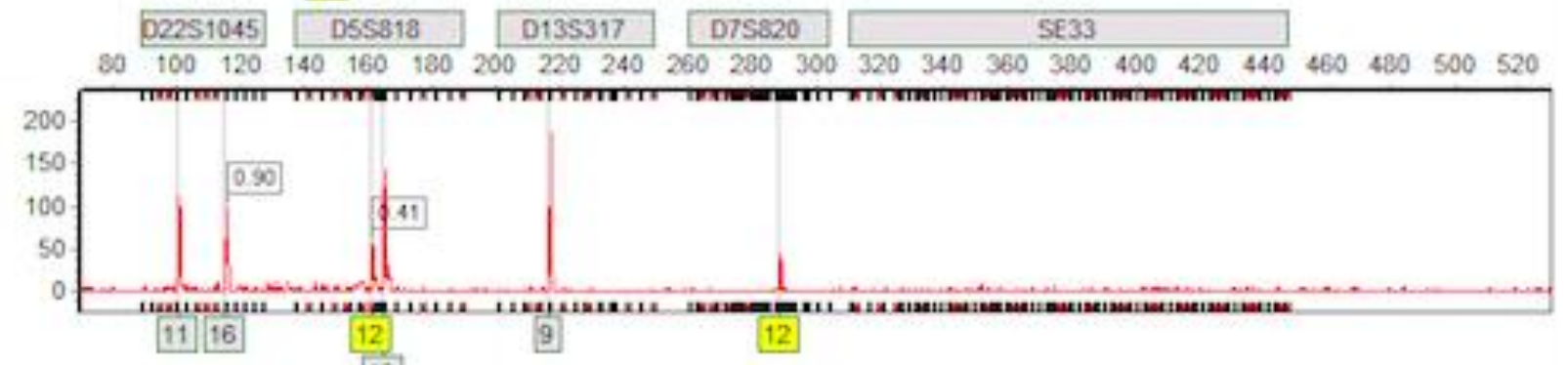

13

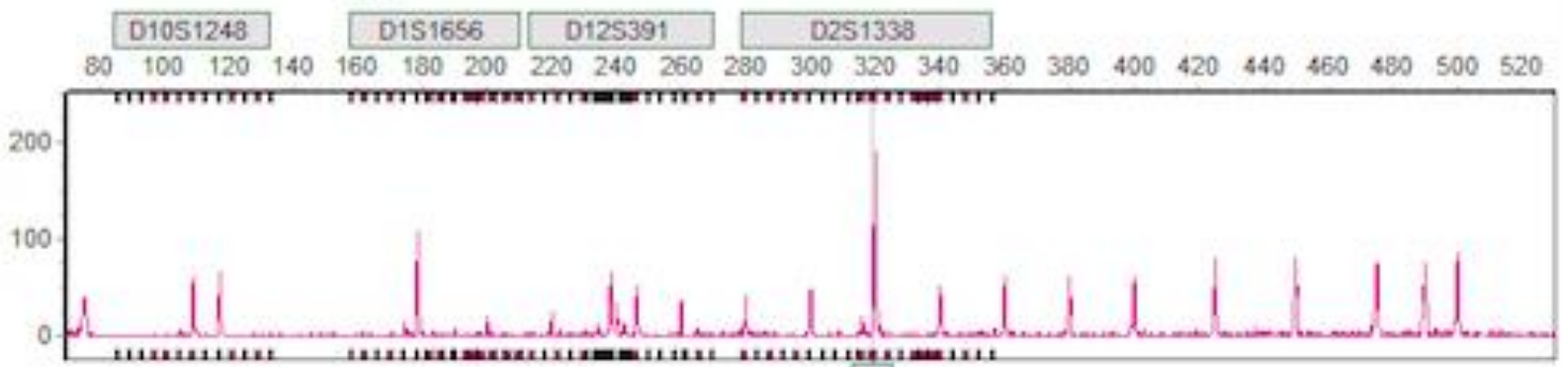

20

Figure 24. RapidHIT ${ }^{\mathrm{TM}} 200$ DNA profile for participant $\mathrm{F}$ degraded under $85 / 50$ 


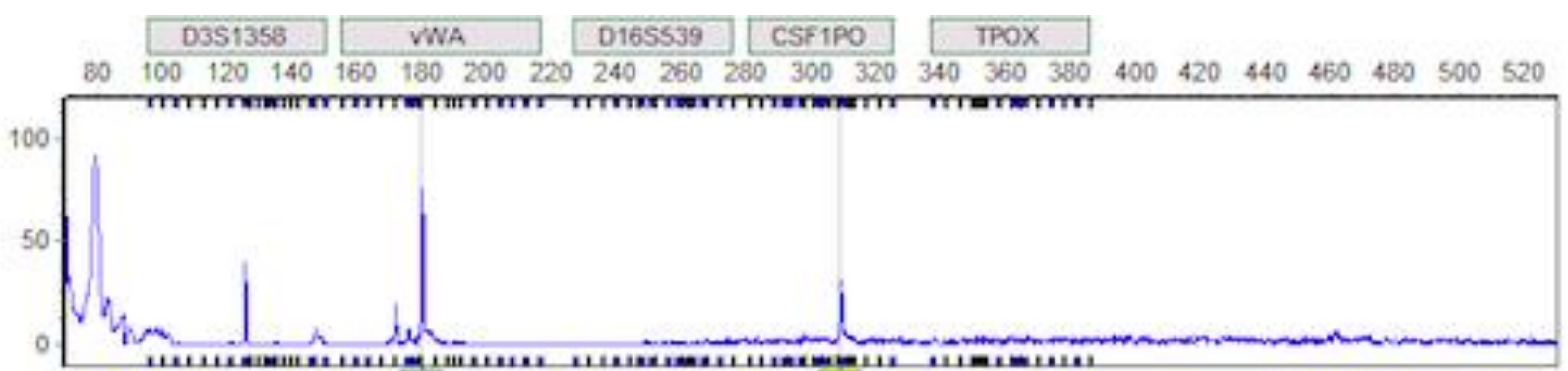

16

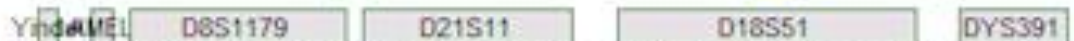
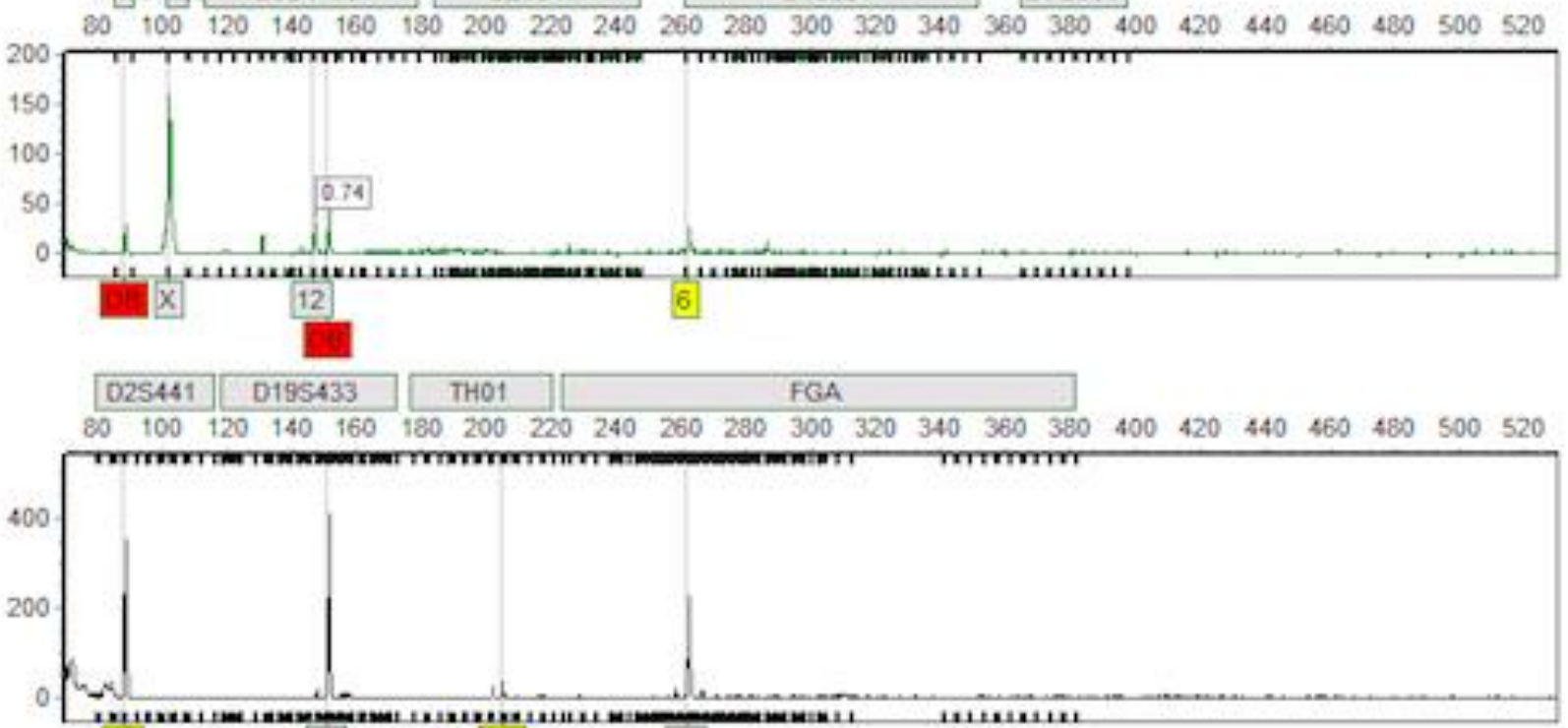
10
14
9.3
22

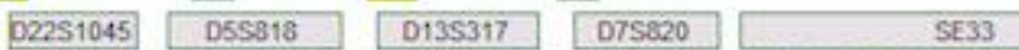

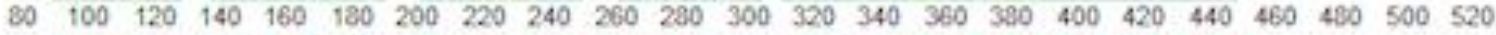

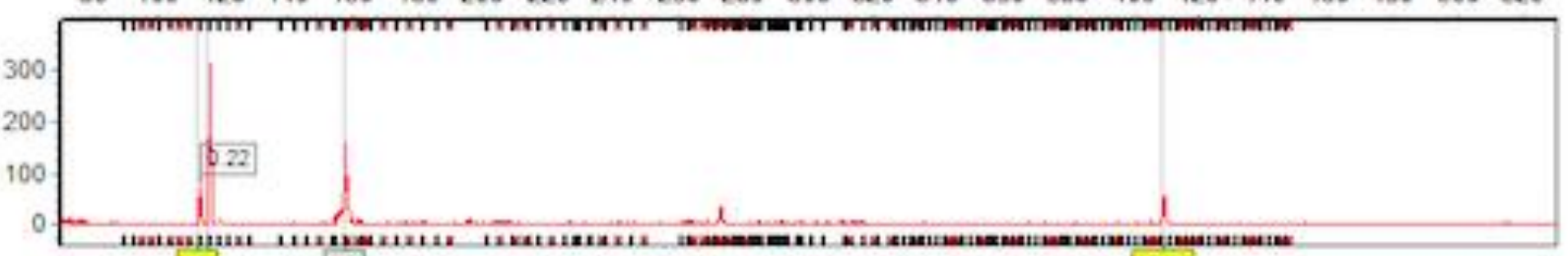

15]

11

282

16.

\begin{tabular}{|l|l|l|l|}
\hline D10S1248 & D1S1656 & D125391 & D2S1338 \\
\hline
\end{tabular}

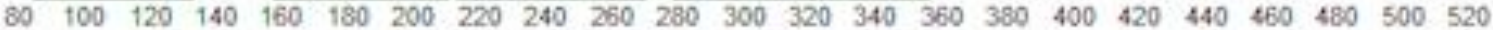

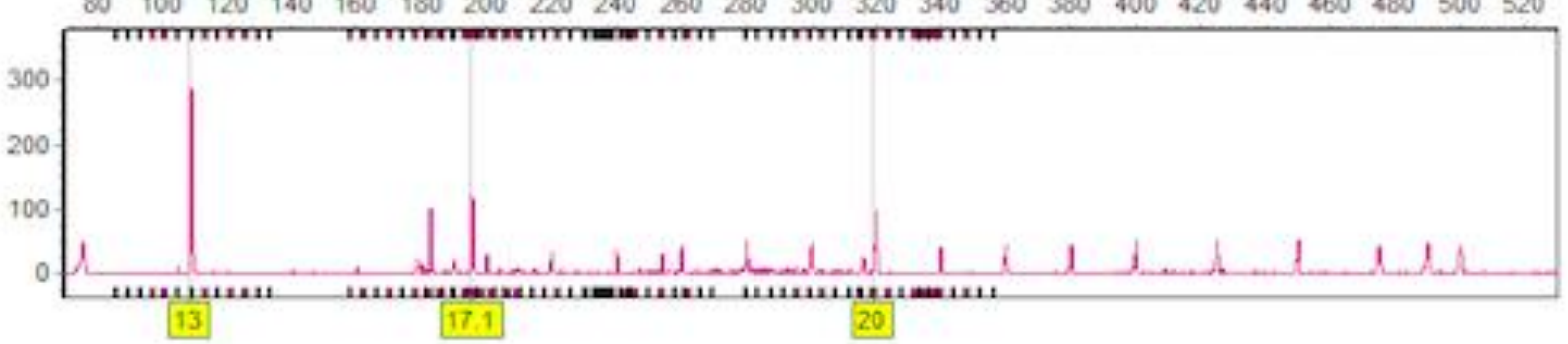

Figure 25. RapidHIT ${ }^{\mathrm{TM}} 200$ DNA profile for participant $\mathrm{G}$ degraded under $85 / 50$ 

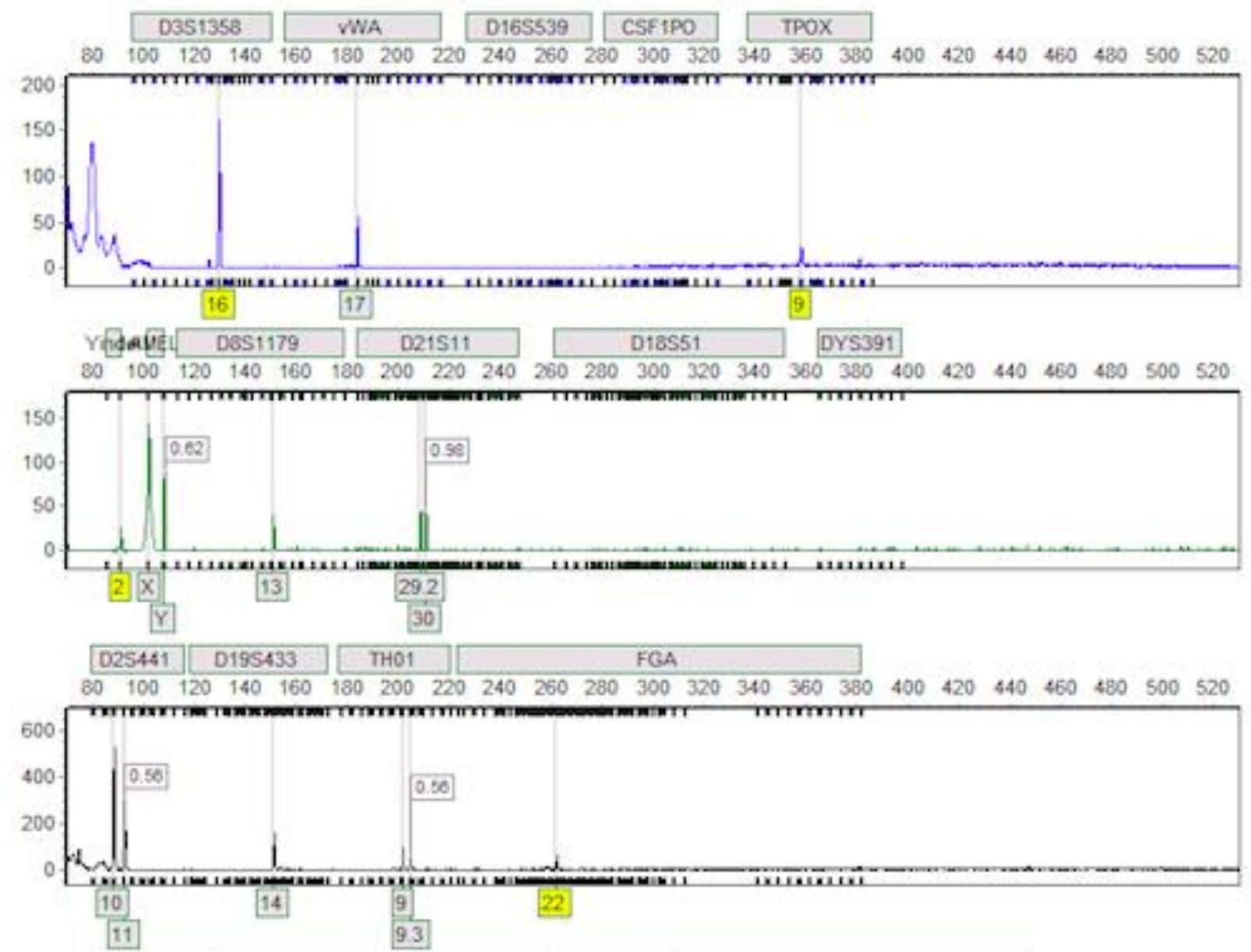

11

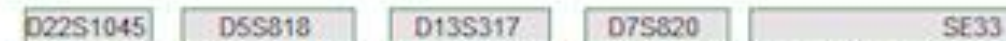

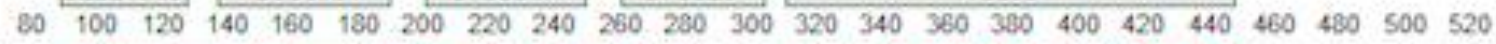

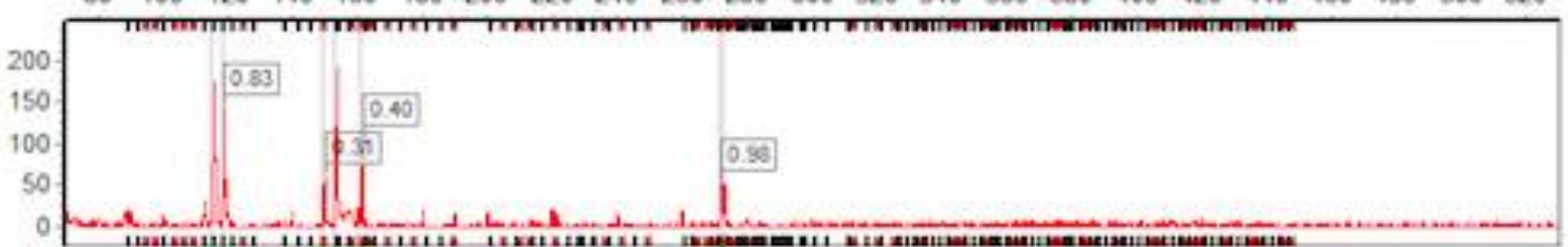

0 -

16 - 12

$17 \quad 10$

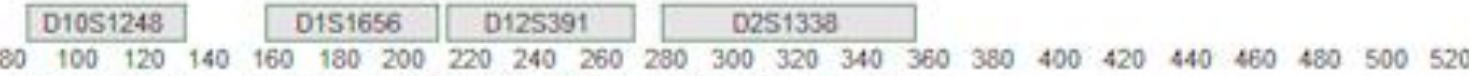

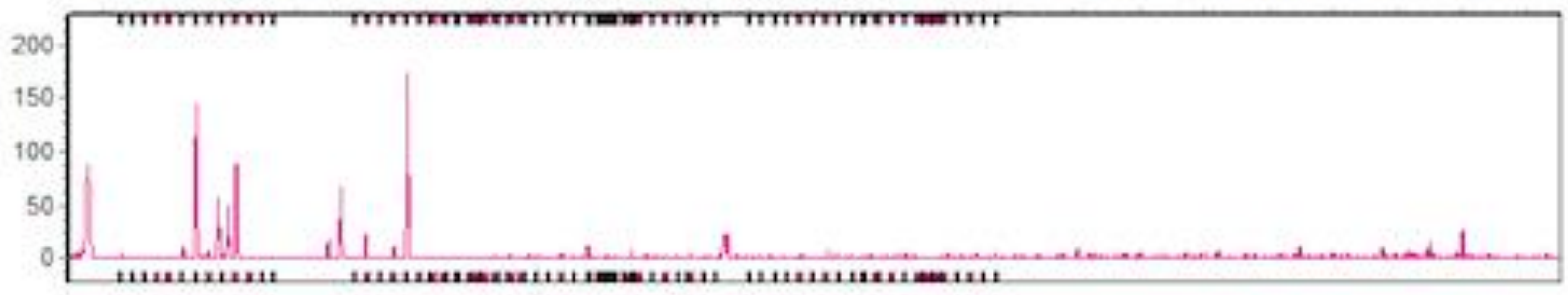

Figure 26. RapidHIT ${ }^{\mathrm{TM}} 200$ DNA profile for participant B degraded under 95/40 


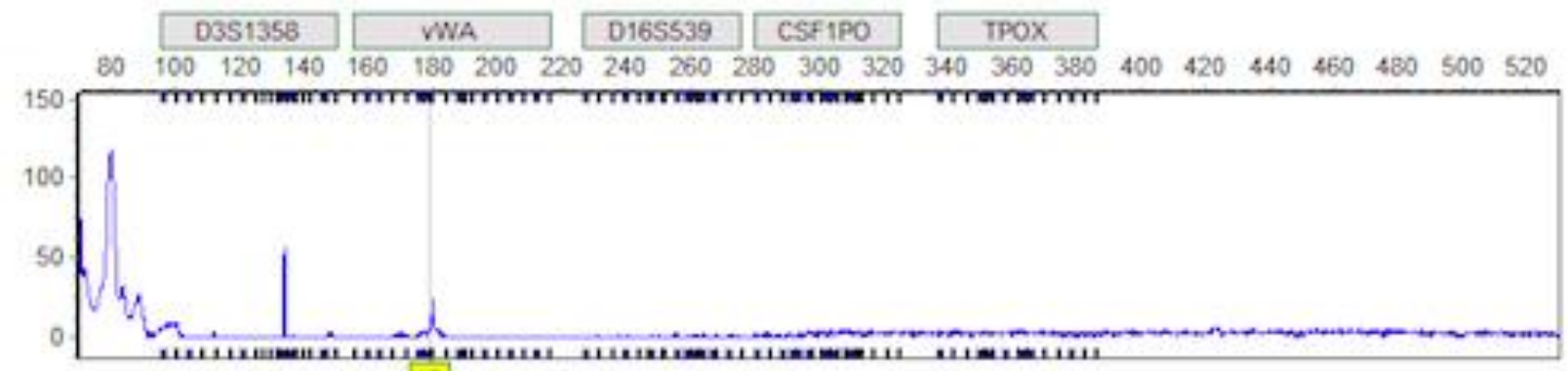

16

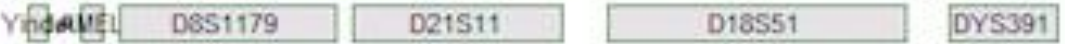

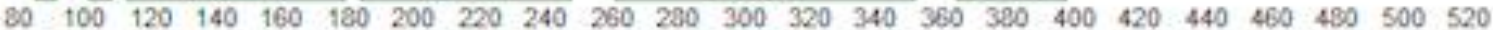

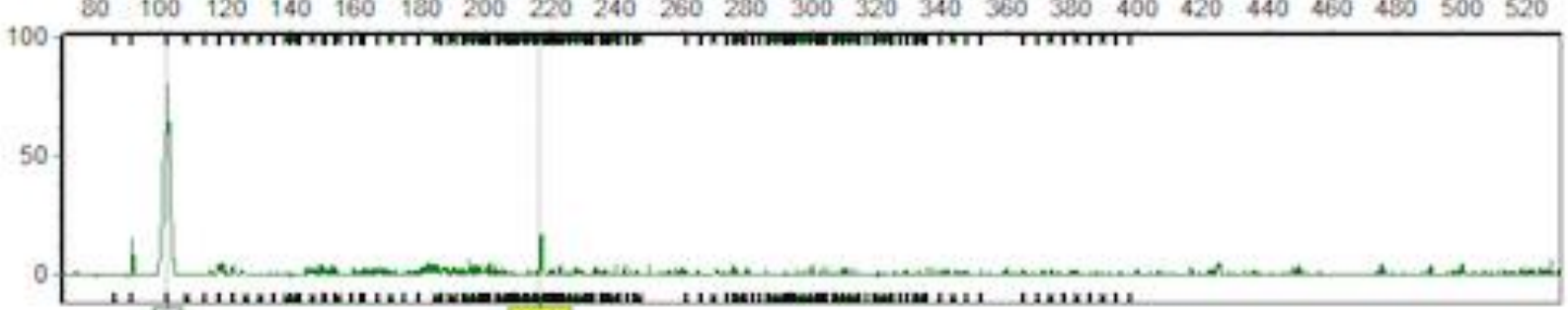

$x \mid \frac{312}{31}$

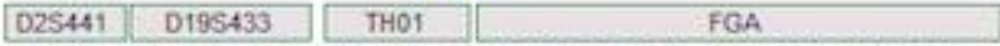

$\begin{array}{lllllllllllllllllllllll}80 & 100 & 120 & 140 & 160 & 180 & 200 & 220 & 240 & 260 & 280 & 300 & 320 & 340 & 360 & 380 & 400 & 420 & 440 & 460 & 480 & 500 & 520\end{array}$

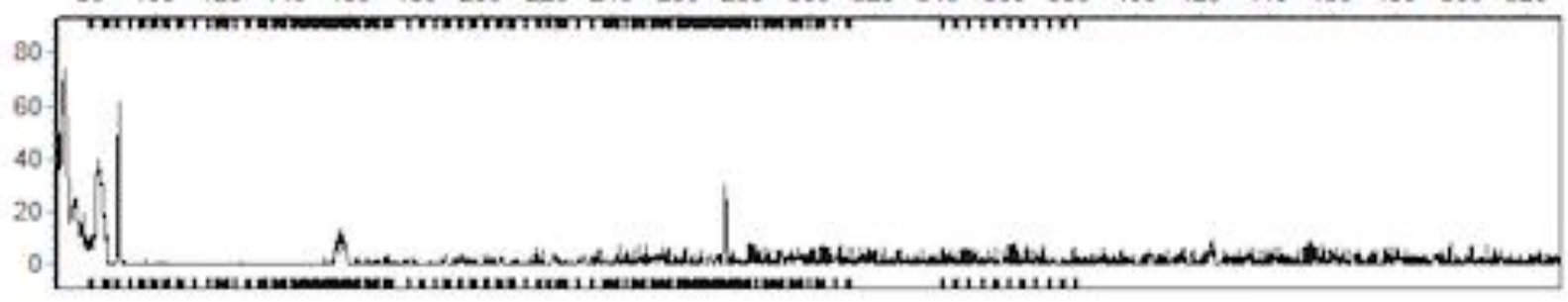

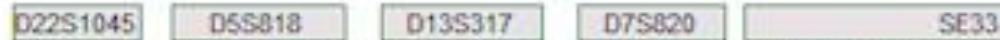

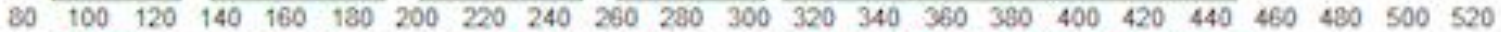

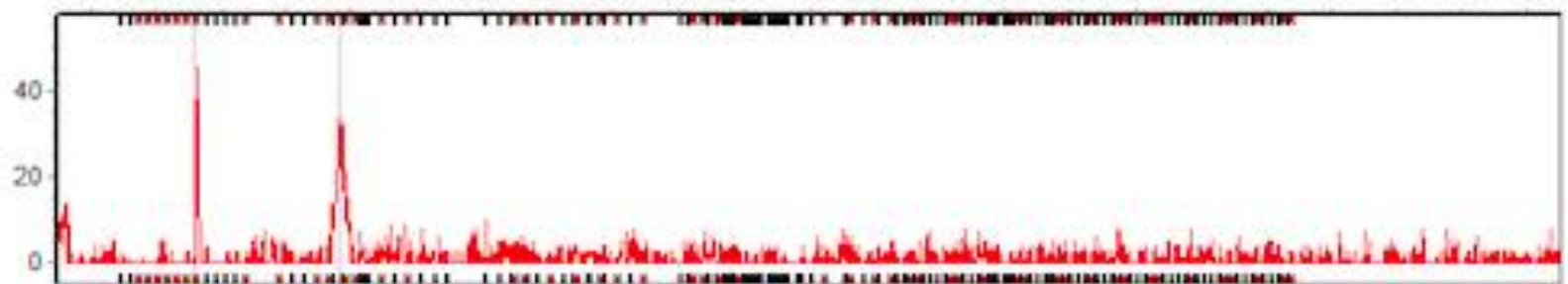

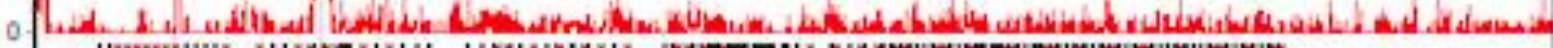

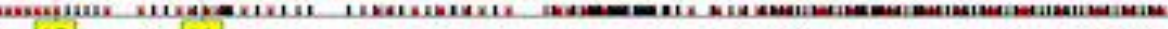

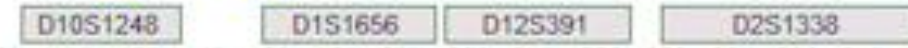

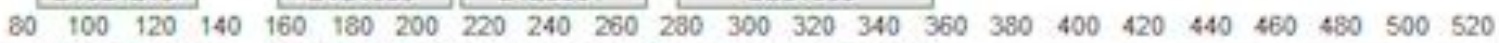

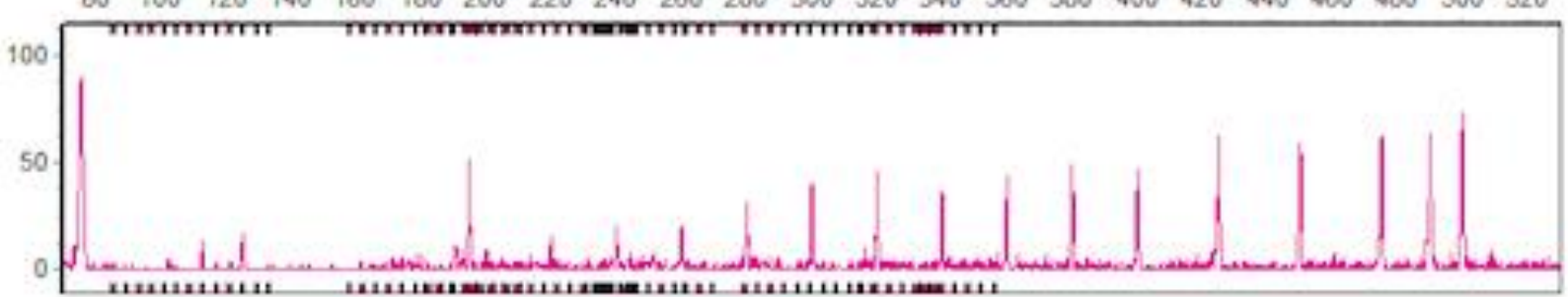

Figure 27. RapidHIT ${ }^{\mathrm{TM}} 200$ DNA profile for participant D degraded under 95/40 


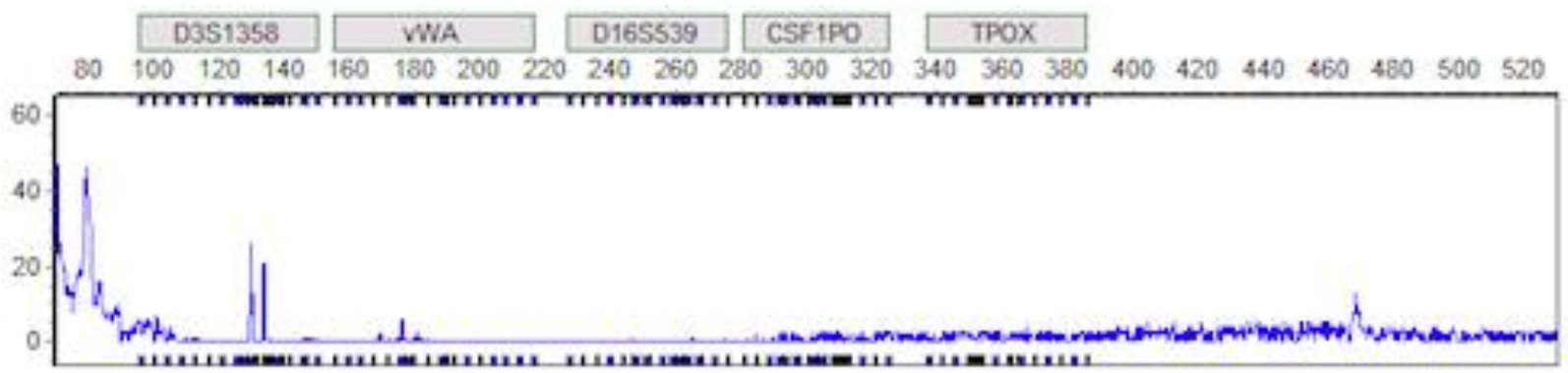

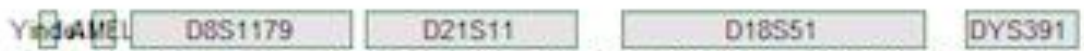

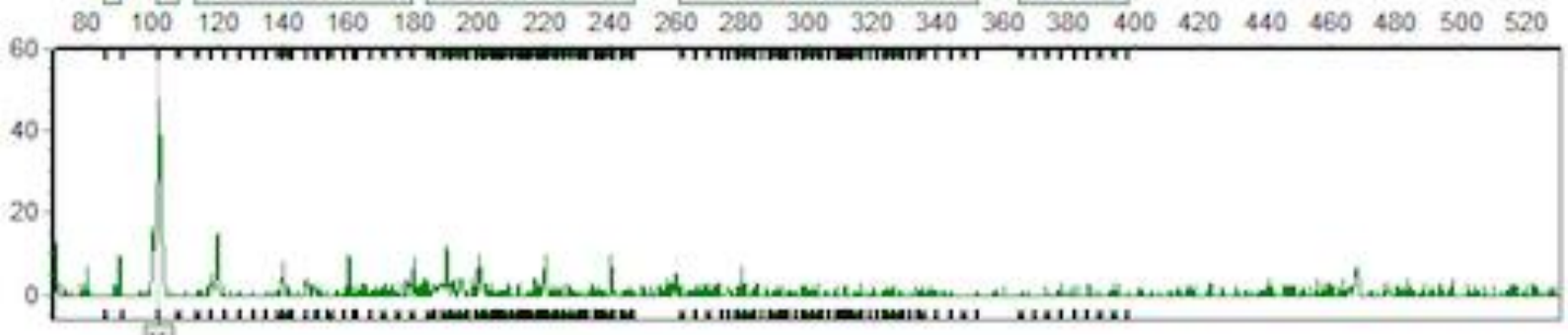

$\mathrm{X}$

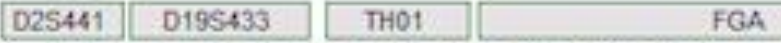

$\begin{array}{lllllllllllllllllllllll}80 & 100 & 120 & 140 & 160 & 180 & 200 & 220 & 240 & 260 & 280 & 300 & 320 & 340 & 360 & 380 & 400 & 420 & 440 & 460 & 480 & 500 & 520\end{array}$

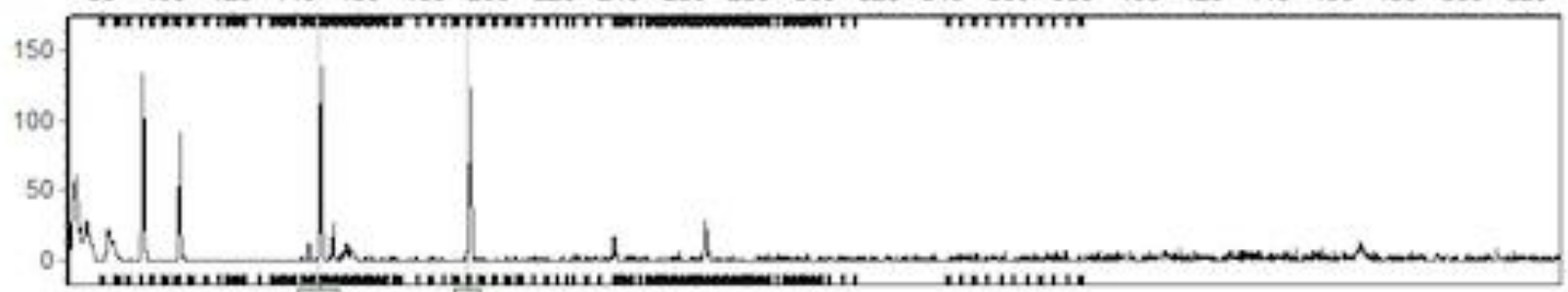

13) 7

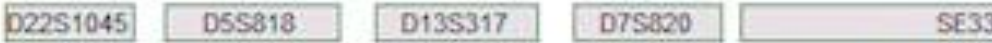

(90) $\begin{array}{llllllllllllllllllllll}100 & 120 & 140 & 160 & 130 & 200 & 220 & 240 & 260 & 280 & 300 & 320 & 340 & 360 & 380 & 400 & 420 & 440 & 460 & 480 & 500 & 520\end{array}$

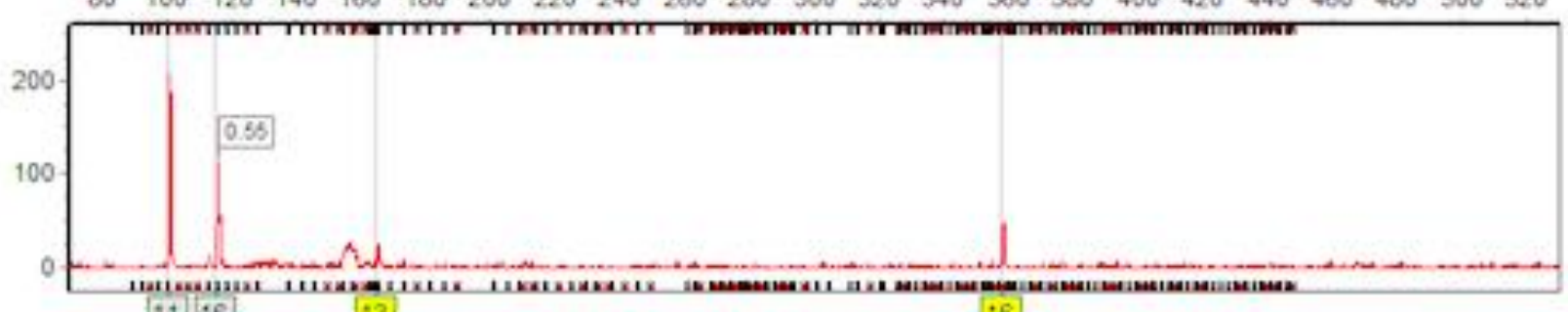
$11[6$

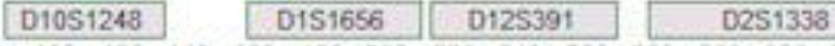

$\begin{array}{lllllllllllllllllllllll}80 & 100 & 120 & 140 & 160 & 180 & 200 & 220 & 240 & 260 & 280 & 300 & 320 & 340 & 360 & 380 & 400 & 420 & 440 & 460 & 480 & 500 & 520\end{array}$

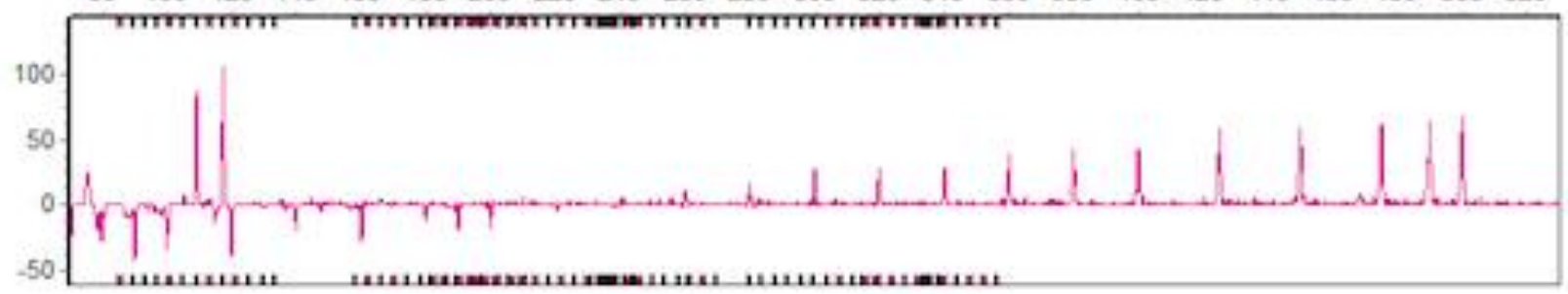

Figure 28. RapidHIT ${ }^{\mathrm{TM}} 200$ DNA profile for participant $\mathrm{F}$ degraded under 95/40 


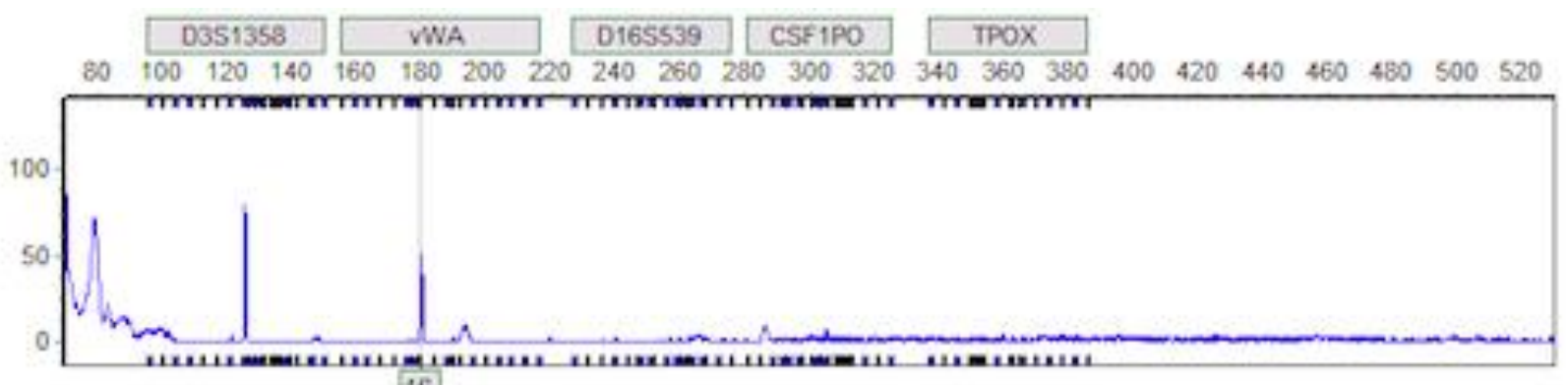

16
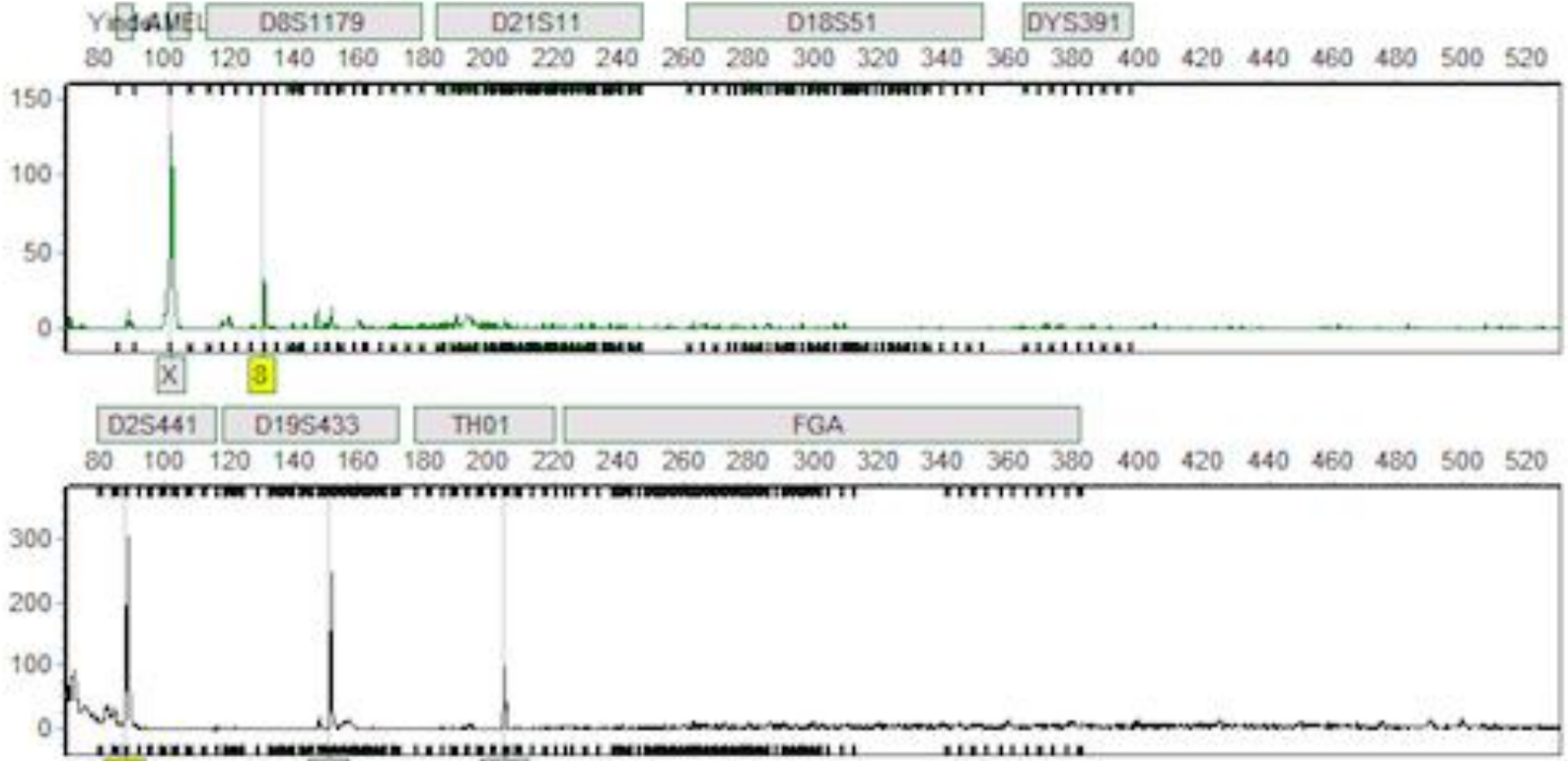

10 14 19.3

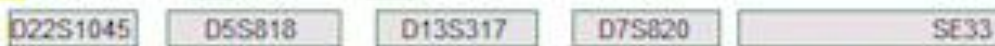

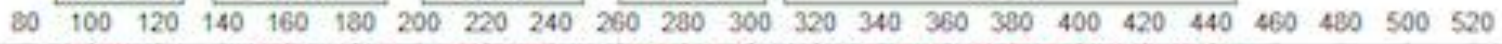

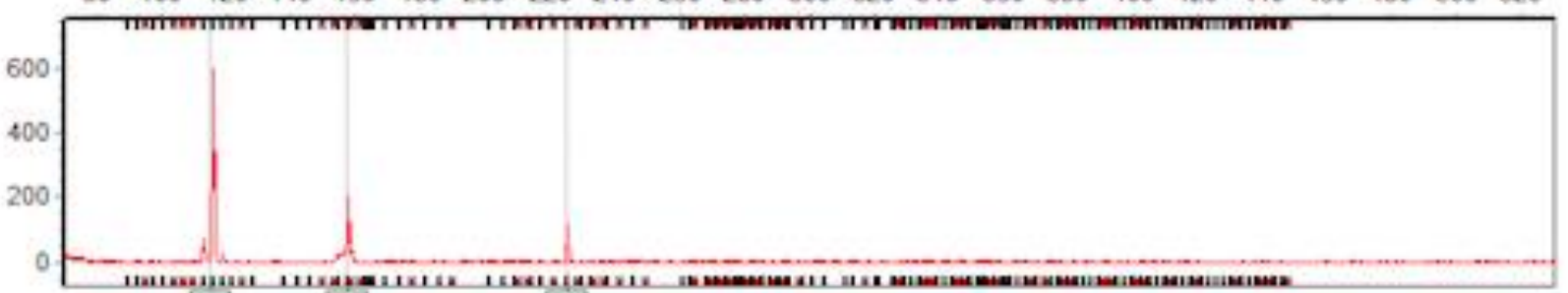

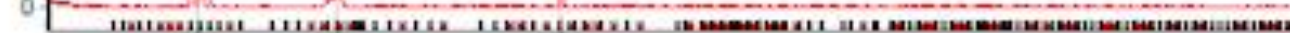

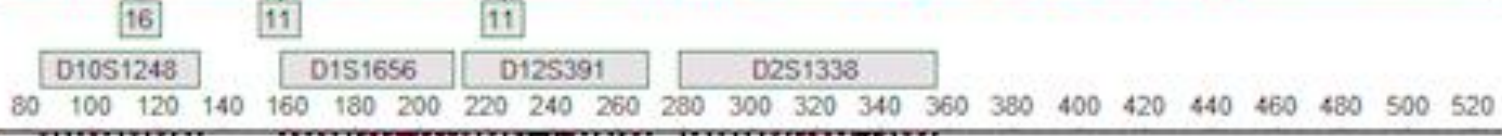

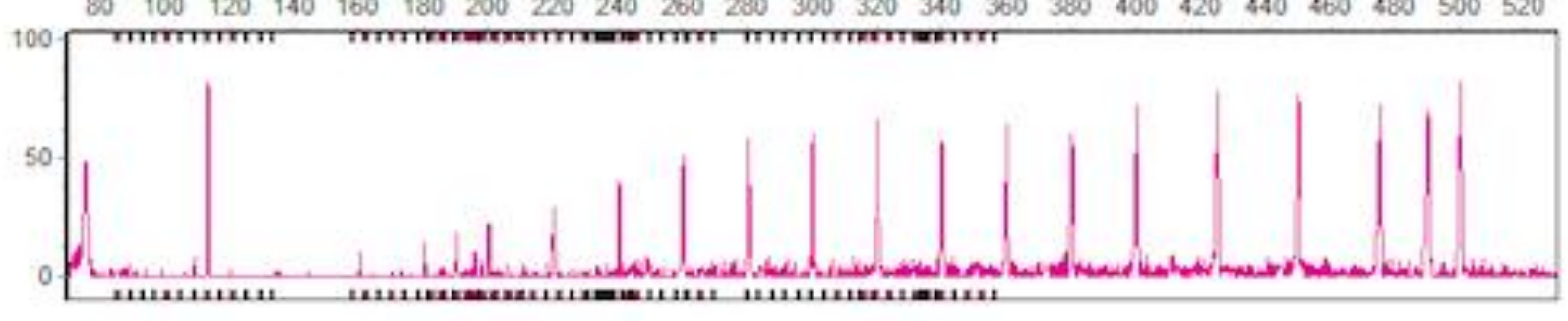

Figure 29. RapidHIT ${ }^{\mathrm{TM}} 200$ DNA profile for participant $\mathrm{G}$ degraded under 95/40 


\subsection{CONCORDANCE STUDY OF DEGRADED SAMPLES FOR HEAT/HUMIDITY}

Evaluation was performed between profiles of degraded samples generated from both methods. Data analysis was completed by analyzing the percent of correct allele calls between the two different methods using the t-test and by comparing the percent of peaks that dropped out.

\section{RESULTS}

A graph comparing the percent of correct allele calls made between the two different methods is shown on Figure 30.

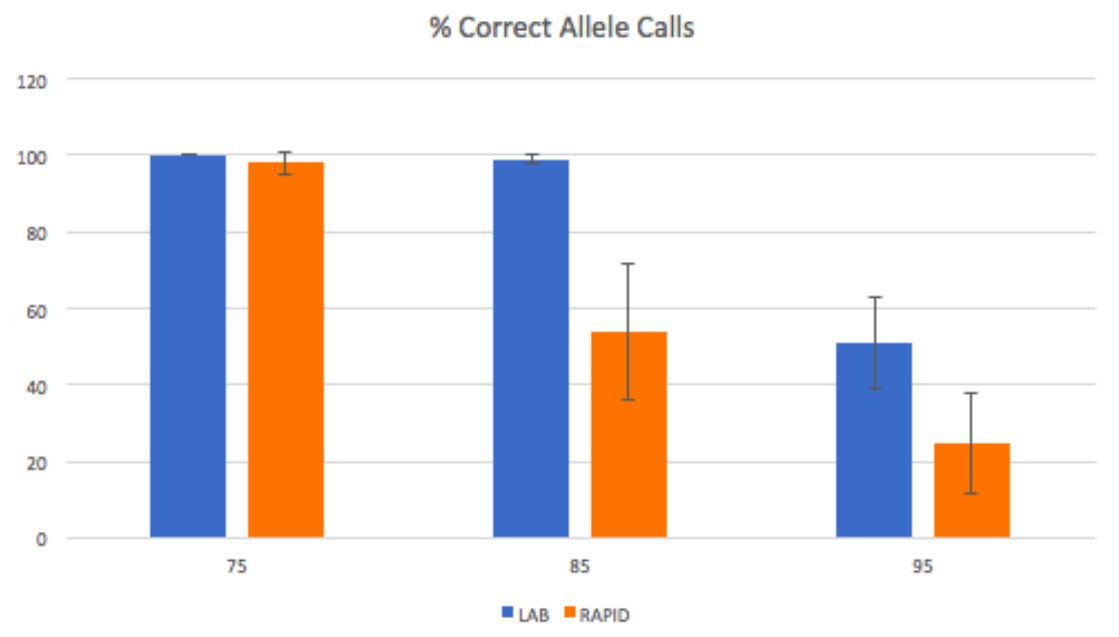

Figure 30. Bar graph of $\%$ Correct Allele Calls between the Laboratory method and RapidHIT ${ }^{\mathrm{TM}} 200$

The t-test between the two different methods on the percent correct allele calls indicates that for blood samples degraded at $75^{\circ} \mathrm{C} / 50 \%$ and $95^{\circ} \mathrm{C} / 40 \%$, there is no significant difference between the laboratory method and RapidHIT ${ }^{\mathrm{TM}} 200$. However, the t-test for blood samples degraded at $85^{\circ} \mathrm{C} / 50 \%$, indicates that there is a significant difference between the laboratory method and RapidHIT $^{\mathrm{TM}} 200$.

A graph comparing the percent of peaks that dropped out between the two different methods is shown on Figure 31. 


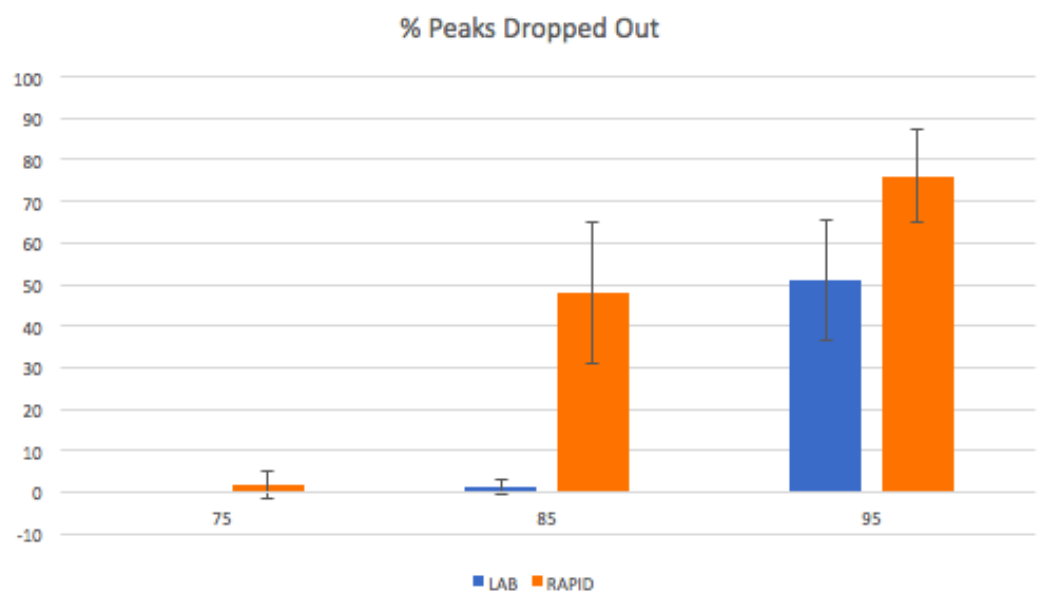

Figure 31. Bar graph of $\%$ of Peaks dropped out between the Laboratory method and RapidHIT ${ }^{\mathrm{TM}} 200$

The RFU was set at 400 for the laboratory method and the default setting for RapidHIT ${ }^{\mathrm{TM}} 200$. There were no peaks that dropped out when blood samples were degraded at $75^{\circ} \mathrm{C} / 50 \%$ and analyzed in the laboratory.

\subsection{PRELIMINARY DEGRADATION STUDY FOR UV}

Blood samples were prepared by placing a drop of blood obtained by pricking a finger with a lancet onto a filter paper for a total of 3 drops. After thoroughly drying, each filter paper was cut as equally as possible into half and stored in a paper envelope. The halved blood drops were exposed to the following duration of UV light using the Nuaire Biological Safety Cabinets (laminar hood) as indicated in Table 5.

\begin{tabular}{|l|}
\hline Duration (hrs) \\
\hline 96 \\
\hline 128 \\
\hline 160 \\
\hline 192 \\
\hline 224 \\
\hline 256 \\
\hline
\end{tabular}

Table 5. The duration of exposure to UV light in Nuaire Biological Safety Cabinets

The samples were set up in the laminar hood as follows. The UV light in the laminar hood was a Sylvania 30 watt tube. The samples were laid out on top of glass beakers starting 5 inches from one end of the UV tube in a linear fashion next to each other. The glass beakers 
were 4 inches from the back of the hood and $24 \mathrm{~cm}$ below the UV light. Prior to UV exposure, the intensity was measured for the area where the samples were placed. It was measured using the sensor from Thor Labs with $254 \mathrm{~nm}$ wavelength. The range of intensity averaged from 800 to 900 microwatts $/ \mathrm{cm}^{2}$.

A total of 6 degraded samples were analyzed using the conventional laboratory method. Extraction was performed according to the technique recommended for Chelex ${ }^{\circledR} 100$. The extracted product was quantified according to the manufacturer's recommendation using Quantifiler $^{\circledR}$ Trio Kit and Applied Biosystems 7500 Real-Time PCR System. After review of data, amplification was performed in duplicate according to the manufacturer's recommendation using GlobalFiler ${ }^{\mathrm{TM}}$ PCR Amplification Kit and GeneAmp ${ }^{\mathrm{TM}}$ PCR System 9700. The amplified products were separated according to the manufacturer's recommendation using Applied Biosystems 3500 Genetic Analyzer and a profile was generated utilizing the GeneMapper ${ }^{\text {TM }}$ ID$\mathrm{X}$ Software. This complete process from preparation of blood sample to separation of amplified product in duplicate was repeated for reproducibility of the degradation process (1st and 2 nd round).

\section{RESULTS}

Review of the degradation indices provided by the analysis using Quantifiler ${ }^{\circledR}$ Trio kit and interpretation of generated profiles were used to determine the three duration of exposure to UV light to be chosen for the main study. Table 6 provides the degradation index (DI) that was generated for samples in $1^{\text {st }}$ and $2^{\text {nd }}$ rounds for the various duration of exposure to UV light.

\begin{tabular}{|l|l|l|l|l|l|}
\hline SAMPLE & ROUND & Duration (hrs) & $\begin{array}{l}\text { Quantity } \\
(\mathrm{ng} / \mathrm{uL})\end{array}$ & DI & DNA PROFILE \\
\hline $1 \mathrm{C}$ & $1^{\text {ST }}$ & 96 & 0.017 & 0.881 & $\sqrt{ }$ \\
\hline $1 \mathrm{D}$ & $1^{\text {ST }}$ & 128 & 0.015 & 0.796 & $\sqrt{ }$ \\
\hline $1 \mathrm{E}$ & $1^{\text {ST }}$ & 160 & 0.008 & 0.935 & $\sqrt{ }$ \\
\hline $1 \mathrm{~F}$ & $1^{\text {ST }}$ & 192 & 0.008 & 0.881 & $\sqrt{ }$ \\
\hline $1 \mathrm{G}$ & $1^{\text {ST }}$ & 224 & 0.002 & 1.443 & $\sqrt{ }$ \\
\hline $1 \mathrm{H}$ & $1^{\text {ST }}$ & 256 & 0.002 & 1.483 & $\sqrt{ }$ \\
\hline & & & & & $\sqrt{ }$ \\
\hline $2 \mathrm{C}$ & $2^{\text {ND }}$ & 96 & 0.010 & 0.914 & $\sqrt{ }$ \\
\hline $2 \mathrm{D}$ & $2^{\text {ND }}$ & 128 & 0.006 & 1.200 & $\sqrt{ }$ \\
\hline $2 \mathrm{E}$ & $2^{\text {ND }}$ & 160 & 0.006 & 0.893 & $\sqrt{ }$ \\
\hline $2 \mathrm{~F}$ & $2^{\text {ND }}$ & 192 & 0.007 & 0.783 & 1.615 \\
\hline $2 \mathrm{G}$ & $2^{\text {ND }}$ & 224 & 0.003 & 2.703 & \\
\hline $2 \mathrm{H}$ & $2^{\text {ND }}$ & 256 & 0.002 & & \\
\hline
\end{tabular}

Table 6. The Degradation Index (DI) for samples in $1^{\mathrm{ST}}$ and $2^{\text {nd }}$ rounds for the various duration of exposure to UV light 
Exposure times of 128, 160 and 224 hours were selected for further study using the quantity, DI and DNA profiles generated.

\subsection{COLLECTION OF BIOLOGICAL SAMPLES FROM INDIVIDUALS FOR UV}

Biological samples from nine participants (1 through 9) were collected following the appropriate Institutional Review Board (IRB) and Institutional Biosafety Committee (IBC) protocol. Two buccal samples from a participant were obtained by using a sterile swab to gently swipe against each inner cheek 5 times. Each sample was stored in a swab box. Three to four drops of blood from a participant were collected on filter papers by pricking a finger with a lancet. After thoroughly drying, each filter paper was cut as equally as possible into half and stored in a paper envelope.

\subsection{BUCCAL SAMPLES FOR UV}

Buccal samples from participants were analyzed using the conventional laboratory method. Extraction was performed according to the technique recommended for Chelex ${ }^{\circledR} 100$. The extracted product was quantified according to the manufacturer's recommendation using Quantifiler ${ }^{\circledR}$ Trio Kit and Applied Biosystems 7500 Real-Time PCR System. After review of

data, amplification was performed in duplicate using the half reaction protocol for GlobalFiler ${ }^{\mathrm{TM}}$ PCR Amplification Kit and GeneAmp ${ }^{\mathrm{TM}}$ PCR System 9700. The amplified products were separated according to the manufacturer's recommendation using Applied Biosystems 3500 Genetic Analyzer and a profile was generated utilizing the GeneMapper ${ }^{\mathrm{TM}}$ ID-X Software. This profile was used as reference profile for comparison to the degraded profile.

\subsection{DEGRADATION OF BIOLOGICAL SAMPLES FROM INDIVIDUALS FOR UV}

The pairs of halved blood drops from four participants were set up on two opposite sides of the laminar hood as indicated in the preliminary degradation study for UV and on one side of another laminar hood. The pairs were removed after duration of exposure to UV light of 128 , 160 and 224 hours. 
The pairs of halved blood drops from five participants were set up on two opposite sides of the laminar hood as indicated in the preliminary degradation study for UV and on one side of another laminar hood. The pairs were removed after duration of exposure to UV light of 128 , 160 and 224 hours.

\subsection{EXTRACTION AND QUANTITATION OF DNA FROM DEGRADED BIOLOGICAL SAMPLES FOR UV}

One half of the degraded blood samples was extracted for DNA according to the technique recommended for Chelex ${ }^{\circledR}$ 100. The other half was allotted for the RapidHIT ${ }^{\mathrm{TM}} 200$ instrument. The extracted product was quantified according to the manufacturer's recommendation using Quantifiler ${ }^{\circledR}$ Trio Kit and Applied Biosystems 7500 Real-Time PCR System. Data generated is indicated in Table 7.

\section{RESULTS}

\begin{tabular}{|l|ll|l|}
\hline SAMPLE & Duration (hrs) & QUANTITY (ng/uL) & DI \\
\hline 1A & 128 & 0.010 & 1.060 \\
\hline 2A & 128 & 0.010 & 1.041 \\
\hline 3A & 128 & 0.007 & 0.750 \\
\hline 4A & 128 & 0.009 & 1.298 \\
\hline 5A & 128 & 0.030 & 1.046 \\
\hline 6A & 128 & 0.009 & 2.593 \\
\hline 7A & 128 & 0.020 & 1.064 \\
\hline 8A & 128 & 0.009 & 0.468 \\
\hline 9A & 128 & 0.049 & 0.771 \\
\hline & & & \\
\hline 1B & 160 & 0.022 & 0.716 \\
\hline 2B & 160 & 0.009 & 1.223 \\
\hline 3B & 160 & 0.009 & 0.661 \\
\hline 4B & 160 & 0.012 & 1.490 \\
\hline 5B & 160 & 0.022 & 1.079 \\
\hline 6B & 160 & 0.009 & 1.715 \\
\hline 7B & 160 & 0.015 & 0.793 \\
\hline 8B & 160 & 0.018 & 1.164 \\
\hline 9B & 160 & 0.004 & 0.389 \\
\hline & & & \\
\hline 1C & 224 & 0.007 & 0.892 \\
\hline 2C & 224 & 0.017 & 1.045 \\
\hline 3C & 224 & 0.008 & 2.165 \\
\hline 4C & 224 & 0.005 & 1.988 \\
\hline 5C & 224 & 0.017 & 1.411 \\
\hline 6C & 224 & 0.003 & 2.413 \\
\hline
\end{tabular}




\begin{tabular}{|l|l|l|l|}
\hline $7 C$ & 224 & 0.006 & 0.813 \\
\hline $8 C$ & 224 & 0.028 & 0.952 \\
\hline $9 C$ & 224 & 0.021 & 1.018 \\
\hline
\end{tabular}

Table 7. The Quantity and Degradation Index (DI) for the participants' degraded samples for various duration of exposure to UV light

\subsection{AMPLIFICATION OF DNA FROM DEGRADED BIOLOGICAL SAMPLES FOR} UV

Amplification was performed in duplicate using the half reaction protocol for GlobalFiler ${ }^{\mathrm{TM}}$ PCR Amplification Kit and GeneAmp ${ }^{\mathrm{TM}}$ PCR System 9700. The amplified products were separated according to the manufacturer's recommendation using Applied Biosystems 3500 Genetic Analyzer and a profile was generated utilizing the GeneMapper ${ }^{\mathrm{TM}}$ IDX Software.

\section{RESULTS}

For the nine participants and each of the three different duration of exposure to UV light, a total of 50 profiles were generated and reviewed. All the profiles with exposure to 128, 160 and 224 hours of UV light had all the correct alleles called with either no or varying drop out. The profiles for three of the participants (4, 6 and 8$)$ are shown in Figures 32, 33, 34, 35, 36, 37, 38,39 and 40. 

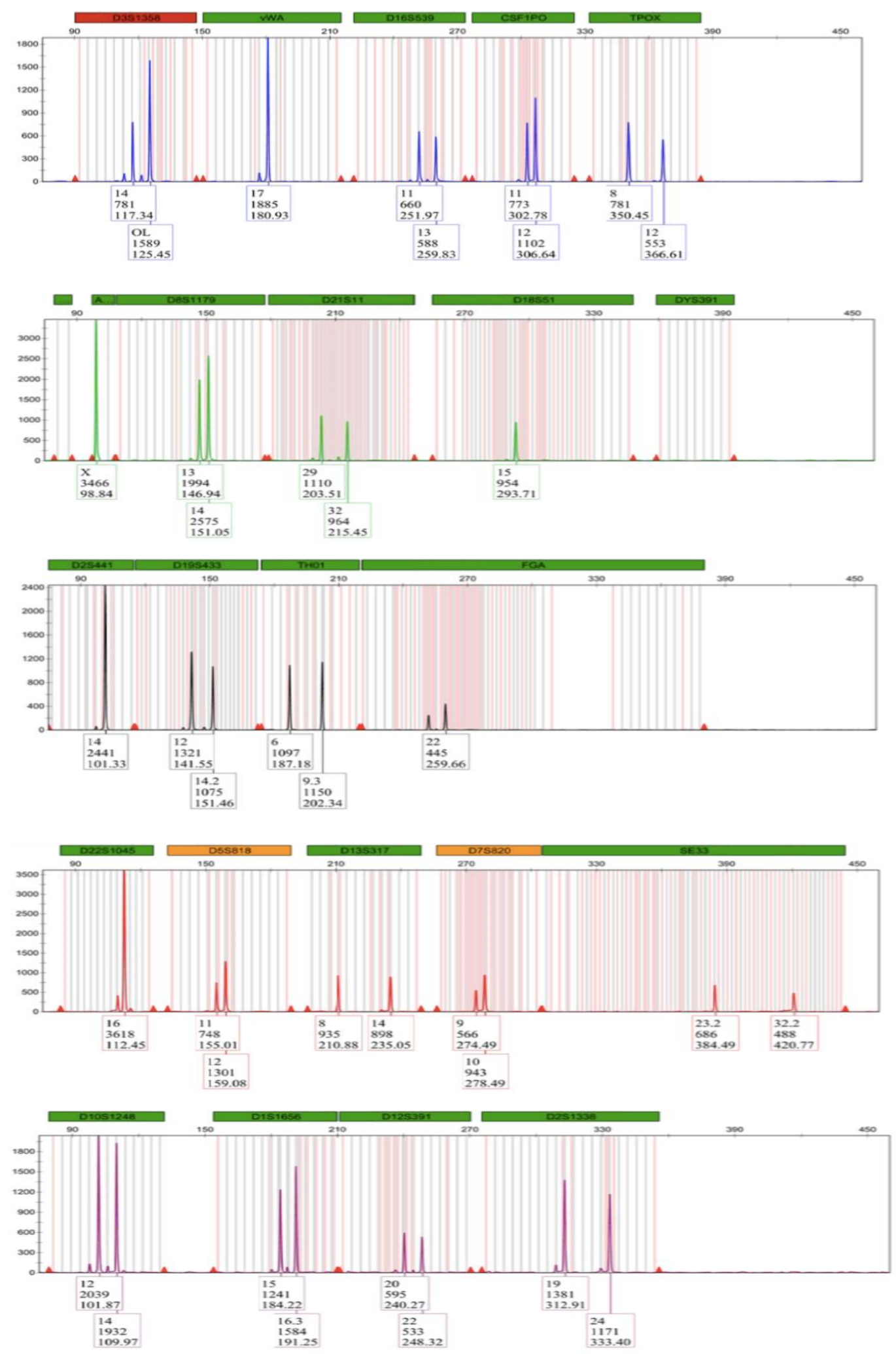

Figure 32. DNA profile for participant 4 degraded with 128 hours of exposure to UV light 

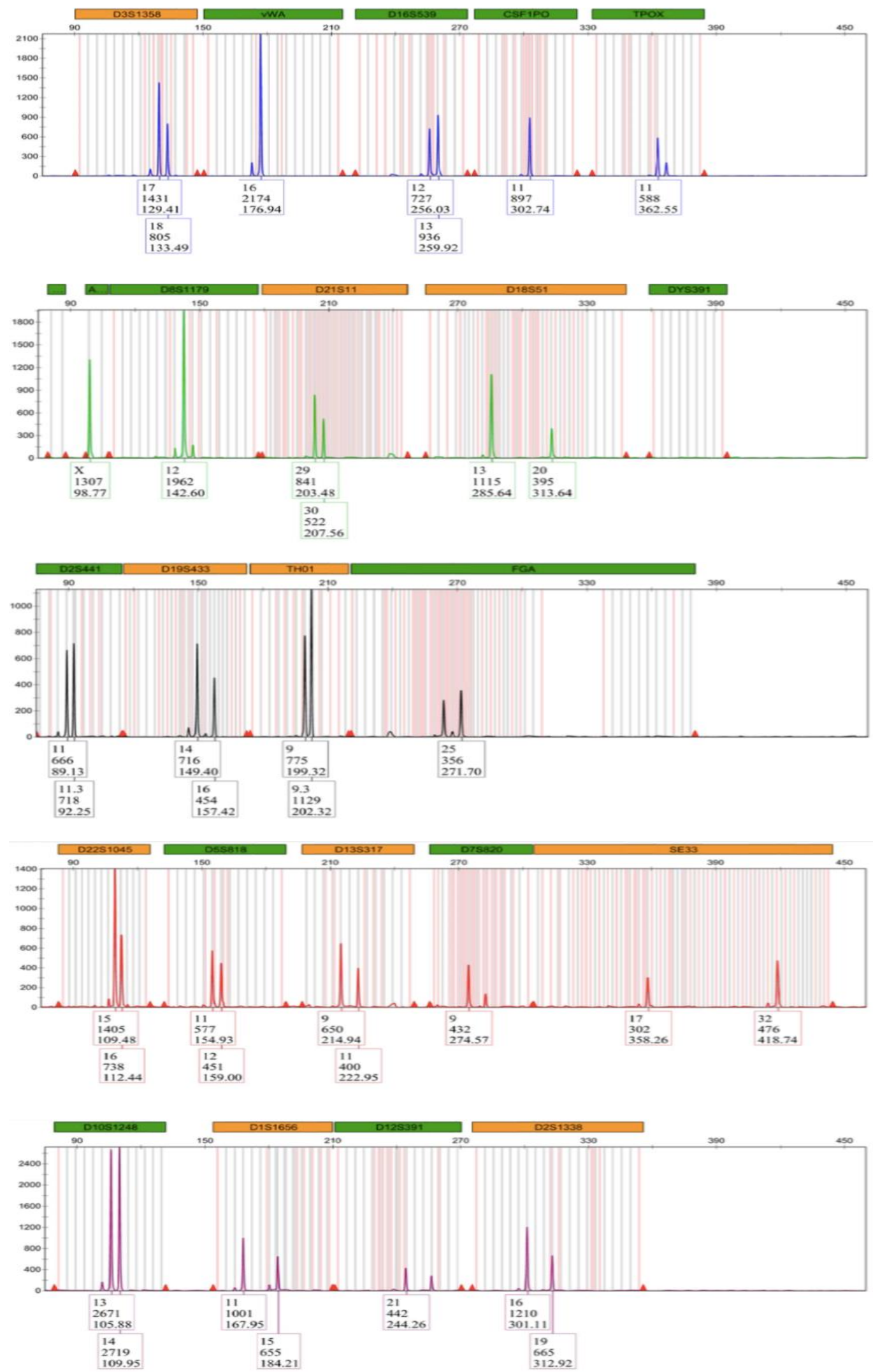

Figure 33. DNA profile for participant 6 degraded with 128 hours of exposure to UV light 

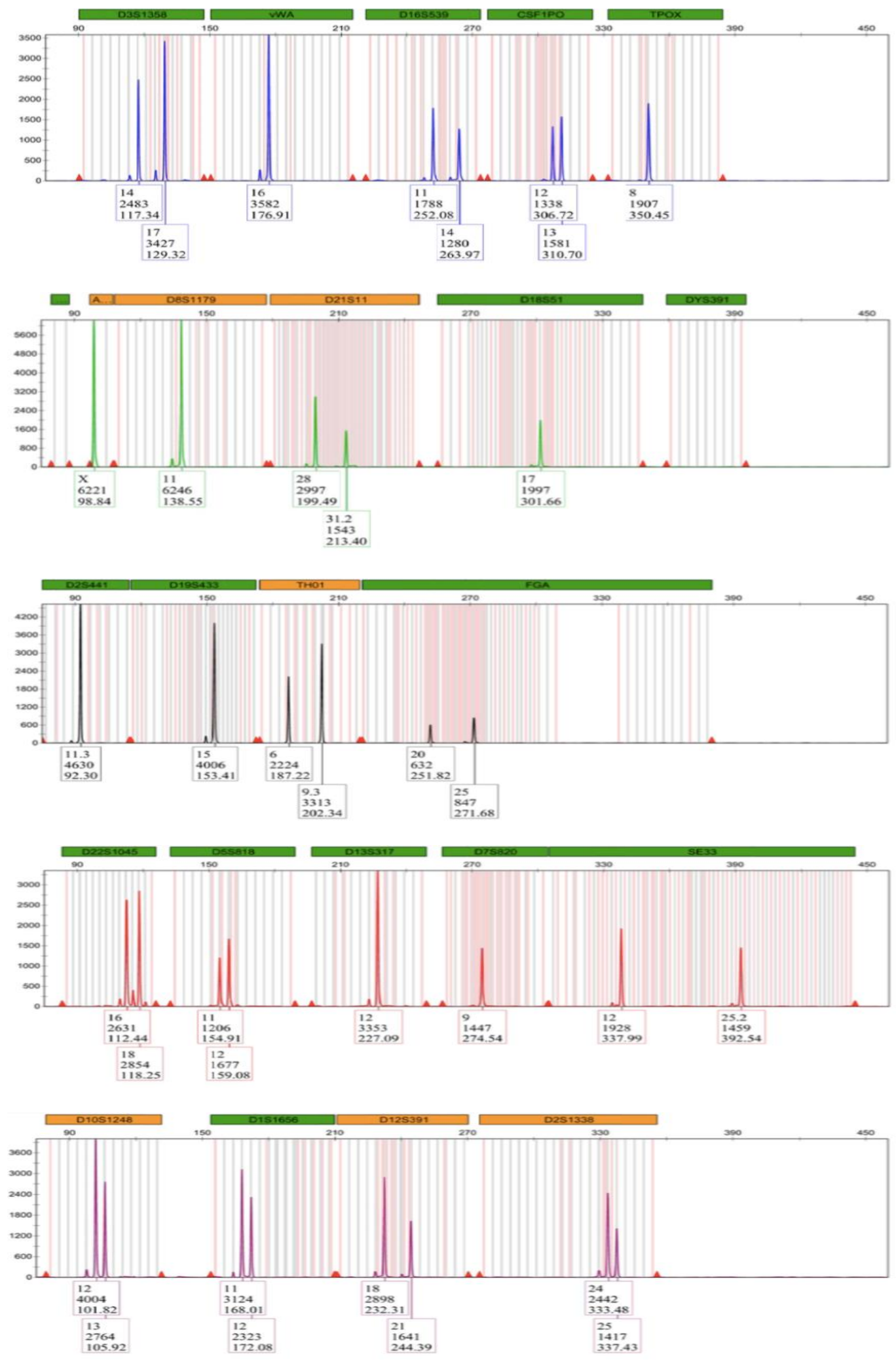

Figure 34. DNA profile for participant 8 degraded with 128 hours of exposure to UV light 


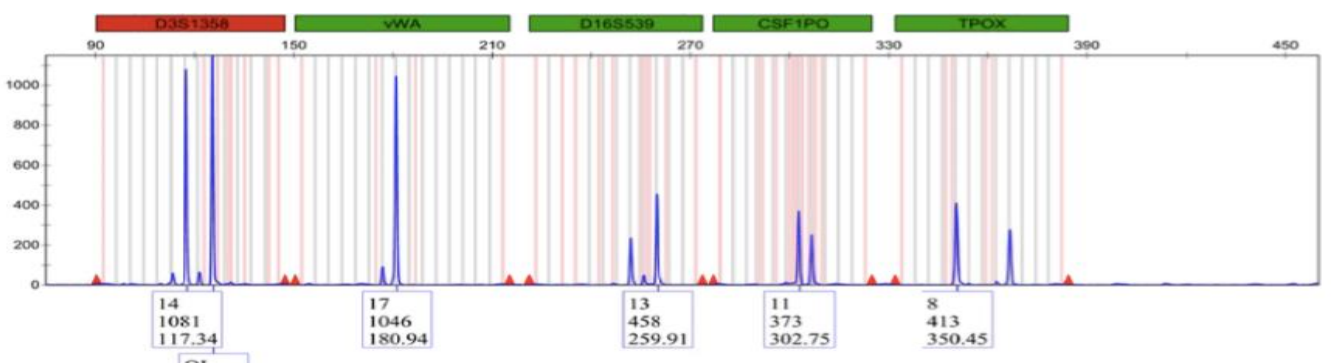

$\mathrm{OL}$
1150
125.42
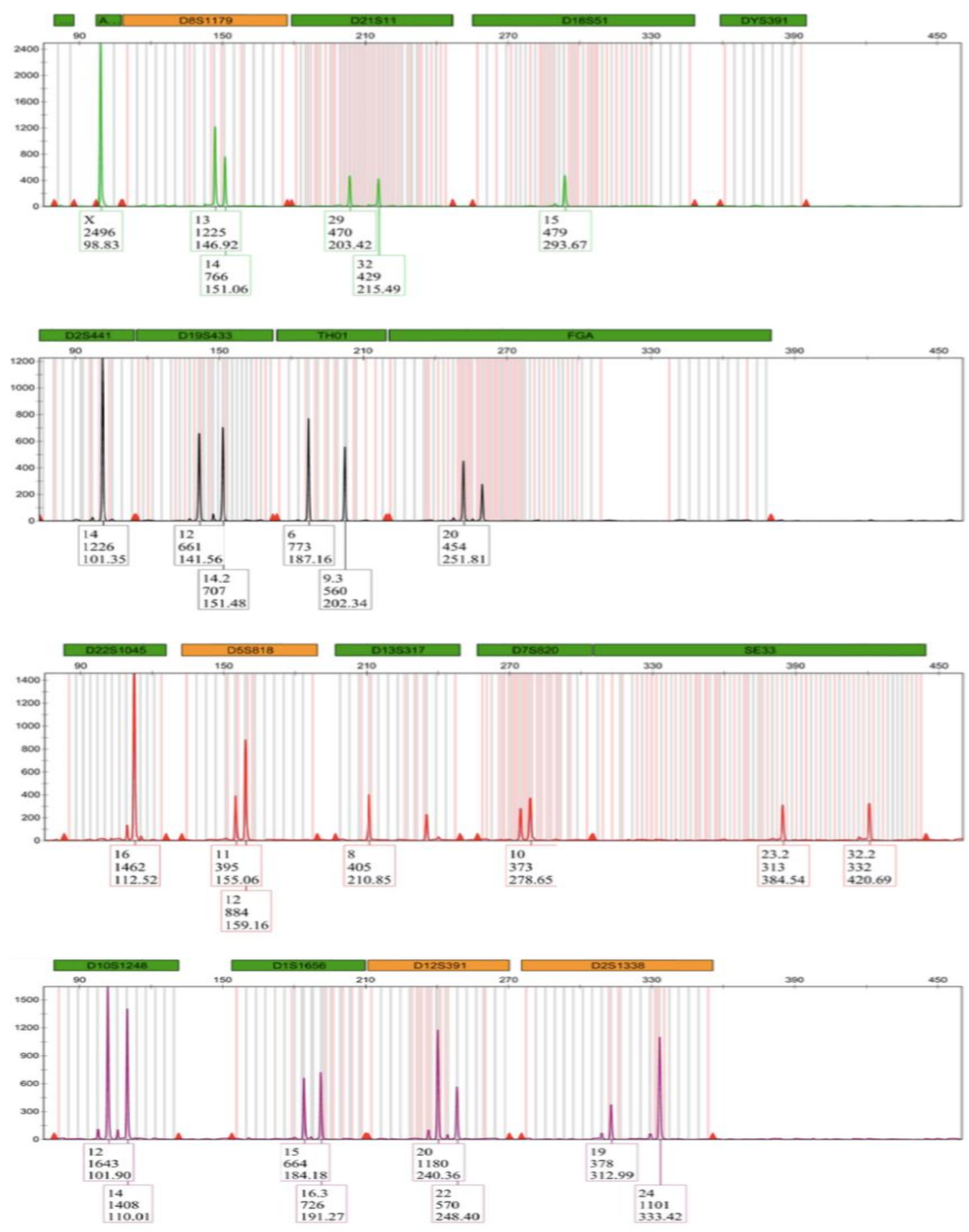

Figure 35. DNA profile for participant 4 degraded with 160 hours of exposure to UV light 

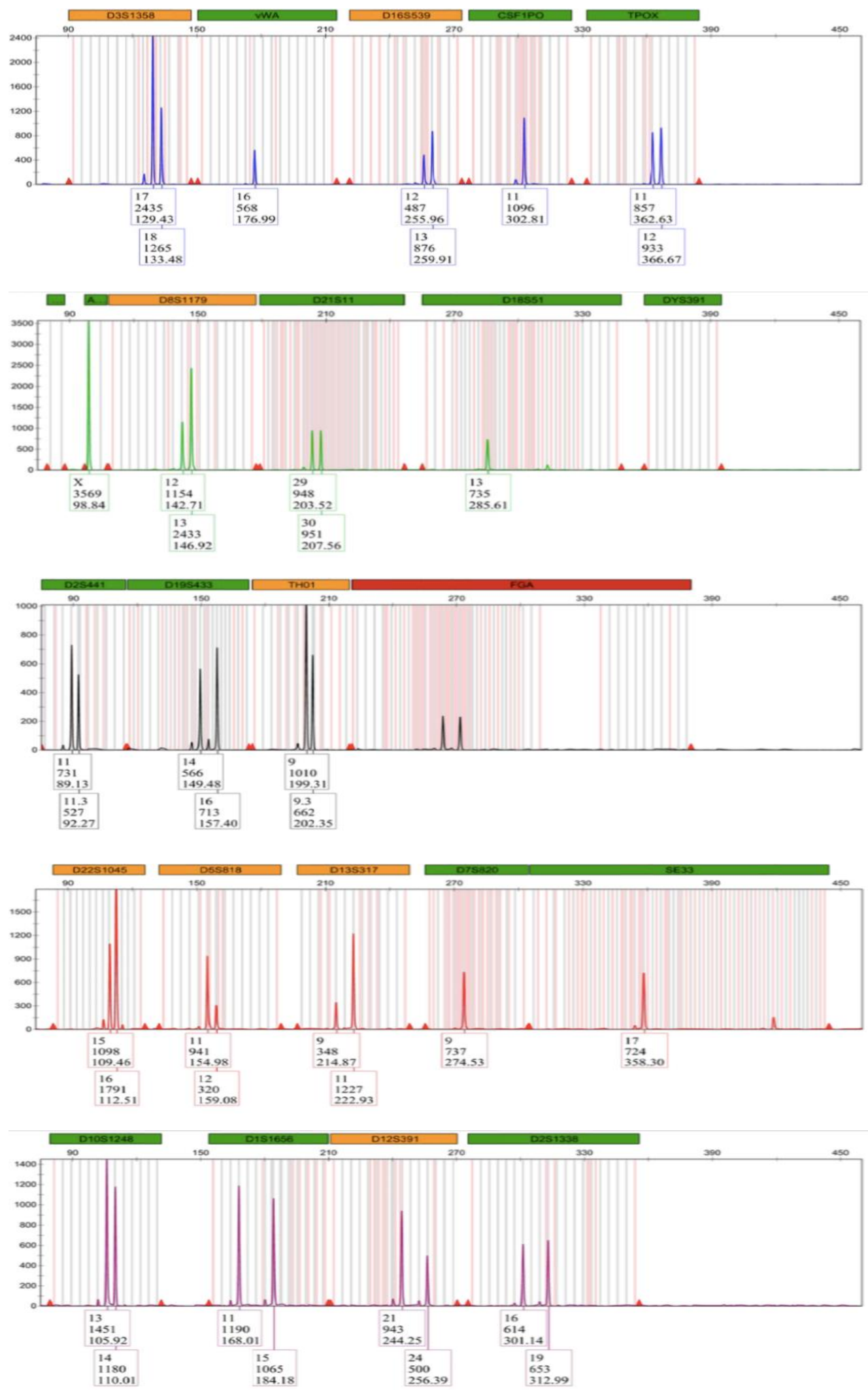

Figure 36. DNA profile for participant 6 degraded with 160 hours of exposure to UV light 

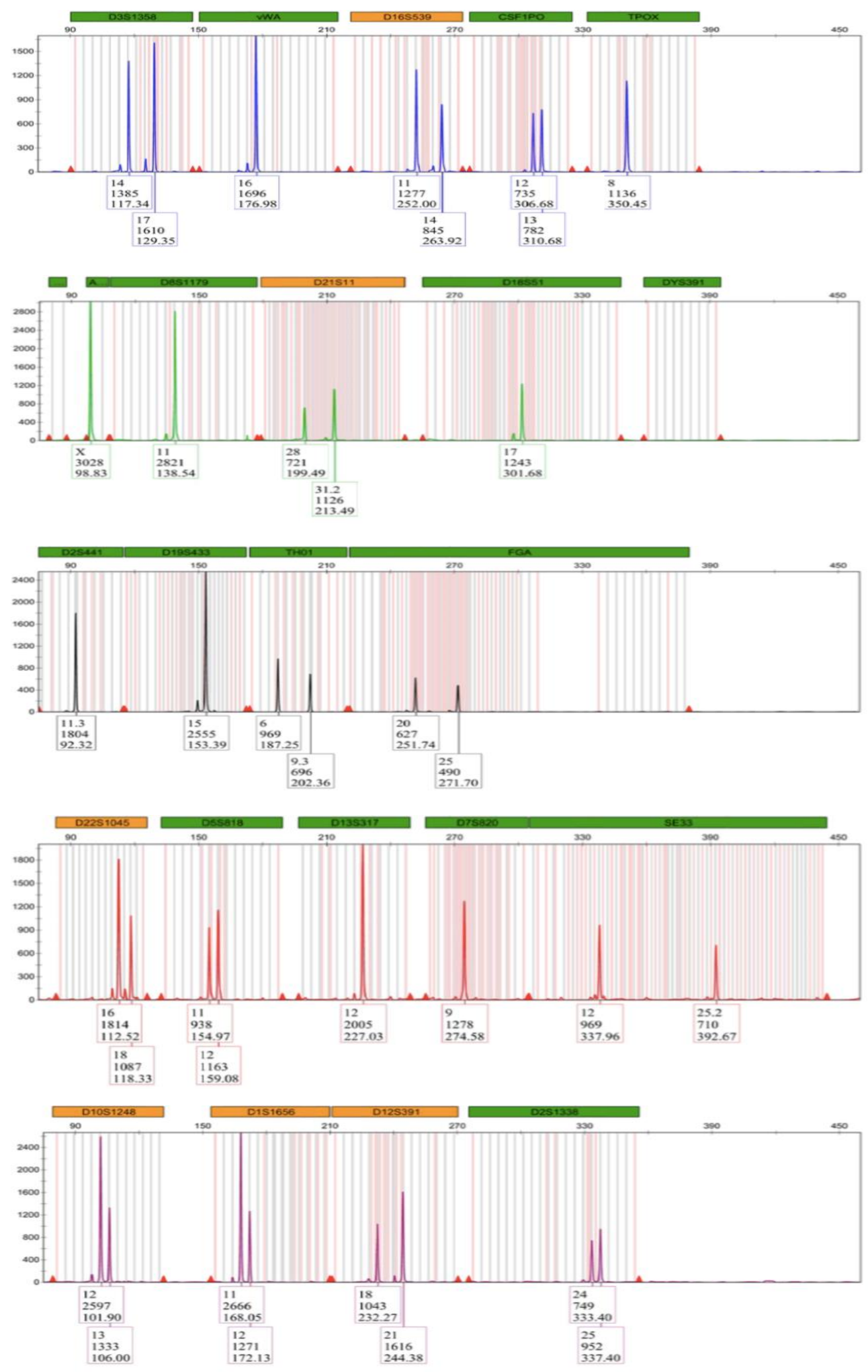

Figure 37. DNA profile for participant 8 degraded with 160 hours of exposure to UV light 

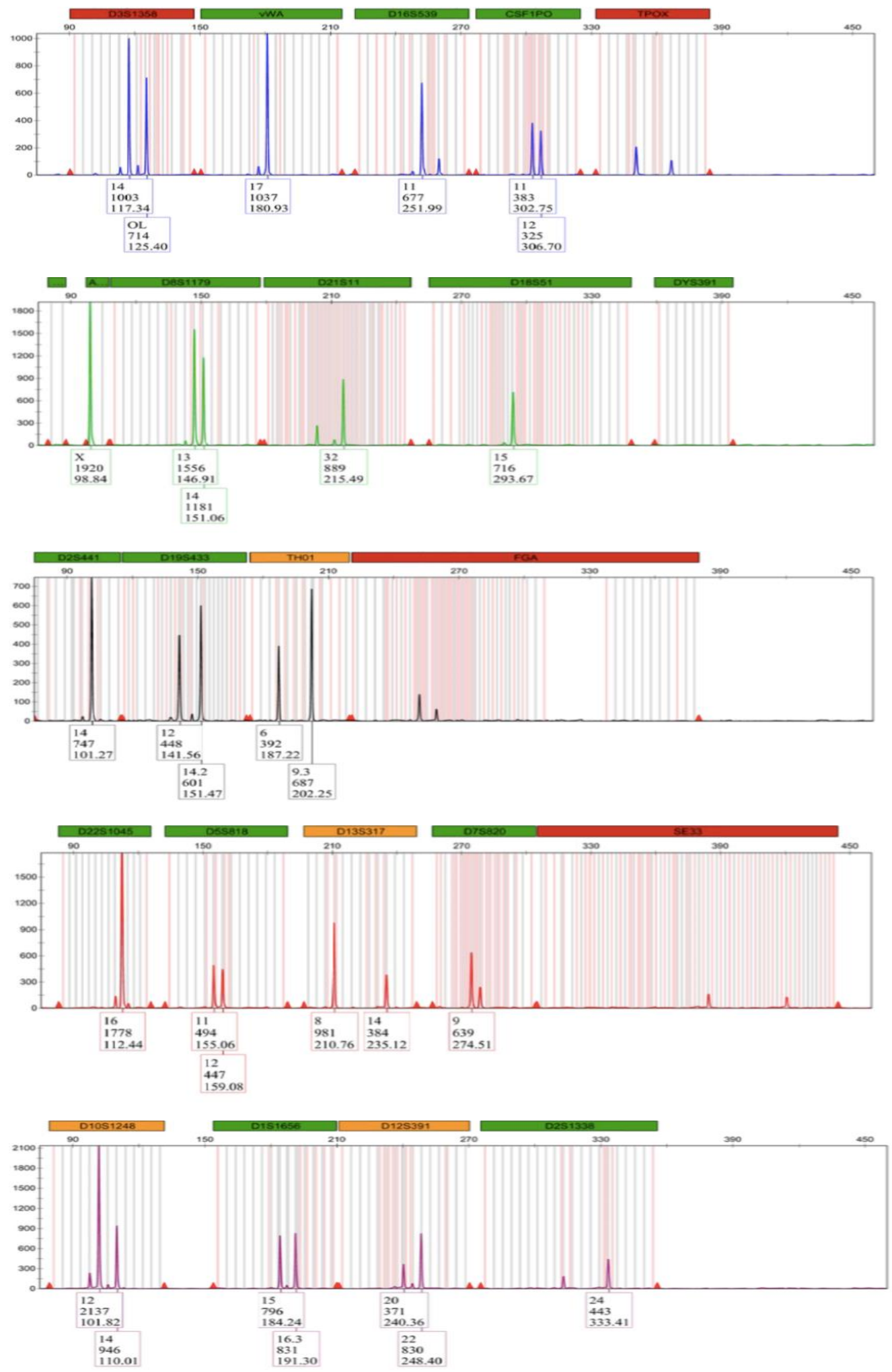

Figure 38. DNA profile for participant 4 degraded with 224 hours of exposure to UV light 

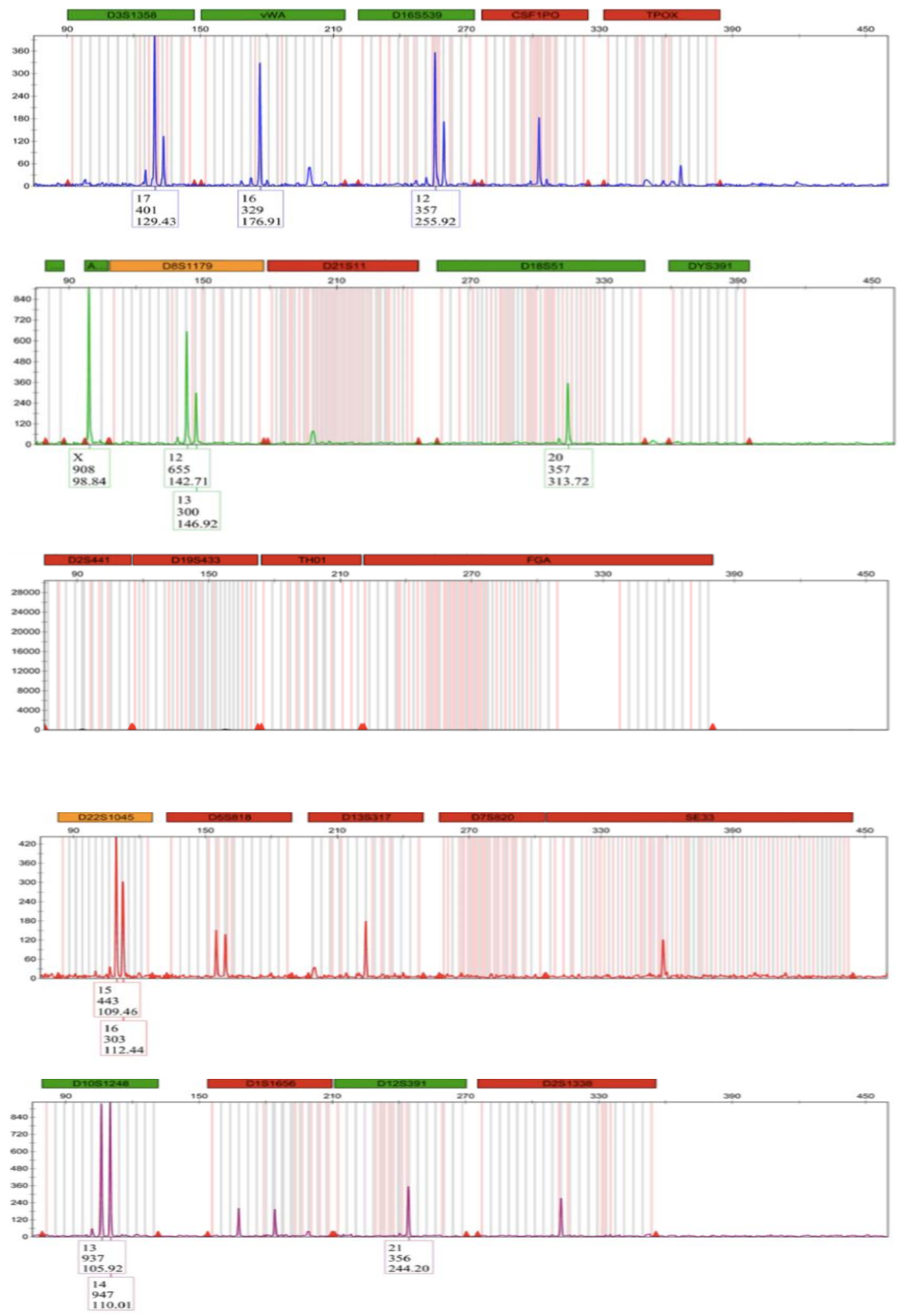

Figure 39. DNA profile for participant 6 degraded with 224 hours of exposure to UV light 

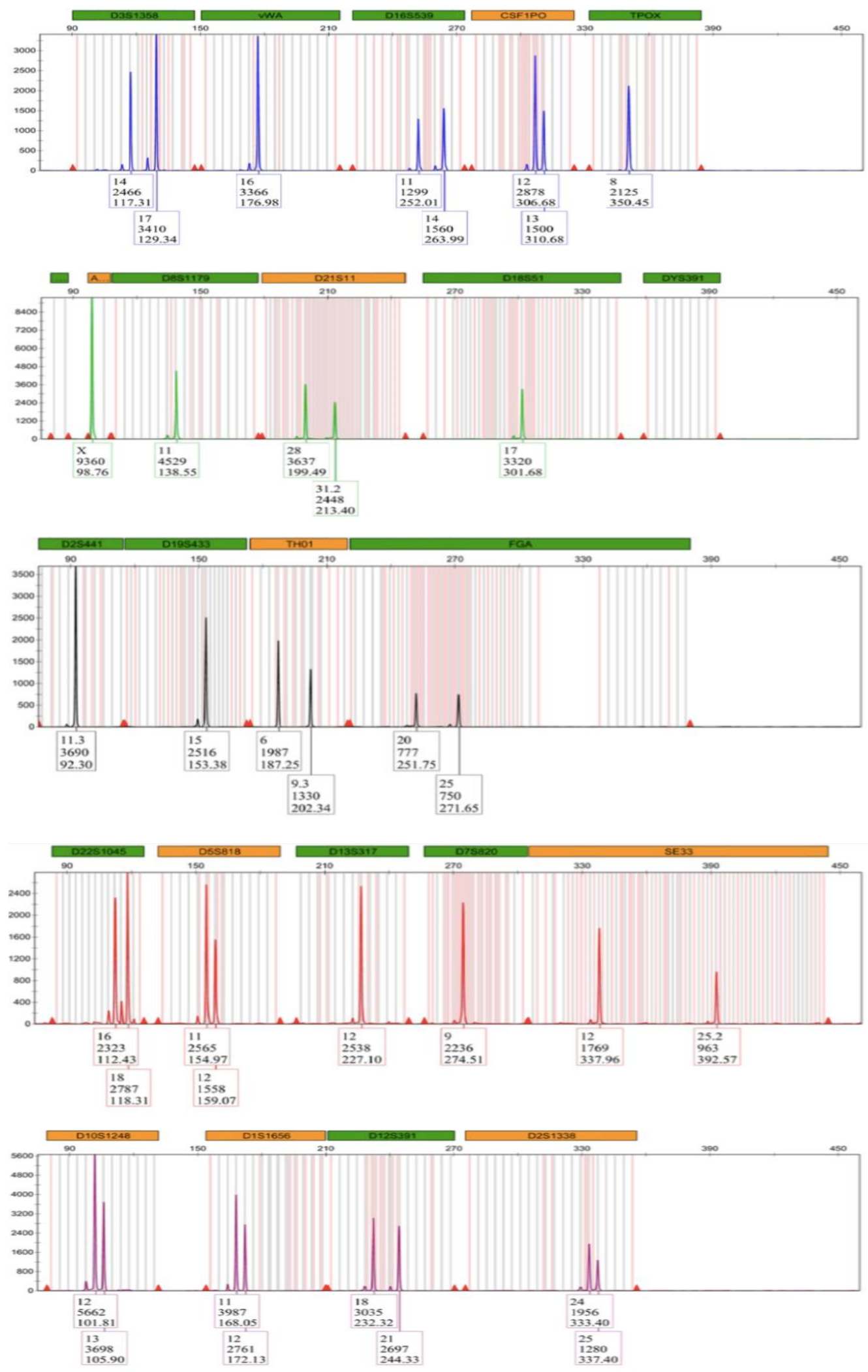

Figure 40. DNA profile for participant 8 degraded with 224 hours of exposure to UV light 


\subsection{RAPIDHIT ${ }^{\mathrm{TM}} 200$ ANALYSIS OF DEGRADED SAMPLES FOR UV}

All degraded samples were run on RapidHIT ${ }^{\mathrm{TM}} 200$ instrument with an allelic ladder. Samples were run using "run other samples" and profiles were generated by the GeneMarker ${ }^{\circledR}$ HID software. One participant's buccal sample was run along with one of the runs of the degraded samples.

\section{RESULTS}

For the nine participants and each of the three different duration of exposure to UV light, a total of 27 profiles were generated and reviewed. Seven of the profiles degraded in any of the three durations of exposure had complete drop out. The rest of the profiles had limited allele calls and most of those allele calls were drop in. The profiles for three of the participants $(4,6$ and 8) are shown in Figures 41, 42, 43, 44, 45, 46, 47, 48 and 49. The one buccal sample that was run had full and concordant profile. 

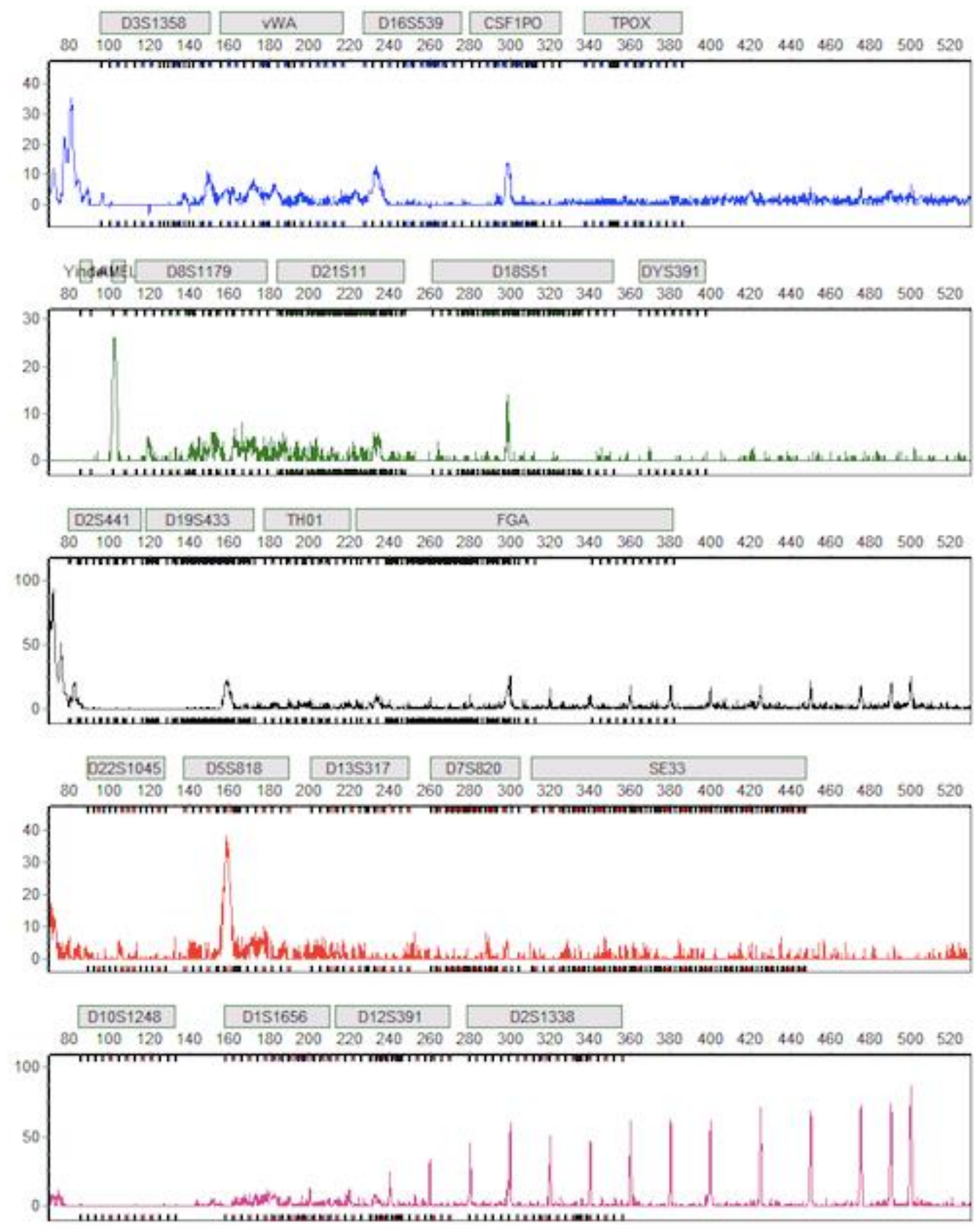

Figure 41. RapidHIT ${ }^{\mathrm{TM}} 200$ DNA profile for participant 4 degraded with 128 hours of exposure to UV light 

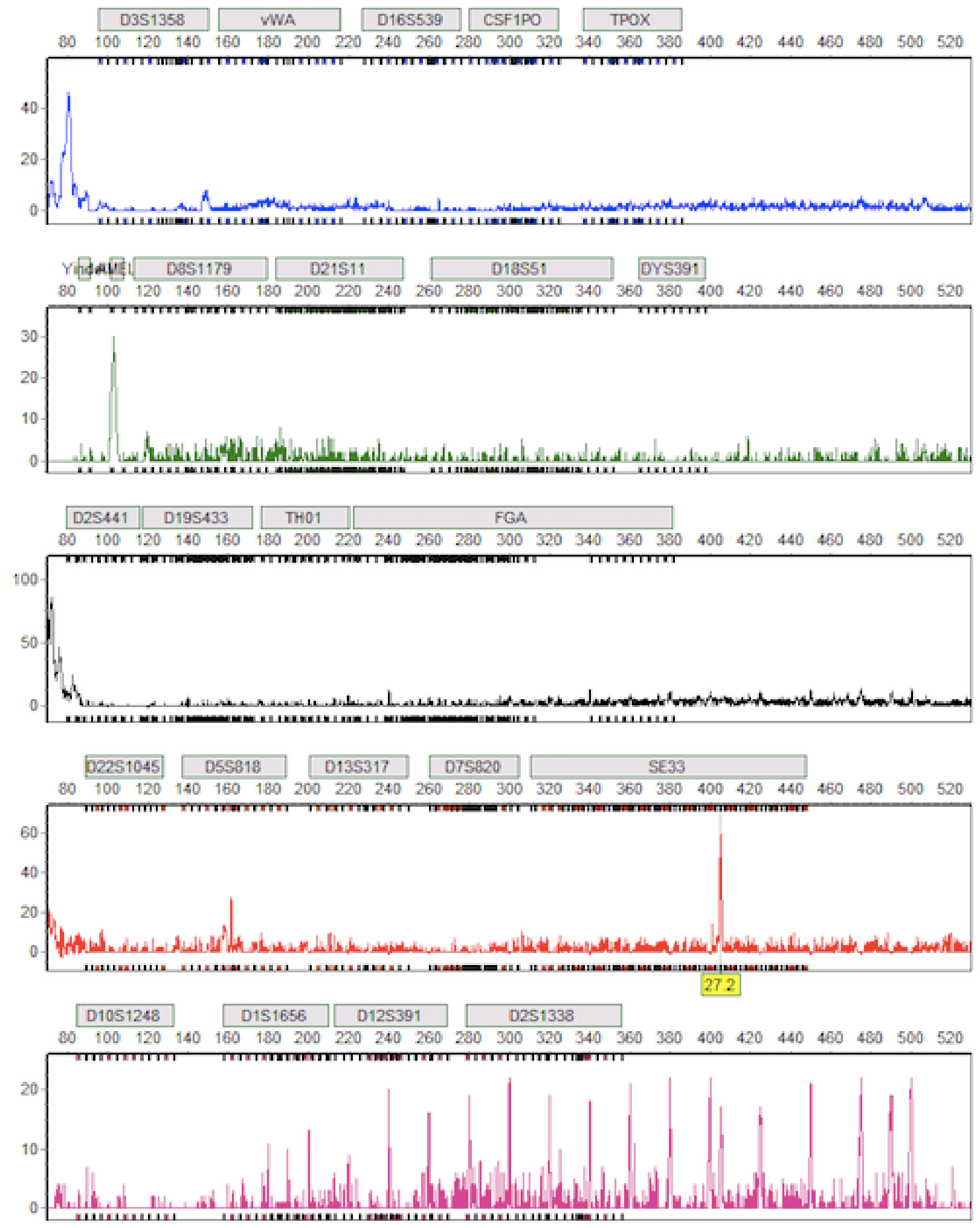

Figure 42. RapidHIT ${ }^{\mathrm{TM}} 200$ DNA profile for participant 6 degraded with 128 hours of exposure to UV light 

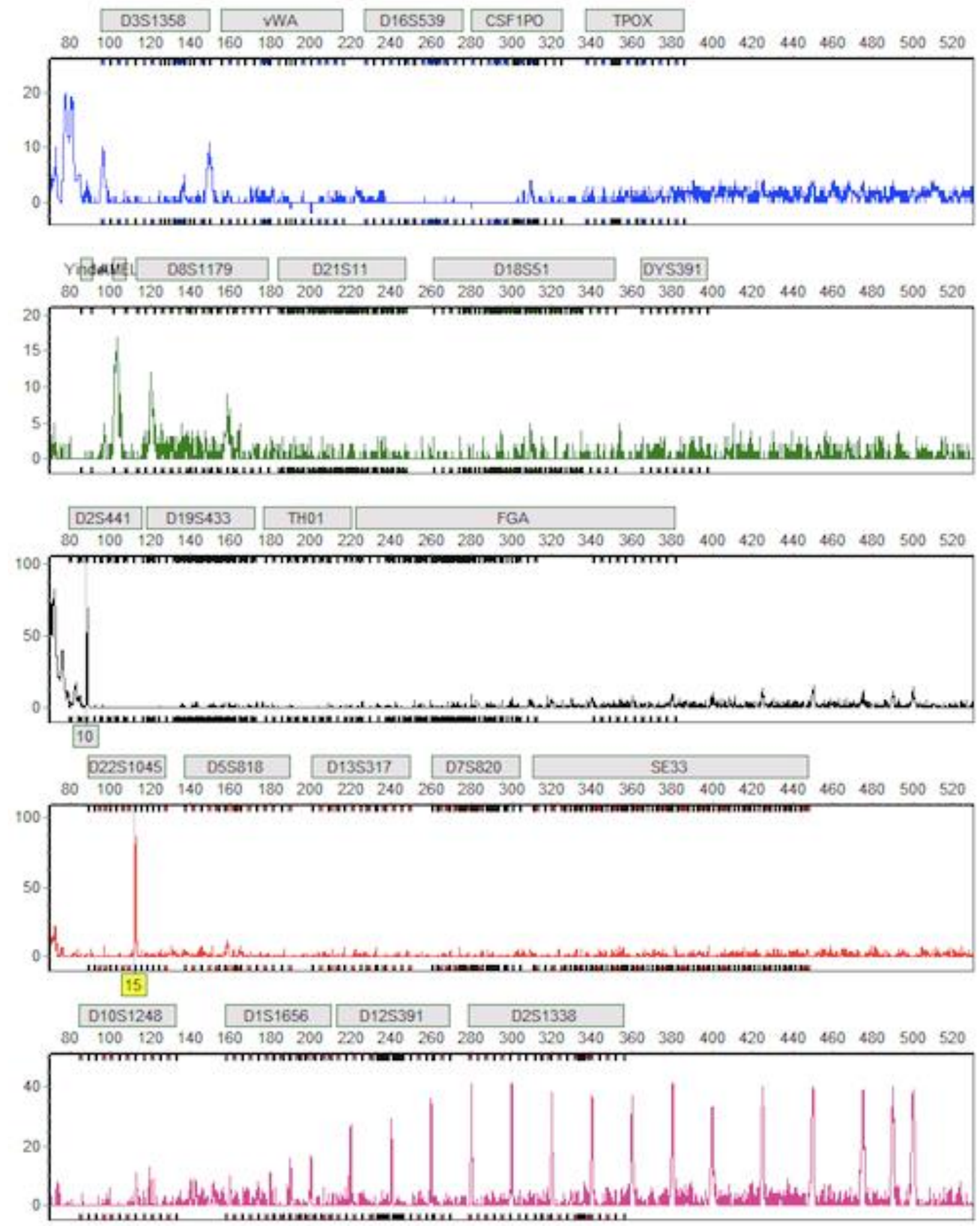

Figure 43. RapidHIT ${ }^{\mathrm{TM}} 200$ DNA profile for participant 8 degraded with 128 hours of exposure to UV light 

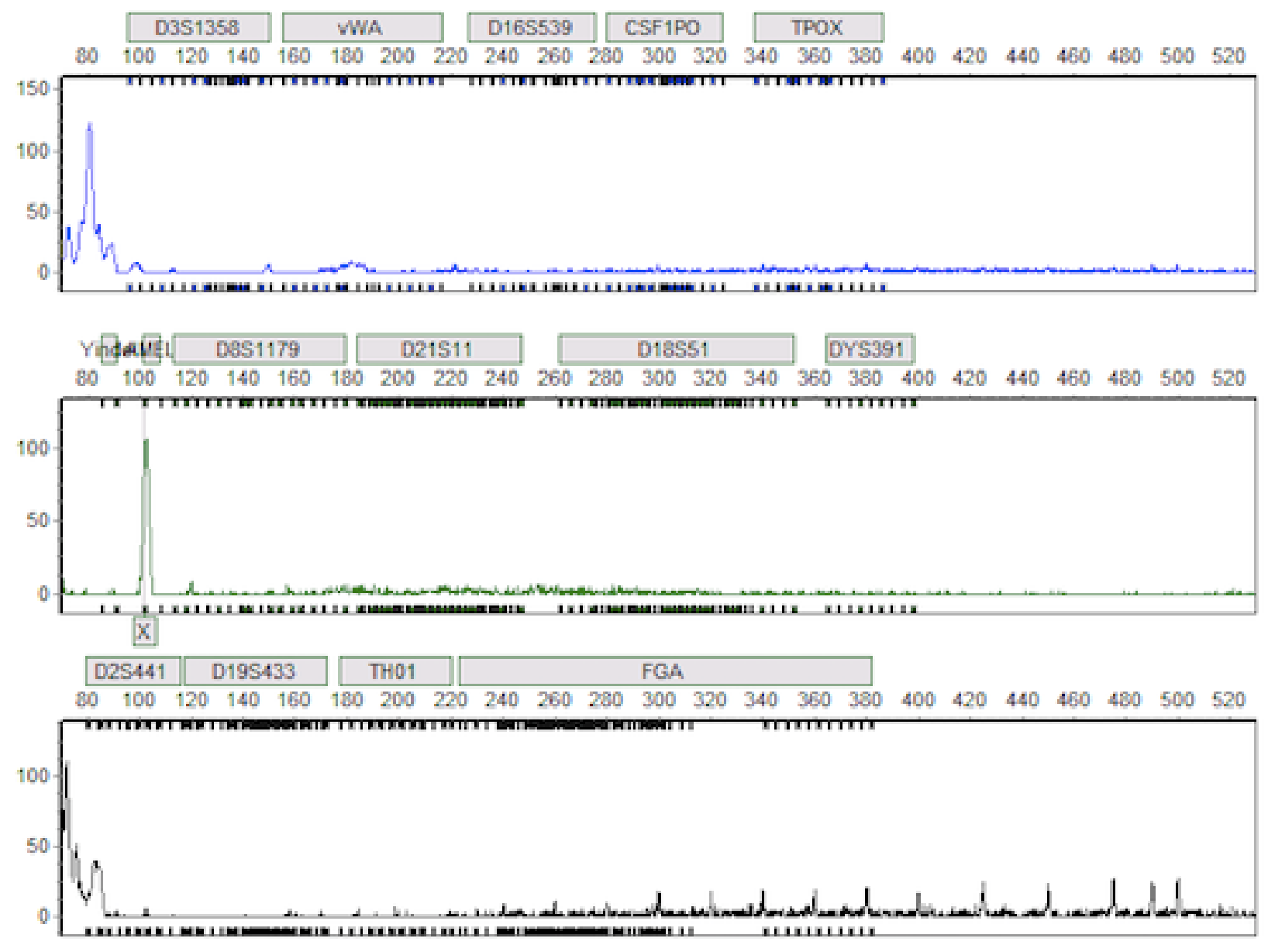

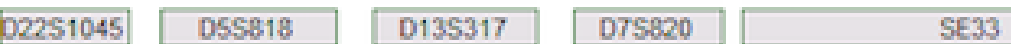

$80 \begin{array}{llllllllllllllllllllll}100 & 120 & 140 & 160 & 180 & 200 & 220 & 240 & 260 & 280 & 300 & 320 & 340 & 360 & 380 & 400 & 420 & 440 & 460 & 480 & 500 & 520\end{array}$
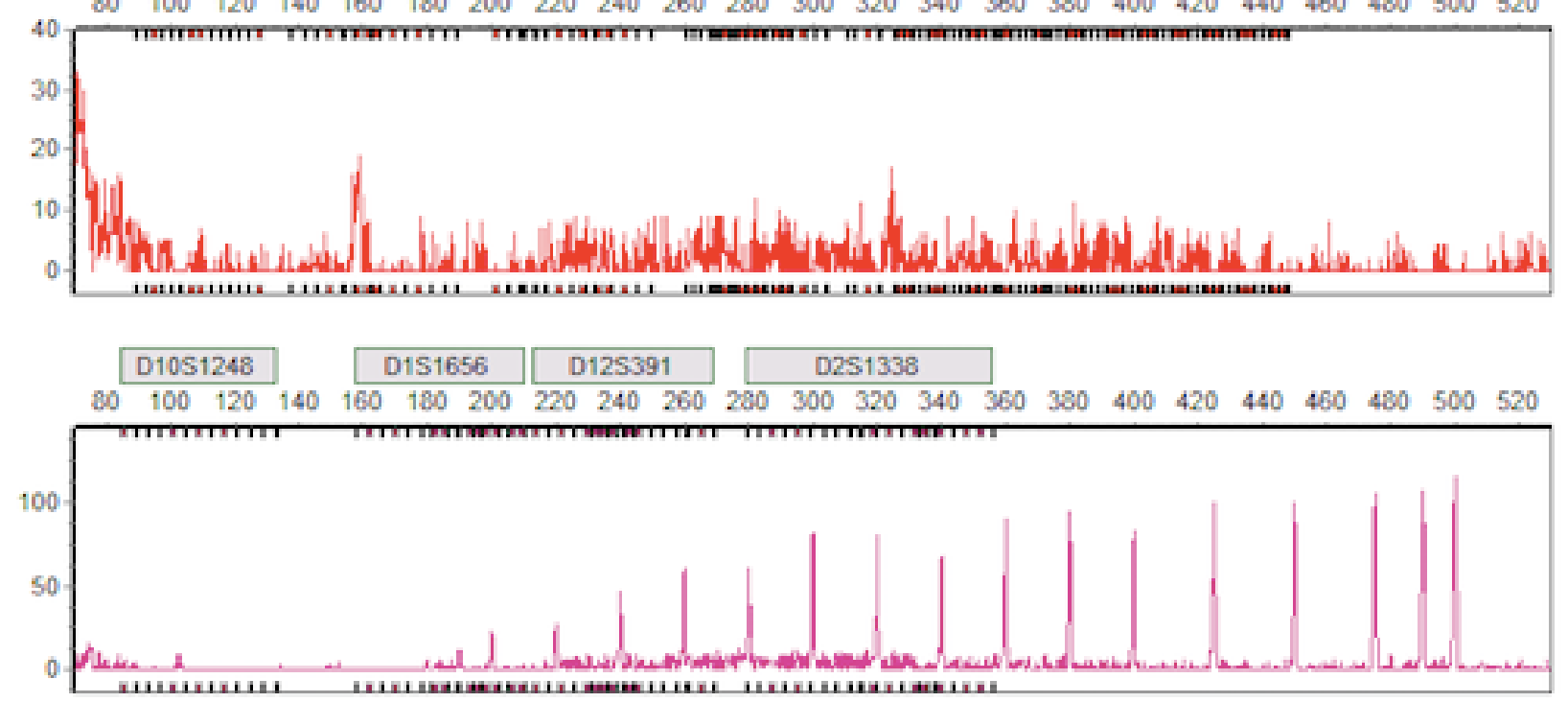

Figure 44. RapidHIT ${ }^{\mathrm{TM}} 200$ DNA profile for participant 4 degraded with 160 hours of exposure to UV light 

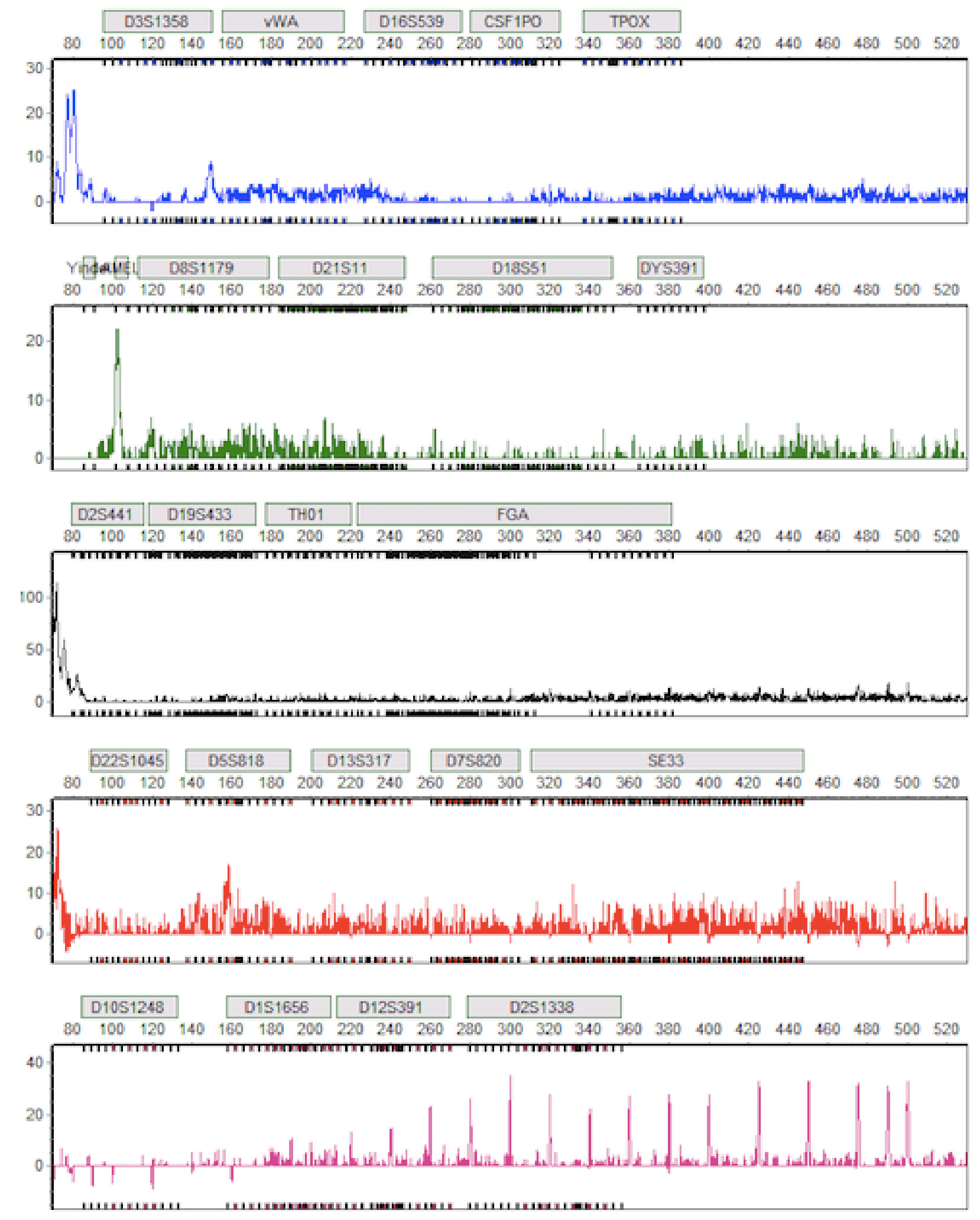

Figure 45. RapidHIT ${ }^{\mathrm{TM}} 200$ DNA profile for participant 6 degraded with 160 hours of exposure to UV light 

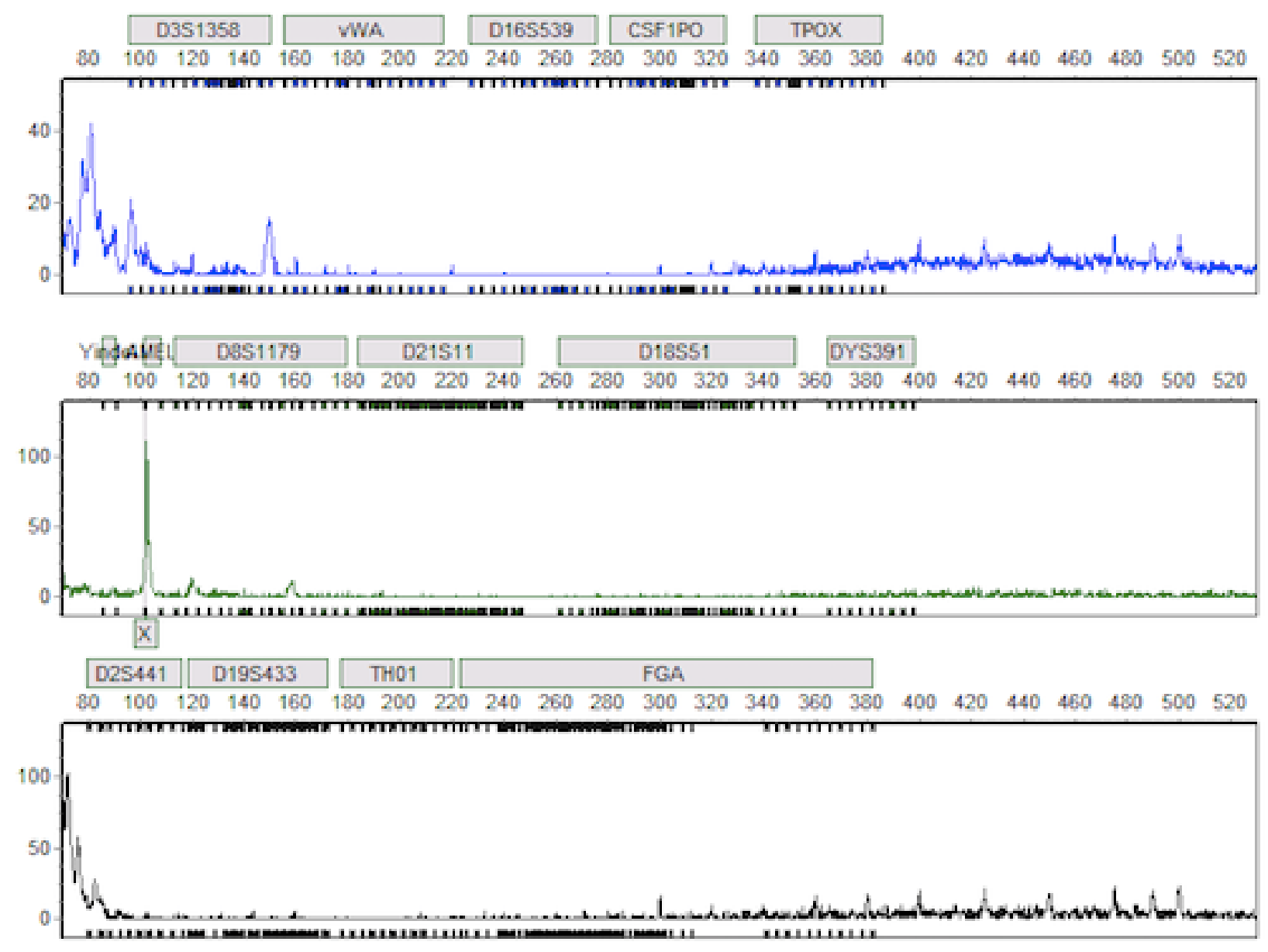

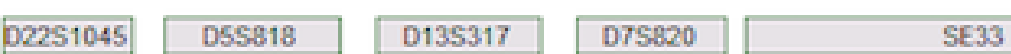

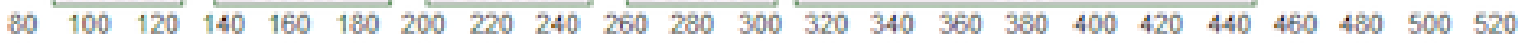
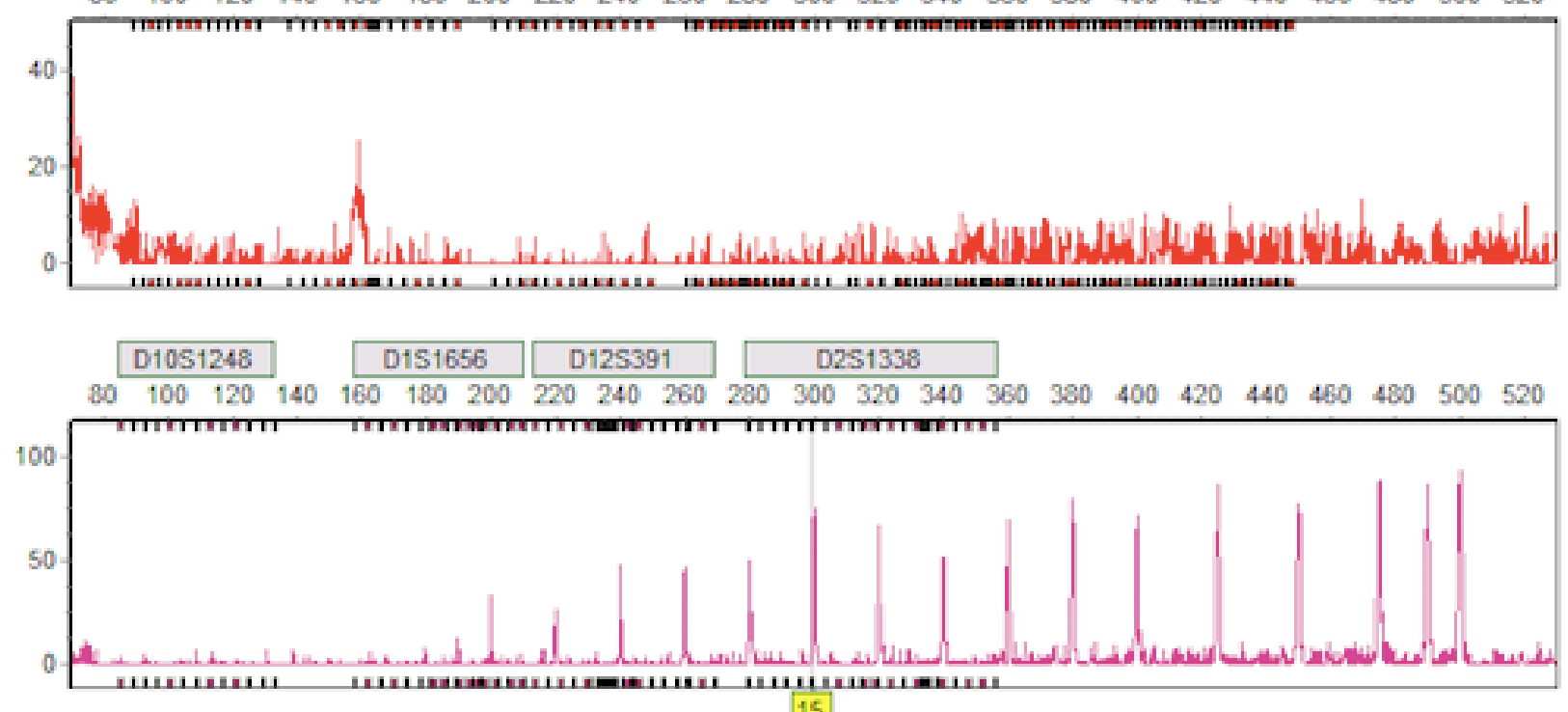

15

Figure 46. RapidHIT ${ }^{\mathrm{TM}} 200$ DNA profile for participant 8 degraded with 160 hours of exposure to UV light 

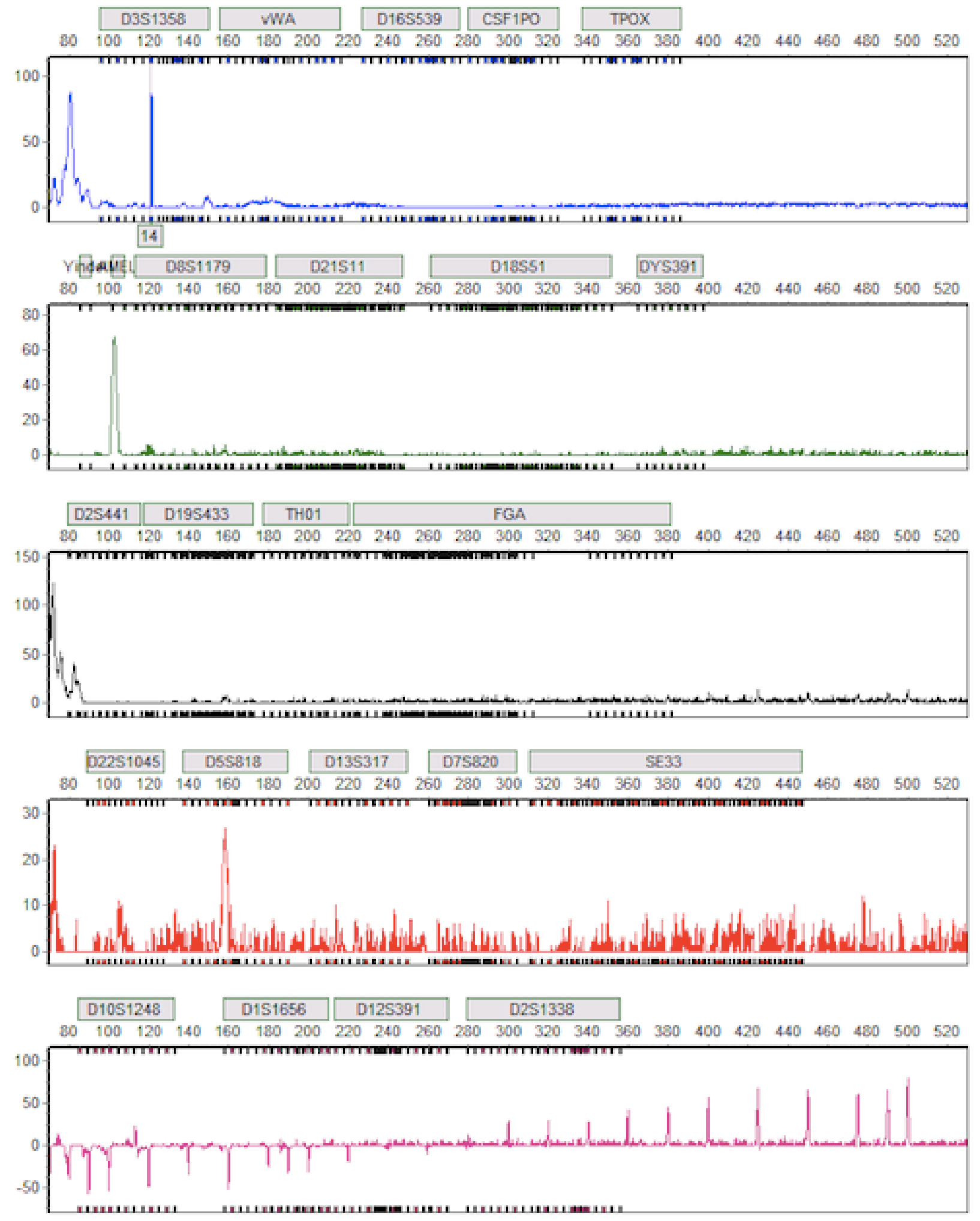

Figure 47. RapidHIT ${ }^{\mathrm{TM}} 200$ DNA profile for participant 4 degraded with 224 hours of exposure to UV light 


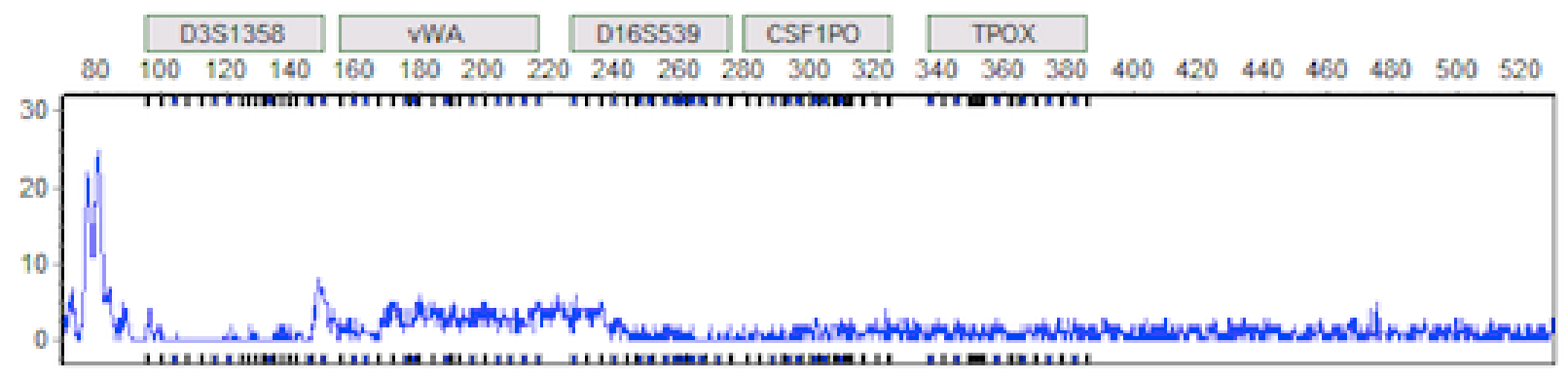

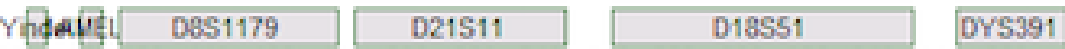

$80 \begin{array}{llllllllllllllllllllll}800 & 120 & 140 & 160 & 180 & 200 & 220 & 240 & 260 & 280 & 300 & 320 & 340 & 360 & 380 & 400 & 420 & 440 & 460 & 480 & 500 & 520\end{array}$

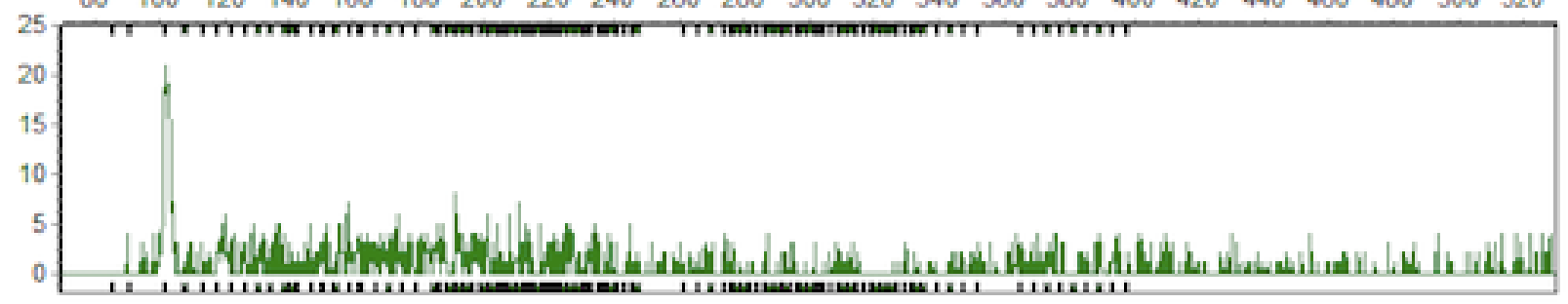

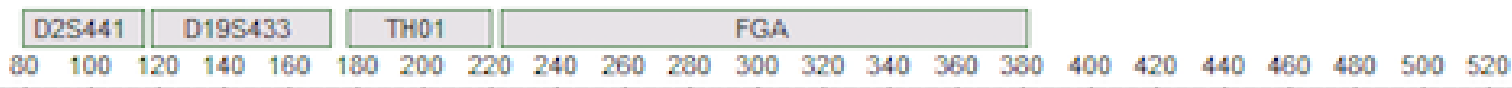

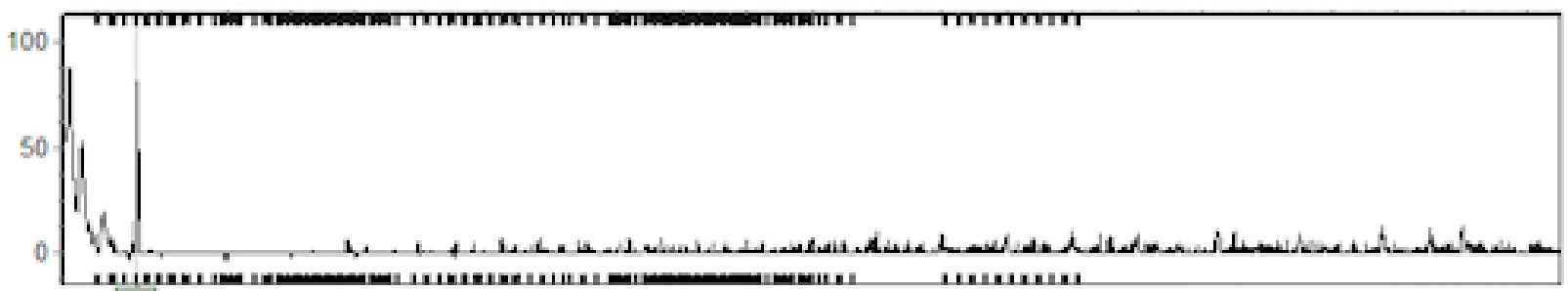

11

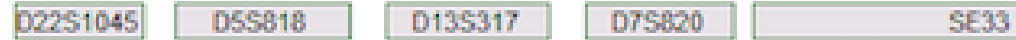

$80 \quad \begin{array}{llllllllllllllllllllll}100 & 120 & 140 & 160 & 180 & 200 & 220 & 240 & 260 & 280 & 300 & 320 & 340 & 360 & 380 & 400 & 420 & 440 & 460 & 480 & 500 & 520\end{array}$
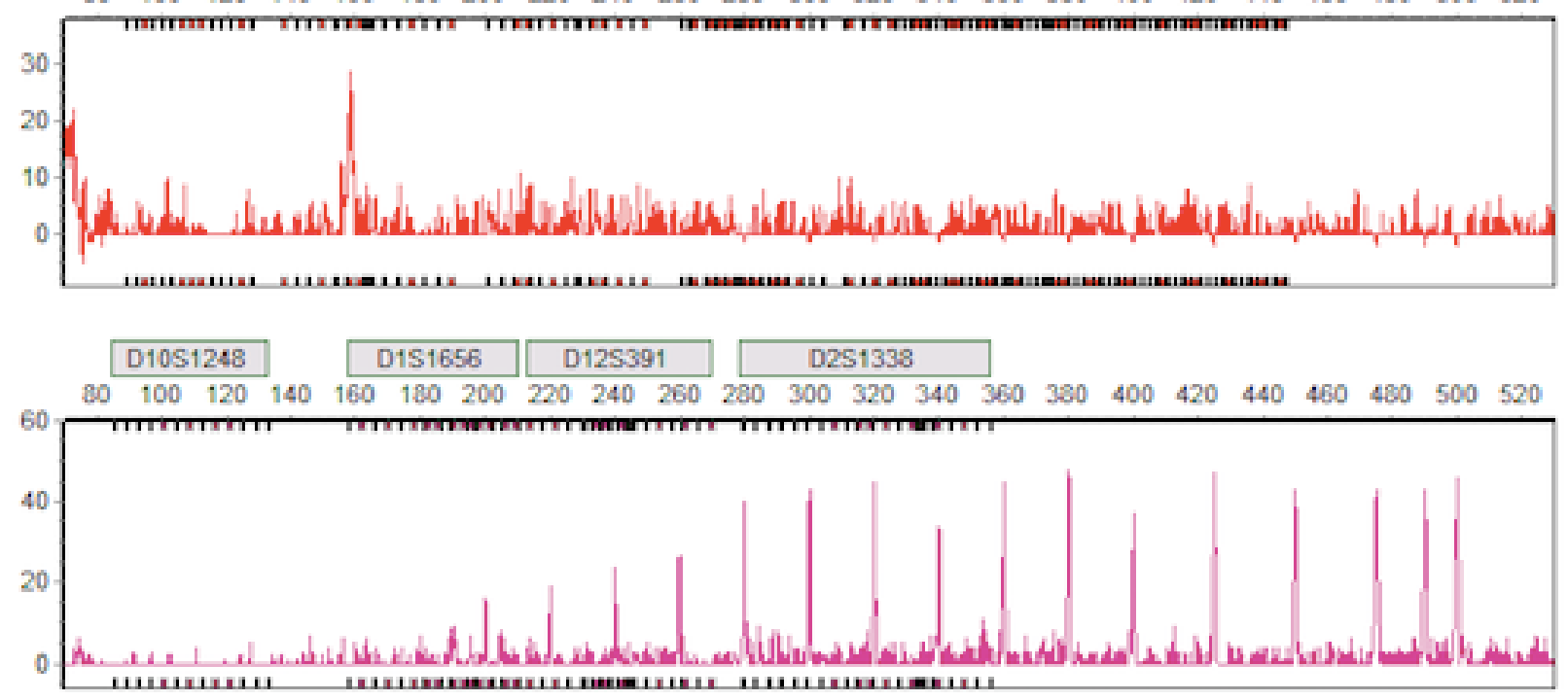

Figure 48. RapidHIT ${ }^{\mathrm{TM}} 200$ DNA profile for participant 6 degraded with 224 hours of exposure to UV light 

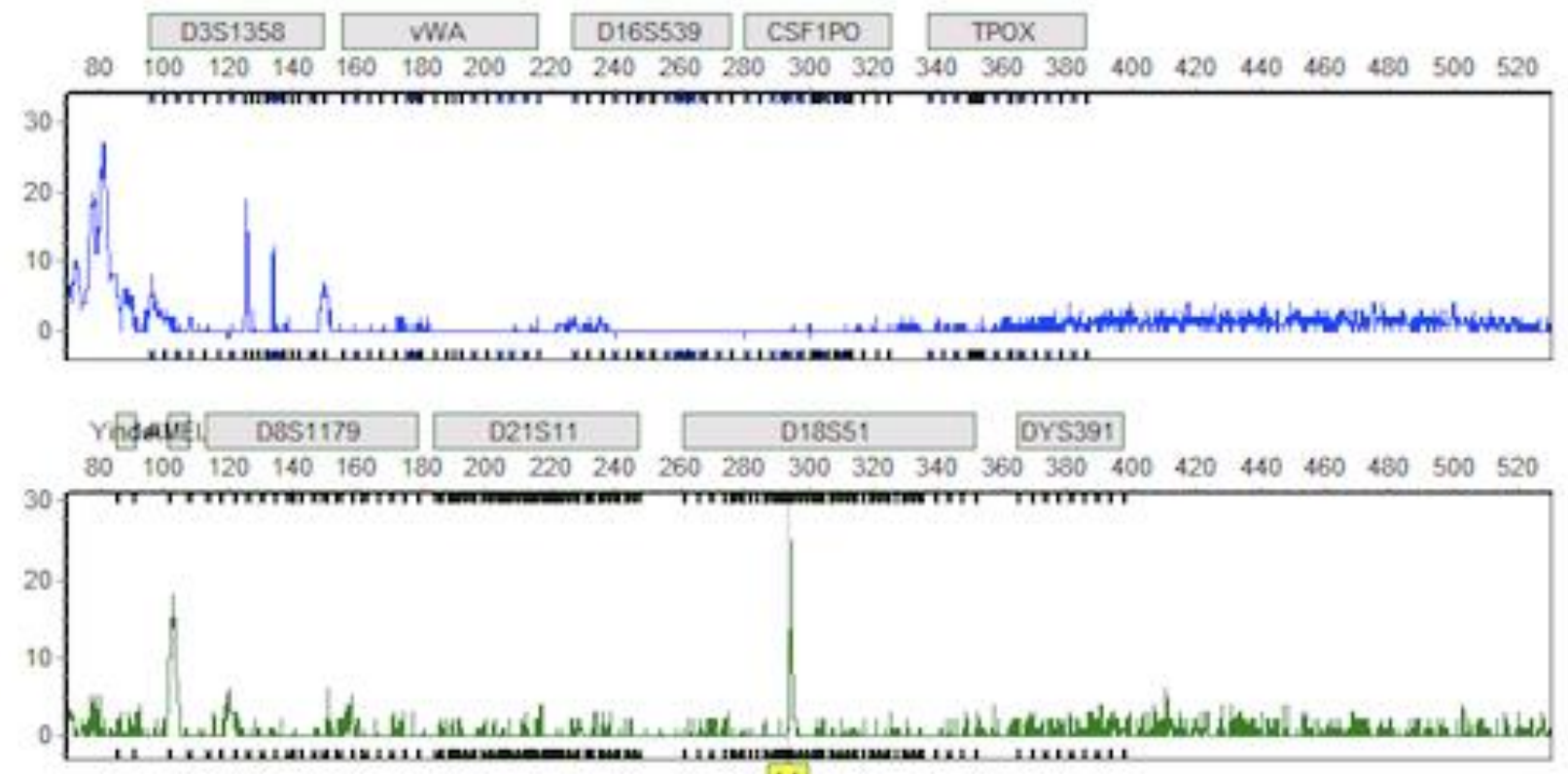

14
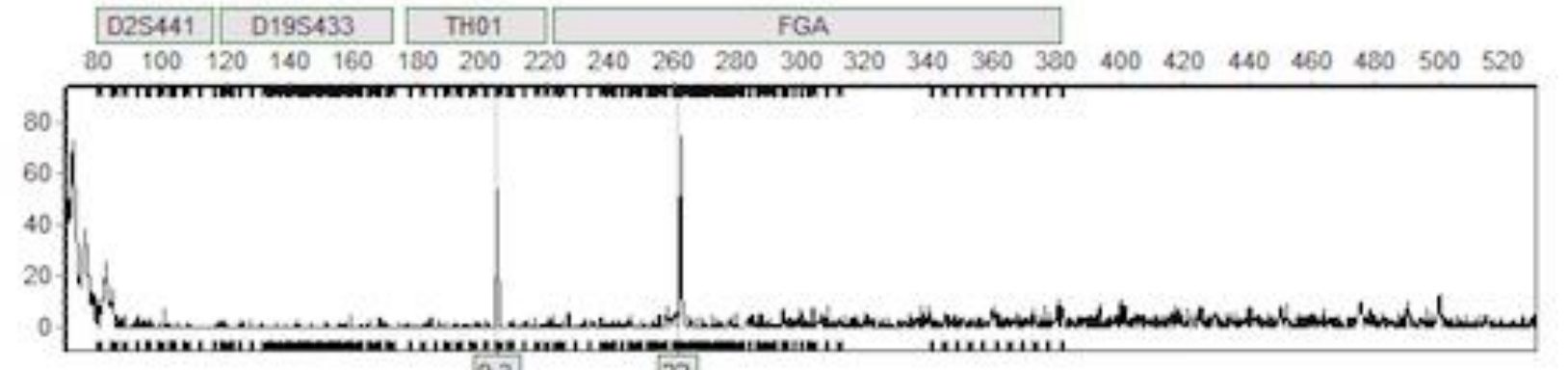

$$
293 \quad 22
$$

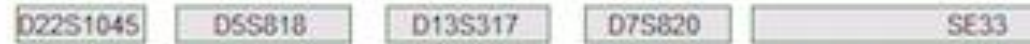

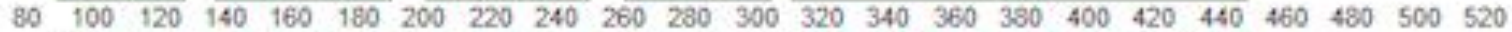

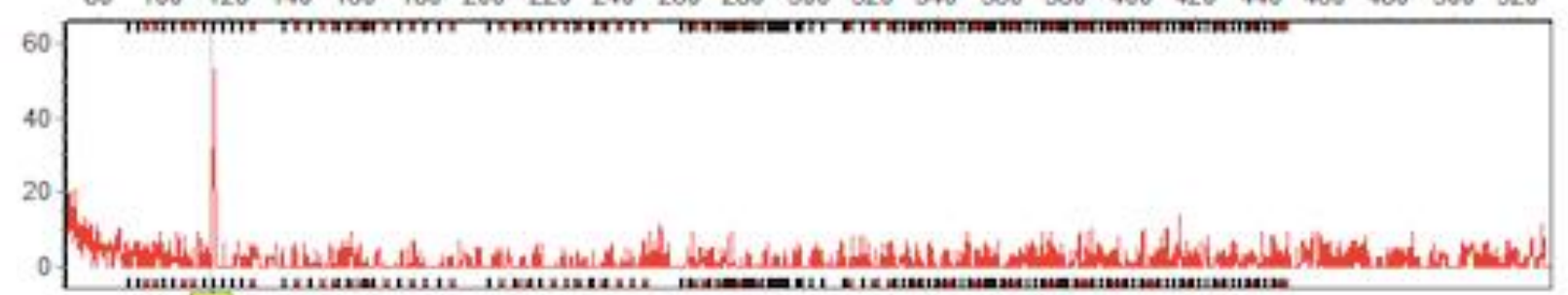
16

\begin{tabular}{|l|l|l|l|}
\hline D10S1248 & D1S1656 & D12S391 & D2S1338 \\
\hline
\end{tabular}

$\begin{array}{lllllllllllllllllllllllll}80 & 100 & 120 & 140 & 160 & 180 & 200 & 220 & 240 & 260 & 280 & 300 & 320 & 340 & 360 & 380 & 400 & 420 & 440 & 460 & 480 & 500 & 520\end{array}$

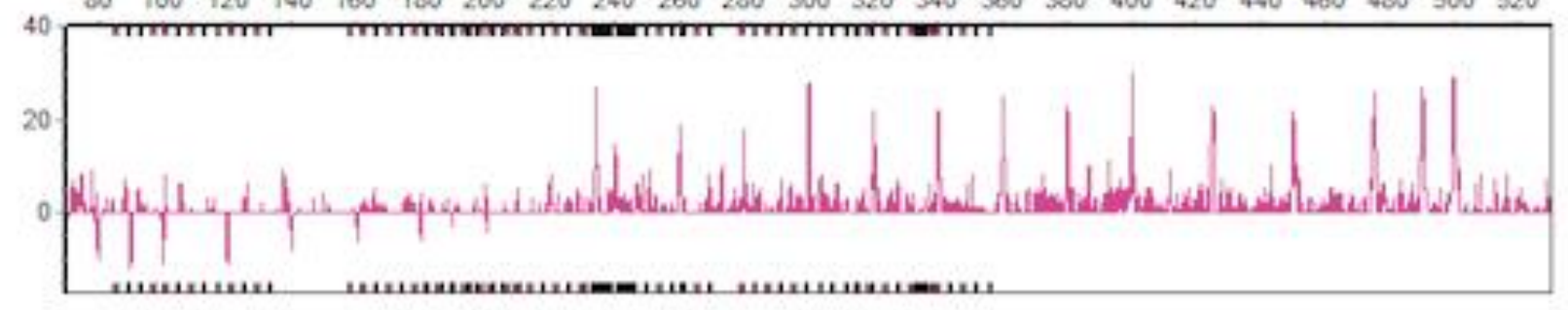

Figure 49. RapidHIT ${ }^{\mathrm{TM}} 200$ DNA profile for participant 8 degraded with 224 hours of exposure to UV light 


\subsection{CONCORDANCE STUDY OF DEGRADED SAMPLES FOR UV}

Evaluation was performed between profiles of degraded samples generated from both methods. Data analysis was completed by analyzing the percent of correct allele calls between the two different methods using the t-test and by comparing the percent of peaks that dropped out.

\section{RESULTS}

A graph comparing the percent of correct allele calls made between the two different methods is shown on Figure 50.

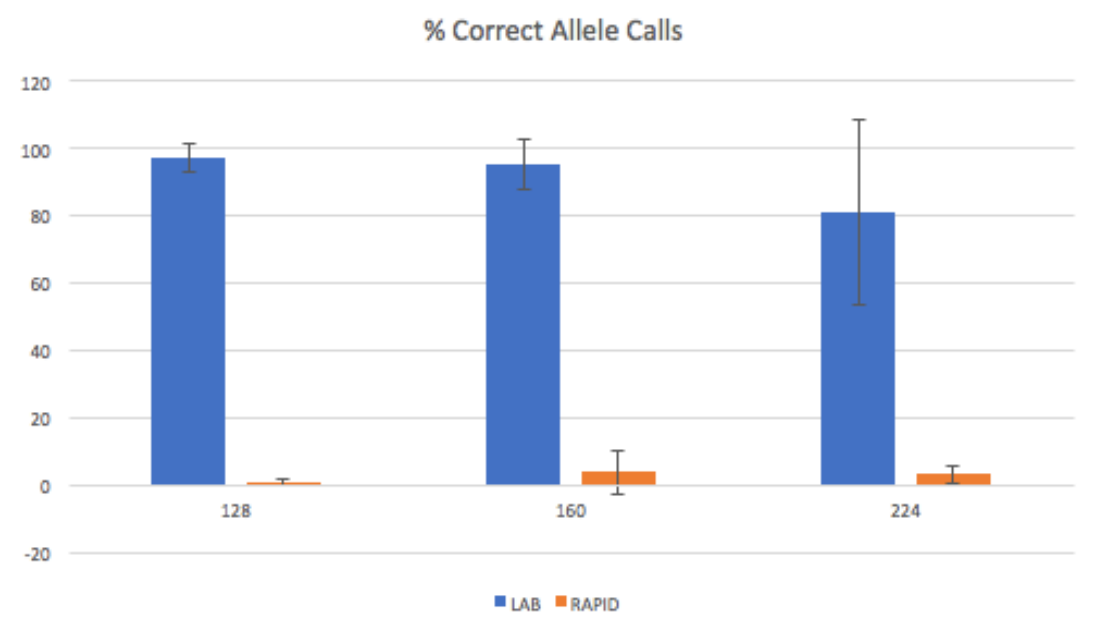

Figure 50. Bar graph of $\%$ Correct Allele Calls between the Laboratory method and RapidHIT ${ }^{\mathrm{TM}} 200$

The t-test between the two different methods on the percent correct allele calls indicates that for blood samples degraded with duration of 128, 160 and 224 hours of exposure to UV light, there is a significant difference between the laboratory method and RapidHIT ${ }^{\mathrm{TM}} 200$.

A graph comparing the percent of peaks that dropped out between the two different methods is shown on Figure 51. 


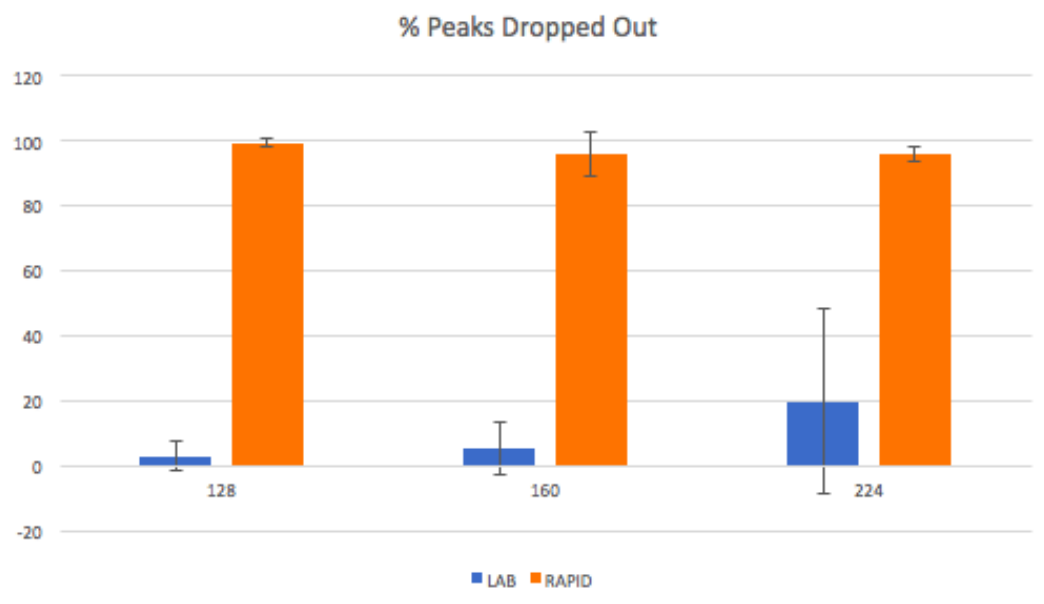

Figure 51. Bar graph of $\%$ of Peaks dropped out between the Laboratory method and RapidHIT 200

The RFU was set at 300 for the laboratory method and the default setting for RapidHIT ${ }^{\mathrm{TM}} 200$.

\section{DISCUSSION}

Most forensic samples tend to be degraded but when blood samples are exposed to heat and humidity for up to as high as $75^{\circ} \mathrm{C}$ with $50 \%$ humidity for 24 hours, the degradation index indicates that the blood samples did not degrade and this correlates to DNA profiles that are complete and accurate. Starting from exposure of blood samples at $85^{\circ} \mathrm{C}$ with $50 \%$ humidity for 24 hours, the degradation index begins to increase and slight degradation occurs. The DNA profiles generated from this exposure is accurate and mostly complete except for occasional allele drop out at the TPOX locus. It is at $95^{\circ} \mathrm{C}$ with $40 \%$ humidity exposure where substantial alleles drop out and DNA is degraded. The temperature of $95^{\circ} \mathrm{C}$ is unusually high to be found at a crime scene so in most cases, the DNA from blood samples should be able to be used to generate a good quality profile as long as it is within a 24 hour time frame and not over $50 \%$ humidity.

When comparing the DNA profiles generated from methods used in the conventional laboratory method versus the RapidHIT ${ }^{\mathrm{TM}} 200$ instrument for blood samples degraded with high heat and humidity, the conventional laboratory method provides more complete and accurate DNA profiles than RapidHIT ${ }^{\mathrm{TM}} 200$ instrument as expected. However, the t-test shows that there is no significant difference between the laboratory method and RapidHIT ${ }^{\mathrm{TM}} 200$ for blood samples degraded at $75^{\circ} \mathrm{C} / 50 \%$ and $95^{\circ} \mathrm{C} / 40 \%$ and therefore, when there is an expedited need for a DNA profile, RapidHIT ${ }^{\mathrm{TM}} 200$ instrument can be used. The t-test for blood samples degraded 
at $85^{\circ} \mathrm{C} / 50 \%$, indicates that there is a significant difference between the laboratory method and RapidHIT $^{\mathrm{TM}} 200$ so obtaining the DNA profile from the laboratory method is preferred. However, as mentioned before, temperatures as high as $85^{\circ} \mathrm{C}$ will not likely occur at a crime scene so RapidHIT ${ }^{\mathrm{TM}} 200$ will be useful in generating DNA profiles for blood degraded with heat and humidity. In order to relate what a typical crime scene would be exposed to with regard to heat, the average weather temperature is $13^{\circ} \mathrm{C}$ but to conduct my study, degradation had to happen with drop out in the DNA profile and so the temperature was increased.

When blood samples are exposed to UV light for a duration of 128, 160 and 224 hours, the degradation index did not indicate that higher degradation index correlated with longer exposure to UV light. This is probably due to the variation in how much blood was provided in a drop from the participants. However, when comparing the DNA profiles generated from methods used in conventional laboratory versus the RapidHIT ${ }^{\mathrm{TM}} 200$ instrument for blood samples degraded with UV light, the t-test shows that there is a significant difference between the laboratory method and RapidHIT ${ }^{\mathrm{TM}} 200$ at each of the duration of exposure. Therefore, blood samples exposed to measured UV light of $254 \mathrm{~nm}$ wavelength with a range of intensity from 800 to 900 microwatts $/ \mathrm{cm}^{2}$ for about 5 to 10 days should be analyzed using the laboratory method because RapidHIT ${ }^{\mathrm{TM}} 200$ does not generate good quality DNA profiles for blood degraded with this type of exposure.

In order to relate what a typical crime scene would be exposed to with regard to UV light, the UVC has a wavelength between 220 and 290nm but this portion is not exposed to humans because it is absorbed in the atmosphere (Zeman, n.d.). The wavelengths in UVC radiation have the highest energies, coincide with maximal absorption by DNA and would be extremely damaging to genetic material had it been exposed to humans (Girard et al., 2011). The most common portion of UV sunlight is UVA that has a wavelength between 320 and 400nm with an average maximum intensity of 5.6 microwatts $/ \mathrm{cm}^{2}$ obtained during a study conducted in India (Zeman, n.d.; Balasaraswathy et al., 2002). UVA is weakly absorbed by DNA and therefore, damage to DNA was thought to be limited although this perspective has been changing (Girard et al., 2011). UVB has a wavelength between 290 and 320nm with an average maximum intensity of 29.8 microwatts $/ \mathrm{cm}^{2}$ obtained during a study conducted in India. This portion of UV radiation is most destructive because it has enough energy to cause photochemical damage to cellular DNA and it is not completely absorbed by the atmosphere (Zeman, n.d.; Balasaraswathy 
et al., 2002). Since degradation had to happen in my study, the wavelength in UVC radiation which is also the germicidal portion of the UV was utilized with a lengthy exposure time regardless of whether these parameters were typical in a crime scene.

RapidHIT $^{\mathrm{TM}} 200$ instrument is not useful when DNA in blood is degraded with UV light as compared to high heat and humidity. The degradation index from samples exposed to $95^{\circ} \mathrm{C} / 40 \%$ humidity ranged between 4 and 13 suggesting moderate to significant degradation. Yet these DNA profiles generated from RapidHIT ${ }^{\mathrm{TM}} 200$ were better than the DNA profiles generated from any of the samples exposed to UV light where the degradation index ranged between 0.6 and 3. For RapidHIT ${ }^{\mathrm{TM}} 200$, one factor that seems to impact the generation of a good quality DNA profile is the quantity of DNA in the sample. All samples exposed to UV light had low quantities of DNA, under the typical target of 1 ng recommended for amplification. One method UV degrades DNA is by dimerization which distorts the DNA structure and results in low quantity of DNA (Devone et al., n.d.).

Degradation Index (DI) that is calculated automatically by HID Real-Time PCR Analysis Software when the SA quantification result is divided by the LA quantification result for each sample can reveal samples that are degraded. In more degraded samples, the LA quantity result decreases disproportionately relative to the SA quantity result, so that the DI ratio increases with increasing levels of DNA degradation. However, an experiment to evaluate DI in the

Quantifiler $^{\mathrm{TM}} \mathrm{HP}$ and Trio DNA Quantification Kits User Guide indicate that allele counts show that the expected recovery of genotype information from degraded samples is influenced not just by the DI, but also by the total amount of DNA added to STR assay reactions. When comparing a DI of 562 and DI of 17, similar allele counts were obtained despite the wide difference in the DNA degradation level between the samples. This was considered to be likely because the more highly degraded fraction contained a much higher concentration of DNA, allowing more DNA to be added to STR assay PCRs (ThermoFisher Scientific, 2017).

\section{CONCLUSION}

DNA has become an essential piece of evidence in forensic science but the processing time it takes to generate a DNA profile is long. One of the instruments created for rapid DNA technology is the RapidHIT ${ }^{\mathrm{TM}}$ 200. Law enforcement can obtain a good quality DNA profile from a buccal swab using this instrument but there is limited information on its value with crime 
scene type samples that tend to have degraded DNA. Two possible methods DNA can degrade is with exposure to high heat with humidity and UV light. This study showed that in either types of DNA degradation, the conventional laboratory method generated more accurate and complete DNA profiles than RapidHIT ${ }^{\mathrm{TM}} 200$. However, the data indicates that RapidHIT ${ }^{\mathrm{TM}} 200$ can generate a useful DNA profile for blood samples exposed to heat and humidity unlike those exposed to UV light. Therefore, RapidHIT ${ }^{\mathrm{TM}} 200$ can be a resourceful instrument at a crime scene where there is high heat and humidity but no UV light exposure such as a hot house.

It has been mentioned that in my study with UV light, that higher DI did not correlate with longer exposure to UV light and this was most likely due to variation in how much blood was provided in a drop from the participants. Future studies can further evaluate UV degradation where the amount of blood provided by participants would be the same quantity instead of estimated with a drop and also compare the DNA profiles generated using the two different methods on other types of degraded biological samples. 


\section{REFERENCES}

Alshehhi, A., \& Roy, R. (2015, Jul 30). Generating Rapid DNA Profiles from Crime Scene Samples Commonly Encountered in the United Arab Emirates. Journal of Forensic Research, 6(4), 296-307.

Augenstein, S. (2017, Aug 22). Rapid DNA Act Signed into Law, Setting Target of 90 Minute CODIS Profiles. Retrieved April 27, 2019, from https://www.forensicmag.com/article/2017/08/rapid-dna-act-signed-law-settingtarget-90-minute-codis-profiles.

Balasaraswathy, P., Kumar, U., Srinivas, C., \& Nair, S. (2002, Jul-Aug). UVA and UVB in Sunlight, Optimal Utilization of UV Rays in Sunlight for Phototherapy. Indian J Dermatol Venereol Leprol, 68(4), 198-201.

Bode Cellmark. (n.d.). BodeHITS Local DNA Database. Retrieved September 6, 2016, from http://www.bodecellmark.com/bodehits.

Butler, J. (2010). Fundamentals of forensic DNA typing. Amsterdam: Academic Press/Elsevier.

Callaghan, T. (n.d.). Rapid DNA Analysis in the Police Booking Suite: "FBI Initiative for Reference Sample Point of Collection Analysis". Retrieved September 6, 2016, from https://www.promega.com/ /media/files/resources/conference\%20proceedings/ishi\%202 2/oral\%20presentations/callaghan.pdf?la=en.

Carney, C., Whitney, S., Vaidyanathan, J., Persick, R., Noel, F., Vallone, P., Rosmos, E., Tan, E., Grover, R., Turingan, R., French, J., \& Selden, R. (2019, May). Developmental Validation of the ANDE ${ }^{\mathrm{TM}}$ Rapid DNA System with FlexPlex ${ }^{\mathrm{TM}}$ Assay for Arrestee and Reference Buccal Swab Processing and Database Searching. Forensic Science International: Genetics, 40, 120-130.

Date-Chong, M., Hudlow, W., \& Buoncristiani, M. (2016, Jul). Evaluation of the RapidHIT ${ }^{\mathrm{TM}}$ 200 and RapidHIT GlobalFiler ${ }^{\circledR}$ Express Kit for Fully Automated STR Genotyping. Forensic Science International: Genetics, 23, 1-8.

Devone, D., Adams, J., Czado, N., Rahi, G., \& Lodhi, K. (n.d.). Degradation of DNA in Whole Blood by UV Radiation at Varying Time Lengths of Exposure. Retrieved November 29, 2019 , from https://www.uncfsu.edu/assets/Documents/Biology/Djonnique_UV_degradation.pdf.

DHS. (2013, Feb 8). Privacy Impact Assessment for the Rapid DNA System. Retrieved September 6, 2016, from https://www.dhs.gov/sites/default/files/publications/privacy/PIAs/privacy-pia-rapiddna20130208.pdf. 
DiZinno, J. “90 Minute DNA Profiles on a Fully Validated, Automated System.” $7^{\text {th }}$ International DNA Users' Conference for Investigative Officers, 7 Nov 2013, INTERPOL Headquarters, Lyon, France.

Figarelli, V. "The Arizona DPS Rapid DNA Program.” 2014 American Society of Crime Laboratory Directors, 6 May 2014, Scottsdale, Az.

Gangano, S., Elliott, K., Anoruo, K., Gass, J., Buscaino, J., Jovanovich, S., \& Harris, D. (2013). DNA Investigative Lead Development from Blood and Saliva Samples in Less than Two Hours Using the RapidHIT ${ }^{\mathrm{TM}}$ Human DNA Identification System. Forensic Science International: Genetics Supplement Series, 4(1), e43-e44.

GE Healthcare Life Sciences. (2016). DNAscan Rapid DNA Analysis System. Retrieved September 6, 2016, from http://www.gelifesciences.com/webapp/wcs/stores/servlet/ProductDisplay?categoryld $=364838 \&$ catalog $\mid d=10101 \&$ product $\mid d=71366 \&$ storeld=11787\&langld=-1"langld=-1.

Genomeweb. (2018, Jun 4). FBI Approves ANDE Rapid DNA ID System. Retrieved April 27, 2019, from https://www.genomeweb.com/applied-markets/fbi-approves-ande-rapiddna-id-system\#.XMThmTPMwU0.

Girard, P., Francesconi, S., Pozzebon, M., Graindorge, D., Rochette, P., Drovin, R., \& Sage, E. (2011). UVA-Induced Damage to DNA and Proteins: Direct Versus Indirect Photochemical Processes. Journal of Physics: Conference Series, 261(1).

Gouveia, N., Brito, P., Serra, A., Balsa, F., Andrade, L., Sao Bento, M., Cunha, P., Bogas, V., Lopes, V., \& Porto, M. J. (2015, Dec). Direct Amplification of Reference Samples with GlobalFiler ${ }^{\circledR}$ PCR Amplification Kit. Forensic Science International: Genetics Supplement Series, 5, e135-e137.

Holland, M., \& Wendt, F. (2015, Jan). Evaluation of the RapidHIT ${ }^{\mathrm{TM}}$ 200, an Automated Human Identification System for STR Analysis of Single Source Samples. Forensic Science International: Genetics, 14, 76-85.

Innocence Project. (n.d.). Exonerate the Innocent. Retrieved September 6, 2016, from http://www.innocenceproject.org/exonerate/.

IntegenX. (2012). RapidHIT 200 Human DNA Identification System: Early Customer Data Using Promega Chemistries. Retrieved September 6, 2016, from http://integenx.com/wpcontent/uploads/2012/10/2012-ISHI-Rapid-DNA-Promega-Early-Customer-Poster.pdf.

IntegenX. (2016). RapidHIT ID. Retrieved September 6, 2016, from http://integenx.com/wpcontent/uploads/2016/02/RapidHIT-ID-Brochure-Desktop-DNA-is-here.pdf.

IntegenX. (2016). RapidHIT System for Human Identification. Retrieved September 6, 2016, from http://integenx.com/rapidhit-system/. 
Jackman, T. "FBI Plans 'Rapid DNA' Network for Quick Database Checks on Arrestees.” The Washington Post, 13 Dec. 2018. Retrieved April 27, 2019, from https://www.washington post.com/crime-law/2018/12/13/fbi-plans-rapid-dna-networkquick-database-checks-arrestees/?noredirect=on\&utm term=.543aba5a6bcd.

Johnson, J. (2013). Study Reveals 10 Factors in Wrongful Conviction Cases. Retrieved September 6, 2016, from http://www.american.edu/media/news/SPA_News_WrongfulConvictions-Study.cfm.

Johnson, M. (2015, Sep 3). IntegenX Launches Next-Generation Rapid Forensic DNA Platform. Retrieved September 6, 2016, from http://integenx.com/wpcontent/uploads/2015/09/GenomeWeb-Next-Generation-Rapid-Forensic-DNAPlatform.pdf.

Jovanovich, S. “RapidHIT System for Human DNA Identification.” IntegenX, 17 Sep2014, Pleasonton, Ca.

Kofman, A. "The Troubling Rise of Rapid DNA Testing." New Republic, 24 Feb. 2016. Retrieved September 6, 2016, from https://newrepublic.com/article/130443/troublingrise-rapid-dna-testing.

NEC. (2016). Portable DNA Analyzer. Retrieved September 6, 2016, from http://th.nec.com/en_TH/download/brochure/Brochure_PortableDNA_0325_2.pdf.

NEC. (2016). Portable DNA Analyzer. Retrieved September 6, 2016, from http://www.nec.com/en/global/solutions/biometrics/products/portable_dna_analyzer.html.

NIJ. (2012). DNA Sample Collection from Arrestees. Retrieved September 6, 2016, from http://www.nij.gov/topics/forensics/evidence/dna/pages/collection-from-arrestees.aspx.

OJP. (2011). The DNA Backlog. Retrieved September 6, 2016, from http://ojp.gov/newsroom/factsheets/ojpfs_dnabacklog.html.

PR Newswire. (2018, March 16). Thermo Fisher Scientific Acquires IntegenX, Provider of Leading Rapid DNA Technology for Human Identification. Retrieved April 27, 2019, from https://www.prnewswire.com/news-releases/thermo-fisher-scientific-acquiresintegenx-provider-of-leading-rapid-dna-technology-for-human-identification300615538.html.

Promega. (n.d.). Powerplex 16 System. Retrieved September 8, 2016, from https://www.promega.com/products/genetic-identity/str-amplification/powerplex-16system/?activeTab=0.

Ritter, N. “Identifying Remains: Lessons Learned from 9/11.” NIJ Journal, no. 256, Jan 2007, http://nij.gov/journals/256/Pages/lessons-learned.aspx. 
Steffen, C., Romsos, E., Coble, M., \& Vallone, P. (n.d.). Countdown to 2017 Internal Validation of the New CODIS Loci. Retrieved September 8, 2016, from http://ishinews.com/countdown-to-2017-internal-validation-of-the-new-codis-loci/\#.

Thacker, C., Oguzturun, C., Ball, K., \& Syndercombe Court, D. (2006, Apr). An Investigation into Methods to Produce Artificially Degraded DNA. International Congress Series, $1288,592-594$.

ThermoFisher Scientific. (n.d.). AmpFLSTR Identifiler PCR Amplification Kit. Retrieved September 8, 2016, from https://www.thermofisher.com/order/catalog/product/4322288\#/4322288.

ThermoFisher Scientific. (2012, Sep 17). Life Technologies Sets New Worldwide Standard for Criminal Forensic Testing with Introduction of GlobalFiler Kit. Retrieved September 8, 2016, from http://ir.thermofisher.com/investors/news-and-events/news-releases/lifetechnologies-archive/life-technologies-archive-details/2012/Life-Technologies-SetsNew-Worldwide-Standard-for-Criminal-Forensic-Testing-with-Introduction-ofGlobalFiler-Kit/default.aspx.

ThermoFisher Scientific. (2012). GlobalFiler ${ }^{\mathrm{TM}}$ Express PCR Amplification Kit User Guide. $1-91$.

ThermoFisher Scientific. (2015). GeneMapper® ID-X Software v1.5 Reference Guide. $1-66$.

ThermoFisher Scientific. (2016). GlobalFiler ${ }^{\mathrm{TM}}$ PCR Amplification Kit User Guide. 1-165.

ThermoFisher Scientific. (2017). Quantifiler ${ }^{\mathrm{TM}}$ HP and Trio DNA Quantification Kits User Guide. 1-114.

Verheij, S., Clarisse, L., van der Berge, M., \& Sijen, T. (2013). RapidHIT ${ }^{\mathrm{TM}}$ 200, A Promising System for Rapid DNA Analysis. Forensic Science International: Genetics Supplement Series, 4(1), e254-e255.

Wang, D., Gopinath, S., Lagace, R., Norona, W., Hennessy, L., Short, M., \& Mulero, J. (2015, Nov). Developmental Validation of the GlobalFiler ${ }^{\circledR}$ Express PCR Amplification Kit: A 6 Dye Multiplex Assay for the Direct Amplification of Reference Samples. Forensic Science International: Genetics, 19, 148-155.

Zeman, G. (n.d.) Ultraviolet Radiation. Retrieved October 6, 2019, from https://hps.org/hpspublications/articles/uv.html. 